luciana Teixeira de Campos Cella

\title{
Avaliação da injeção percutânea de etanol como tratamento primário para carcinoma hepatocelular em cirróticos
}

\author{
Dissertação apresentada à Faculdade de Medicina \\ da Universidade de São Paulo para obtenção do \\ título de Mestre em Ciências
}

Área de Concentração: Gastroenterologia Clínica Orientadora: Dra. Denise Cerqueira Paranaguá Vezozzo

São Paulo 


\section{Dados Internacionais de Catalogação na Publicação (CIP)}

Preparada pela Biblioteca da

Faculdade de Medicina da Universidade de São Paulo

Creprodução autorizada pelo autor

\section{Cella, Luciana Teixeira de Campos}

Avaliação da injeção percutânea de etanol como tratamento primário para carcinoma hepatocelular em cirróticos / Luciana Teixeira de Campos Cella. -- São Paulo, 2009.

Dissertação(mestrado)--Faculdade de Medicina da Universidade de São Paulo. Departamento de Gastroenterologia.

Área de concentração: Gastroenterologia Clínica.

Orientadora: Denise Cerqueira Paranaguá Vezozzo.

Descritores: 1.Carcinoma hepatocelular/terapia 2.Fibrose 3.Etanol 4.Prognóstico 5.Sobrevida

USP/FM/SBD-003/09 


\section{Dedicatória}


Aos meus pais, Jair e Alcione

Ao meu esposo, Wener 


\section{Agradecimentos}


Esta dissertação de mestrado significa para mim, a materialização de um desejo pessoal que, com certeza, não poderia ter realizado sozinha. Devo a finalização deste texto a muitas pessoas, a quem gostaria de agradecer sinceramente:

Ao Professor Dr. Flair José Carrilho, por ter-me aberto as portas do Hospital das Clínicas da FMUSP e me possibilitado o contato com um serviço acadêmico de excelência. Chefe visionário, de grande competência, o Professor Flair não se furta a cumprir, como titular do Departamento de Gastroenterologia da Universidade de São Paulo, sua missão de produzir e difundir o conhecimento científico em seu país e no mundo.

À minha orientadora, Dra. Denise Cerqueira Paranaguá Vezozzo, um exemplo de vida e de respeito ao próximo, por tudo o que me ensinou ao longo desses últimos anos. Por sua orientação, paciência, amizade, compreensão, e acima de tudo, por ter depositado em mim toda confiança ao me permitir escrever, nesta tese, sua experiência no tratamento do carcinoma hepatocelular, adquirida ao longo de pelo menos uma década de trabalho contínuo e estudo dedicado.

Aos meus chefes na Secretaria de Saúde do Distrito Federal, Dr. Columbano Junqueira Neto e Mauro Birche de Carvalho, por terem acatado meu pedido de licença junto ao Hospital de Base do Distrito Federal, no ano de 2006, para que pudesse cumprir minhas atividades do programa de pós-graduação em São Paulo. Agradeço por serem pessoas de ampla sabedoria e visão, cujas atitudes reafirmam seu compromisso em permitir o crescimento profissional e pessoal dos colegas que chefiam.

Aos meus professores da Universidade Estadual de Campinas, por terem me ensinado os primeiros passos na Gastroenterologia e por serem até hoje, meus exemplos de conduta e referência de prática da boa medicina: Dra. Elza Cotrim Soares, professora de personalidade marcante e extremo bom-senso, sempre próxima e disposta a dividir sua experiência com seus residentes; Dr. Jazon Romilson de Almeida, um dos médicos mais dedicados e comprometidos com quem tive a oportunidade de conviver e que me introduziu na difícil tarefa de diagnosticar e tratar o carcinoma hepatocelular; e Dr. Alex Vianey Calado França, com sua inteligência, clareza de pensamento e racionalidade que contagiaram a todos que com ele conviveram em sua curta passagem pela UNICAMP. 
Aos professores do Departamento de Gastroenterologia da FMUSP, principalmente nas figuras do Dr. Alberto Queiroz de Farias, com suas essenciais intervenções, sempre vindas nos momentos mais cruciais, como a escolha do tema da tese e a finalização do artigo para publicação; Dra. Suzane Kioko Ono-Nita, por sua competência, boa-vontade e disponibilidade em ajudar, em todos os momentos e em todos os sentidos; Dra. Marta Mitiko Deguti, pela paciência, ética profissional e vocação para a assistência clínica demonstradas nas horas passadas no Ambulatório de Hepatologia; Dra. Cláudia Silva de Oliveira Marques e Dr. Telésforo Bachella, por suas críticas construtivas recebidas na aula de qualificação para o Mestrado.

Aos professores do Departamento de Patologia do HCFMUSP, Dr. Venâncio Avancini Alves e Dr. Evandro Sobroza de Mello, por todas as horas dedicadas aos residentes e pós-graduandos e incansável disposição em estimular a produção científica e em melhorar a qualidade dos trabalhos;

À colega Luciana Oba Onishi Kikuchi, por suas intervenções, opiniões e por ter me orientado em tantas dúvidas surgidas ao longo da coleta de dados, elaboração de textos, pôsteres, tabelas. Também a ela e à colega Aline Chagas de Oliveira por terem organizado o ambulatório de Nódulos Hepáticos e possibilitado a mim e a outros colegas que virão a organização necessária para a produção científica. Ao colega Celso Matielo, por ter iniciado a tabulação dos dados utilizados nesta tese e pelo acompanhamento e seguimento dos pacientes;

Às enfermeiras Míriam Júnia dos Santos e Priscila da Silva Mineiro, que ajudaram valiosamente, tanto nas situações mais corriqueiras do dia-a-dia, quanto no momento crucial de levantamento da sobrevida dos pacientes estudados;

Às secretárias Fátima Gomes e Cláudia Arruda, por sua amizade, apoio técnico e pessoal, tão importantes quando nos encontramos longe de casa, em outra cidade;

À estaticista Júlia Fukushima, por suas horas de dedicação a todos nós da Gastroenterologia da FMUSP e ao apoio essencial na elaboração e interpretação dos resultados estatísticos deste trabalho e de outros realizados;

Finalmente, ao meu esposo Wener e aos meus pais, Jair e Alcione, por sua compreensão, apoio incondicional, e por acreditarem em mim. 
Agradeço em especial o auxílio financeiro do Alves de Queiroz Family Fund for Research ao projeto Hepatologia - Hepatites / Câncer, que viabilizou em parte este projeto de pesquisa. 
Esta tese está de acordo com:

Referências: adaptado de International Committee of Medical Journals Editors (Vancouver)

Universidade de São Paulo. Faculdade de Medicina. Serviço de Biblioteca e Documentação. Guia de apresentação de dissertações, teses e monografias. Elaborado por Anneliese Carneiro da Cunha, Maria Júlia de A.L. Freddi, Maria Fazanelli Crestana, Marinalva de Souza Aragão, Suely Campos Cardoso e Valéria Vilhena. São Paulo: Serviço de Biblioteca e documentação; 2005.

Abreviatura dos títulos dos periódicos de acordo com List of Journals Indexed in Index Medicus. 
Sumário 
Lista de siglas e abreviaturas

Lista de figuras

Lista de tabelas

Resumo

Summary

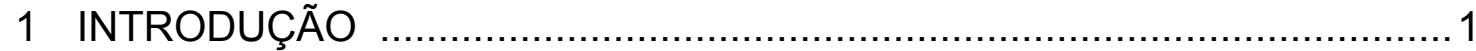

1.1 Epidemiologia do carcinoma hepatocelular..................................... 2

1.2 Estadiamento do carcinoma hepatocelular .................................... 3

1.3 Tratamento do carcinoma hepatocelular ...................................... 5

1.3.1 Terapias ablativas percutâneas .......................................... 6

1.3.1.1 Injeção percutânea de etanol (PEI) ......................... 6

1.3.1.2 Ablação por radiofrequência (RFA) ......................... 9

1.3.2 Ressecção çrúrgica .................................................. 9

1.3.3 Transplante hepático ............................................... 11

1.3.4 Quimioembolização ..................................................... 12

1.3.5 Tratamento sistêmico ................................................ 13

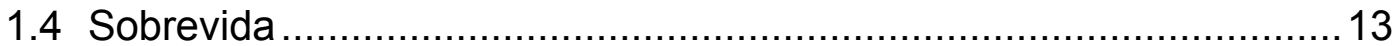

1.4.1 Sobrevida global ....................................................... 13

1.4.2 Sobrevida de séries submetidas a PEI ............................. 14

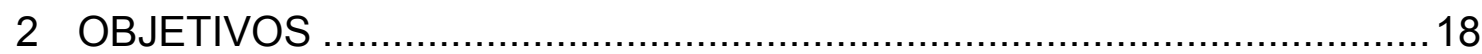

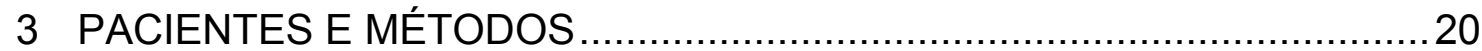

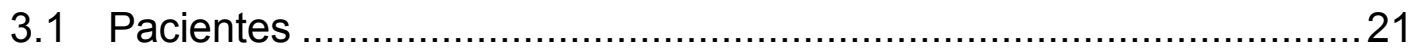

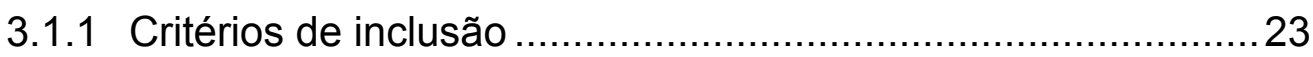

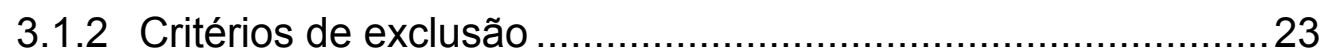

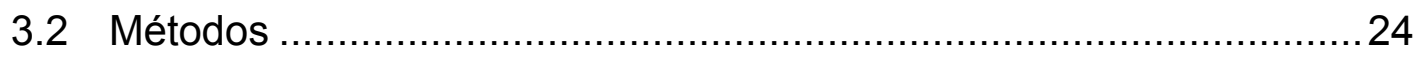

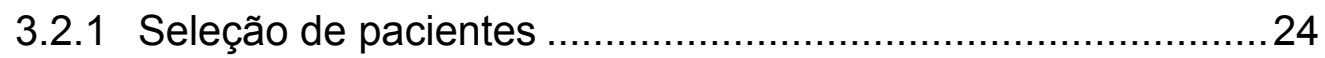

3.2.2 Dados clínicos e laboratoriais ............................................24

3.2.3 Dados relacionados ao diagnóstico e tratamento do $\mathrm{CHC}$......25

3.2.4 Avaliação da resposta ao tratamento ................................27

3.2.5 Avaliação da sobrevida............................................. 28

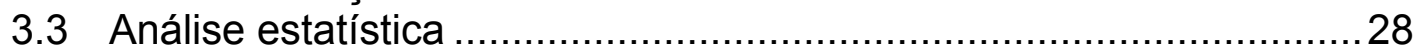

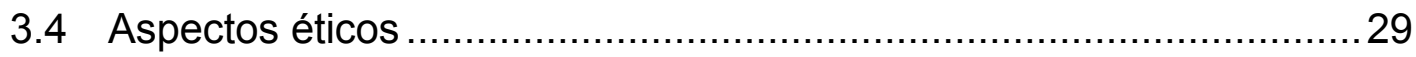

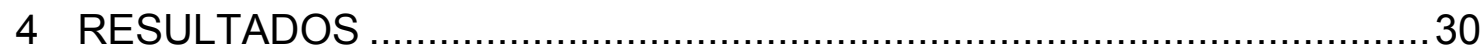

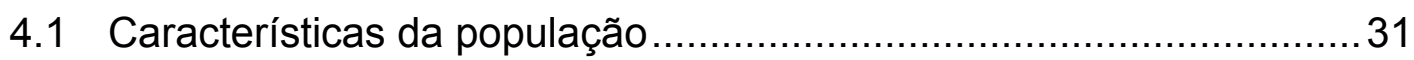

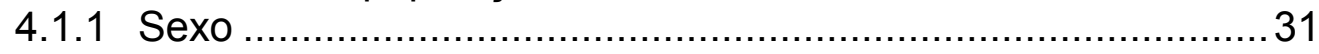

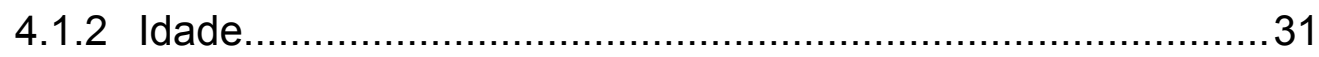

4.1.3 Etiologia da cirrose hepática........................................ 32

4.1.4 Classificação funcional ................................................. 33

4.1.5 Programa de rastreamento ............................................. 34

4.1.6 Níveis de alfa-fetoproteína sérica ...................................... 35

4.2 Características do tumor ........................................................... 36

4.2.1 Número de nódulos tumorais ............................................ 36

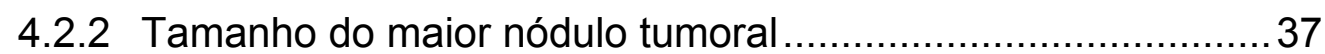

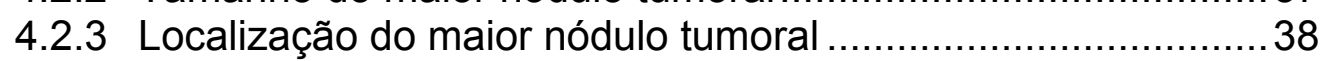

4.2.4 Caracterização do maior tumor à ultra-sonografia..................39

4.2 .5 Invasão vascular........................................................... 40 


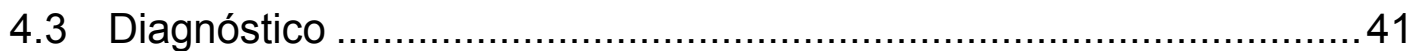

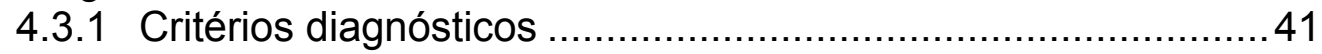

4.3.2 Deteç̧ão do tumor .................................................... 42

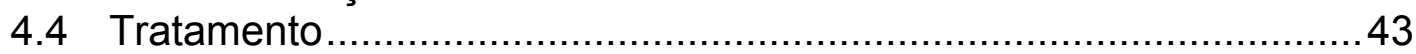

4.4.1 Tamanho do maior tumor à data do tratamento .....................43

4.4.2 Número de sessões de PEI ...............................................4

4.4.3 Volume de etanol injetado no maior tumor ............................45

4.4.4 Resposta ao tratamento ................................................46

4.4.5 Complicações do tratamento ............................................ 49

4.4.6 Segundo tipo de tratamento durante o seguimento ..................50

4.4.6.1 Embolização / Quimioembolização transarterial .........50

4.4.6.2 Transplante hepático ...............................................50

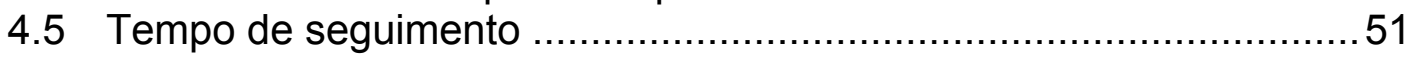

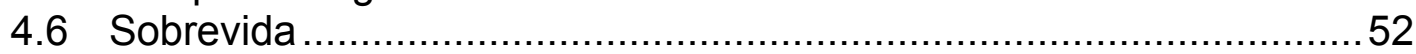

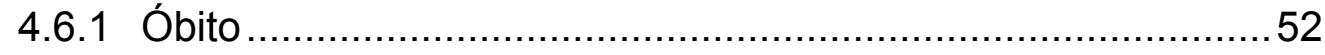

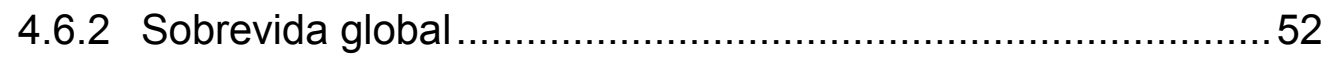

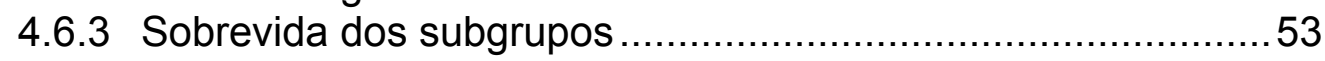

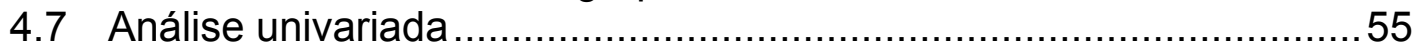

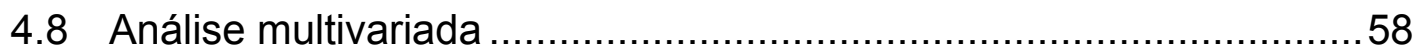

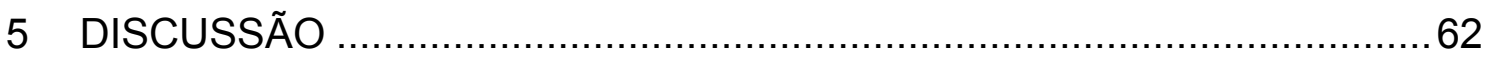

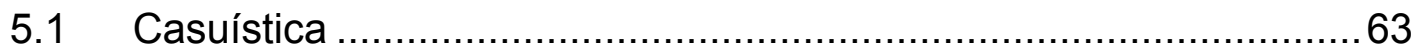

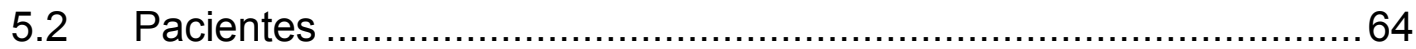

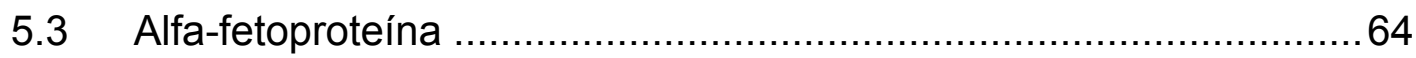

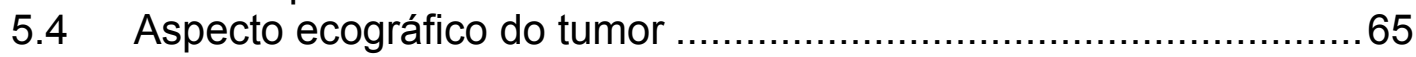

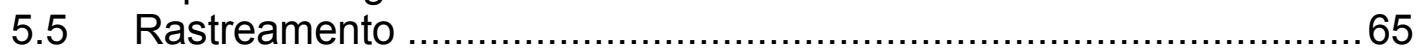

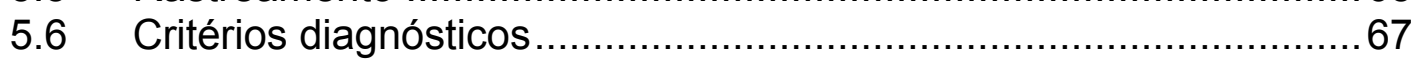

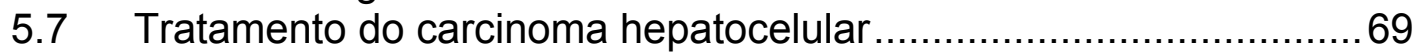

5.8 Injeção percutânea de etanol .................................................... 71

5.9 Avaliação da resposta ao tratamento ...........................................72

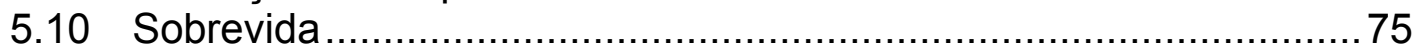

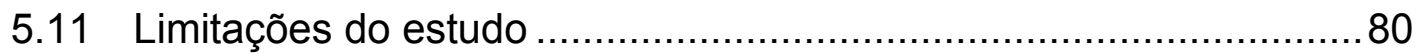

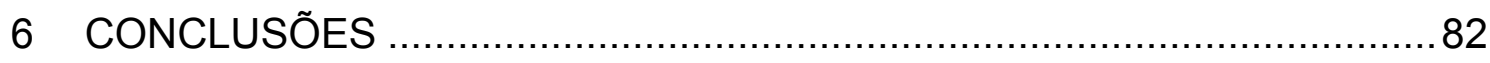

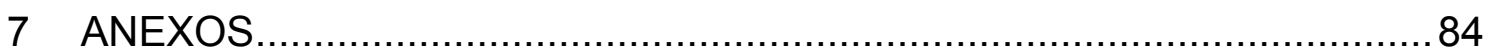

7.1 Anexo I - Solicitação de dispensa do termo de consentimento ...........85

7.2 Anexo II - Aprovação do projeto pelo comitê de ética .........................86

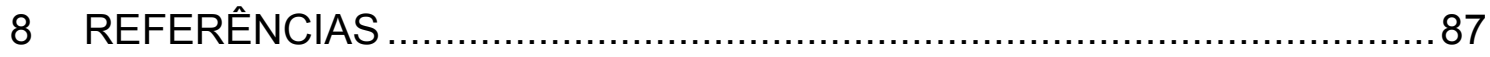


Listas 


\section{LISTA DE SIGLAS E ABREVIATURAS}

$\begin{array}{ll}\text { AASLD } & \text { American Association for the Study of Liver Diseases } \\ \text { AFP } & \text { alfa-fetoproteína } \\ \text { BCLC } & \text { Barcelona Clínic Liver Cancer } \\ \text { CHC } & \text { carcinoma hepatocelular } \\ \text { CAPPesq } & \text { Comitê de Ética para Análise de Projetos de Pesquisa } \\ \text { CLIP } & \text { Cancer of the Liver Italian Program } \\ \text { CNS } & \text { Conselho Nacional de Saúde } \\ \text { CT } & \text { Tomografia computadorizada } \\ \text { CUPI } & \text { Chinese University Prognostic Index } \\ \text { DAM } & \text { Divisão de Arquivo Médico } \\ \text { dl } & \text { decilitro } \\ \text { EASL } & \text { European Association for the Study of the Liver } \\ \text { FMUSP } & \text { Faculdade de Medicina da Universidade de São Paulo } \\ \text { G } & \text { gauge } \\ \text { GETCH } & \text { Groupe d'Étude et de Traitement Du Carcinome } \\ & \text { Hepatocellulaire } \\ \text { HCFMUSP } & \text { Hospital das Clínicas da Faculdade de Medicina da } \\ & \text { Universidade de São Paulo } \\ \text { Jis } & \text { Japan integrated staging score } \\ \text { MELD } & \text { Model of end-stage liver disease } \\ \text { ml } & \text { mililitros } \\ \text { ng } & \text { nanograma } \\ \text { OMS } & \text { Organização Mundial de Saúde } \\ \text { PEI } & \text { Injeção percutânea de etanol } \\ \text { RFA } & \text { ablação por radiofrequência } \\ \text { RNM } & \text { ressonância nuclear magnética } \\ \text { TACE } & \text { quimioembolização transarterial } \\ \text { TAE } & \text { embolização transarterial } \\ \text { UICC } & \text { Union Internationale Contre Le Cancer } \\ & \\ & \end{array}$




\section{LISTA DE FIGURAS}

Figura 1 - Tratamento do CHC no HCFMUSP entre $1997-2005 \ldots \ldots \ldots \ldots . . . .22$

Figura 2 - Distribuição dos pacientes quanto ao sexo........................... 31

Figura 3 - Distribuição dos pacientes quanto à etiologia da cirrose hepática

Figura 4 - Distribuição dos pacientes quanto à classificação funcional de Child-Pugh

Figura 5 - Distribuição de pacientes quanto a estar ou não realizando rastreamento para o carcinoma hepatocelular.

Figura 6 - Distribuição dos pacientes quanto aos níveis de alfafetoproteína sérica obtidos no momento do diagnóstico do $\mathrm{CHC}$

Figura 7 - Distribuição dos pacientes quanto ao número de nódulos tumorais observados à ultra-sonografia no momento do diagnóstico

Figura 8 - Distribuição dos pacientes quanto ao tamanho do maior tumor presente no momento do diagnóstico, avaliado por ultra-sonografia.....

Figura 9 - Distribuição dos pacientes quanto ao lobo hepático em que se localizava o maior tumor

Figura 10 - Número de tumores encontrados em cada segmento hepático, segundo a classificação de Couinaud

Figura 11 - Distribuição dos casos quanto ao aspecto ecográfico do maior tumor.

Figura 12 - Distribuição dos pacientes quanto à presença de invasão vascular macroscópica no momento do diagnóstico

Figura 13 - Distribuição dos casos de acordo com o critério utilizado para diagnóstico do $\mathrm{CHC}$.

Figura 14 - Distribuição dos casos de acordo com o exame de imagem de detecção do tumor

Figura 15 - Distribuição dos casos de acordo com o número de sessões de $\mathrm{PEI}$ que receberam 
Figura 16 - Distribuição dos casos de acordo com o volume total de etanol injetado no maior tumor

Figura 17 Distribuição dos casos de acordo com o tipo de resposta ao tratamento obtida.

Figura 18 - Aspectos tomográficos de nódulo tumoral que obteve resposta completa ao tratamento com PEI

Figura 19 - Aspectos tomográficos de nódulo tumoral que obteve resposta incompleta ao tratamento com PEI

Figura 20 - Distribuição dos casos de acordo com a apresentação de complicações à PEI

Figura 21 - Tipo e número de complicações apresentadas após tratamento com PEI

Figura 22 - Distribuição dos pacientes quanto à realização de um segundo tipo de tratamento subseqüente à $\mathrm{PEI}$

Figura 23 - Curva de sobrevida global 52

Figura 24 - Curvas de sobrevida conforme tamanho do tumor $(<20$ $\mathrm{mm}$ e $>20 \mathrm{~mm}$ ).

Figura 25 - Curvas de sobrevida conforme presença de invasão vascular

Figura 26 - Curvas de sobrevida conforme tipo de resposta ao tratamento com PEI

Figura 27 - Curvas de sobrevida conforme realização de tratamento posterior com TAE ou TACE.

Figura 28 - Curvas de sobrevida conforme pertencer a programa de rastreamento para $\mathrm{CHC}$ 


\section{LISTA DE TABELAS}

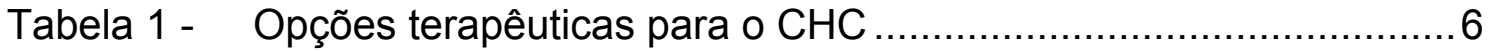

Tabela 2 - Sobrevida de pacientes cirróticos com CHC submetidos a

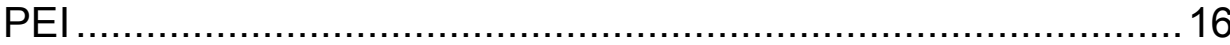

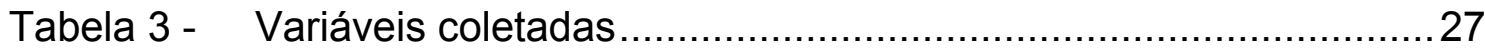

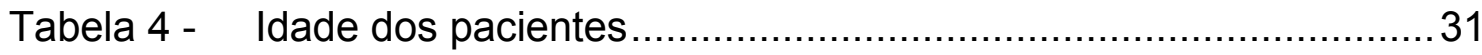

Tabela 5 - Níveis de AFP sérica ao diagnóstico ………………...................35

Tabela 6 - Tamanho do maior nódulo tumoral no momento do diagnóstico, avaliado por ultra-sonografia ....................................37

Tabela 7 - Tamanho do maior nódulo tumoral à data do tratamento .............43

Tabela 8 - Número de sessões de PEl e volume total de etanol injetado

Tabela 9 - Tempo de seguimento dos pacientes, em meses........................51

Tabela 10 - Taxas de sobrevida de 1, 3 e 5 anos em diferentes subgrupos de pacientes......................................................... 54

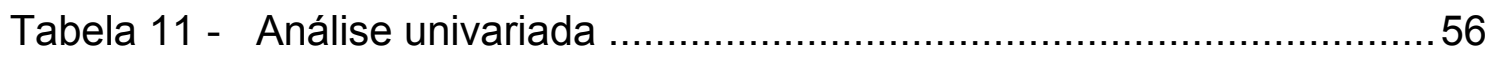

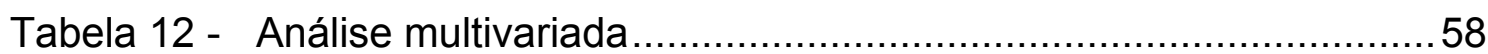


Resumo 
Cella LTC. Avaliação da injeção percutânea de etanol como tratamento primário para carcinoma hepatocelular em cirróticos [dissertação]. São Paulo: Faculdade de Medicina, Universidade de São Paulo; 2009. 102 p.

Introdução: A injeção percutânea de etanol (PEI) é um método de ablação local considerado curativo para carcinomas hepatocelulares $(\mathrm{CHC})$ pequenos. Não há dados sobre PEI para tratamento do $\mathrm{CHC}$ na América Latina. Pacientes e métodos: Incluídos 100 pacientes cirróticos submetidos à $\mathrm{PEI}$ como terapia primária para o $\mathrm{CHC}$ no Serviço de Gastroenterologia do HCFMUSP entre setembro de 1997 e dezembro de 2005. Avaliados resposta ao tratamento e taxa de sobrevida. Resultados: Resposta completa ao tratamento ocorreu em $41 \%$ dos casos. A sobrevida foi de $83 \%$ em 1 ano, $49 \%$ em 3 anos e $29 \%$ em 5 anos, mas no grupo com tumores de até $2 \mathrm{~cm}$, sem invasão vascular e com resposta completa ao tratamento, atingiu $89 \%, 70 \%$ e $70 \%$, respectivamente. Conclusão: PEl apresentou boa sobrevida em pacientes com tumores $\leq 2 \mathrm{~cm}$, sem invasão vascular e resposta completa ao tratamento.

Descritores: 1.Carcinoma hepatocelular/terapia 2.Fibrose 3.Etanol 4.Prognóstico 5.Sobrevida 
Summary 
Cella LTC. Evaluation of percutaneous ethanol injection as first-line therapy for hepatocellular carcinoma in cirrhotic patients [dissertation]. São Paulo: "Faculdade de Medicina, Universidade de São Paulo"; 2009. 102 p.

Introduction: Percutaneous ethanol injection (PEI) is a curative local ablative method for treatment of small hepatocellular carcinoma (HCC). There is no data about PEI for HCC treatment in Latin America. Patients and Methods: A total of 100 consecutive cirrhotic patients were enrolled. All of them had been submitted to PEI as first-line therapy for the treatment of HCC at the Service of Gastroenterology of HCFMUSP in the period of September 1997 to December 2005. Response to treatment and survival rates were assessed. Results: Complete response to treatment was obtained in $41 \%$ of the patients. Survival rates were $83 \%$ in 1 year, $49 \%$ in 3 years and $29 \%$ in 5 years, but in patients with tumors up to $2 \mathrm{~cm}$, no vascular invasion and complete response to treatment, were $89 \%, 70 \%$ and $70 \%$, respectively. Conclusion: PEI is associated with long-term survival in patients with tumors $\leq 2 \mathrm{~cm}$, absence of vascular invasion and complete response to treatment.

Keywords: 1.Hepatocellular carcinoma/therapy 2.Fibrosis 3.Ethanol 4.Prognosis 5.Survival 
1 Introdução 


\subsection{EPIDEMIOLOGIA DO CARCINOMA HEPATOCELULAR}

O carcinoma hepatocelular $(\mathrm{CHC})$ é o câncer hepático mais prevalente em todo o mundo ${ }^{1}$. Constitui a quinta neoplasia de maior mortalidade, chegando a terceiro lugar em regiões de maior prevalência, como Japão e Sudeste asiático ${ }^{2}$. Atualmente, constitui a maior causa de morte em pacientes cirróticos ${ }^{3}$.

A incidência do carcinoma hepatocelular tem aumentado em todo o mundo. No Japão, essa tendência foi observada desde 1975, relacionada principalmente ao aumento da infecção pelo vírus da hepatite C. Nesses últimos 30 anos, o $\mathrm{CHC}$ ocupou o terceiro lugar entre as neoplasias com maior mortalidade em homens e o quinto lugar em mulheres naquele país ${ }^{4}$. Nos Estados Unidos, embora esse tipo de câncer seja considerado infreqüente, o aumento de sua incidência tem sido relatado desde $1999^{1}$. A taxa de incidência anual ajustada por idade aumentou de 2,6 casos / 100.000 habitantes em 1975 para 5,2 casos / 100.000 habitantes em 2001. Nesse período, esse foi o tipo de câncer que mais cresceu entre norteamericanos, em contraste com a diminuição da incidência de vários outros tipos de neoplasia ${ }^{5}$. Atualmente, câncer de fígado e vias biliares constitui a oitava causa de morte por neoplasia nos Estados Unidos. Tendência semelhante tem sido observada em alguns países europeus ${ }^{6}$.

O principal fator de risco para o desenvolvimento do $\mathrm{CHC}$ é a presença de fibrose hepática avançada. Cerca de 80 a $90 \%$ dos casos de CHC surgem em fígados cirróticos e apenas 10 a $20 \%$ em fígados não cirróticos $^{7}$. Cirroses de todas as etiologias podem ser complicadas com CHC, mas a infecção crônica por hepatite B e C é responsável por $80 \%$ dos casos em todo o mundo ${ }^{8}$. O $\mathrm{CHC}$ pode também surgir em outras doenças hepáticas, mas sempre após o desenvolvimento da cirrose, indicando que esse é o verdadeiro fator predisponente para a doença. São raros os casos de $\mathrm{CHC}$ em pacientes com doença de Wilson, cirrose biliar primária, colangite esclerosante primária e hepatite autoimune ${ }^{9}$. Na hemocromatose hereditária, a incidência de $\mathrm{CHC}$ é alta, estimada em $21 \%$ em 5 anos em 
pacientes cirróticos ${ }^{10}$. A esteato-hepatite não alcoólica tem sido proposta mais recentemente como causa de cirrose e associada ao surgimento de $\mathrm{CHC}$.

\subsection{ESTADIAMENTO DO CARCINOMA HEPATOCELULAR}

O prognóstico do $\mathrm{CHC}$ está diretamente relacionado ao seu estágio à apresentação. No clássico trabalho de Okuda et al. ${ }^{11}$, que descreveu a história natural dessa neoplasia, a sobrevida global média dos pacientes era menor que 1 ano. Entretanto, a maioria dos casos incluídos nesse estudo apresentava tumores avançados. Na medida em que foi ocorrendo melhora no diagnóstico do $\mathrm{CHC}$, tumores menores começaram a ser identificados. Tornou-se necessário criar uma classificação que discriminasse melhor o prognóstico desses pacientes, pois tumores detectados em estágios mais precoces possivelmente apresentariam sobrevida diferente da observada no grupo de tumores avançados. Diversos grupos criaram sistemas de estadiamento na tentativa de atender às novas necessidades: surgiram as classificações de GETCH, na França ${ }^{12}$; CLIP, na Itália ${ }^{13}$; Tokyo $^{14}$ e Jis ${ }^{15}$ no Japão; CUPI na China ${ }^{16}$; além do tradicional TNM da Union Internationale contre le Cancer (UICC) $)^{17}$. Todas elas consideram, além do tamanho e outras características do tumor, como invasão vascular e acometimento extra-hepático, o grau de disfunção hepática apresentado pelo paciente. Os maiores problemas nessas classificações são a dificuldade que apresentam em avaliar o prognóstico de pacientes com tumores precoces, como ocorre na CLIP e na CUPI, e a dificuldade de serem empregadas, já que algumas, como a Jis e a TNM baseiam-se em informações histopatológicas dos espécimes ressecados cirurgicamente. Em 1999, foi descrita a classificação de BCLC, da Espanha ${ }^{18}$, que apresenta uma melhor capacidade de separar grupos com $\mathrm{CHC}$ em estágio precoce, intermediário, avançado e terminais, levando em consideração tanto características do tumor quanto função hepática, status físico do paciente e presença de sintomas relacionados à 
doença avaliados por uma classificação da OMS ("performance status") ${ }^{19}$. Além disso, propõe tratamentos diversos para cada classe. Esse modelo proposto mostrou-se capaz de, dentro do grupo de $\mathrm{CHC}$ de estágio precoce, identificar subgrupos que se beneficiarão de tratamentos radicais diferentes.

São considerados pacientes em estágio precoce aqueles com função hepática preservada (Child A), sem sintomas da doença, com tumores uninodulares de até $5 \mathrm{~cm}$ ou até 3 tumores com no máximo $3 \mathrm{~cm}$ de diâmetro cada. Dentro desse grupo encontram-se 2 subgrupos: o estágio muito precoce, que compreende os pacientes com tumores uninodulares de até $2 \mathrm{~cm}$ de diâmetro, e o estágio precoce, onde se situam os demais pacientes. O estágio intermediário compreende pacientes sem sintomas, com tumores multinodulares ou maiores que os incluídos no estágio precoce, Child A ou B, mas sem invasão vascular evidente ou metástases. $O$ estágio avançado engloba pacientes com metástases ou invasão vascular, mas com função hepática razoavelmente preservada, classificados como Child A ou B. Finalmente, o estágio terminal compreende pacientes com função hepática muito alterada, Child $\mathrm{C}$, com sintomas importantes relacionados à doença.

Dentro desse estudo, a sobrevida de pacientes com $\mathrm{CHC}$ precoce foi estimada entre 50 e $75 \%$ em 5 anos, $50 \%$ em 3 anos para o estágio intermediário, $50 \%$ em 1 ano para o estágio avançado e, no estágio terminal, sobrevida média de 6 meses. Esse é o sistema de estadiamento mais usado na atualidade, validado por outros grupos e adotado pelos consensos da AASLD $^{20}$ e EASL ${ }^{21}$.

\subsection{TRATAMENTO DO CARCINOMA HEPATOCELULAR}

No tratamento do $\mathrm{CHC}$ são utilizadas as seguintes modalidades terapêuticas: transplante hepático, ressecção hepática, terapias ablativas percutâneas (como injeção percutânea de agentes esclerosantes, ablação por radiofrequência, crioterapia, ablação por microondas), terapias 
locorregionais (embolização e quimioembolização transarterial) e quimioterapia sistêmica ${ }^{20}$ (tabela 1). Desses métodos, somente os três primeiros são considerados potencialmente curativos ${ }^{21}$. Mesmo assim, ressecção e ablação percutânea não impedem altas taxas de recidiva da neoplasia nas adjacências do tumor tratado e recorrência em outras áreas do fígado cirrótico. Os demais métodos são considerados terapias paliativas, que podem ou não trazer ganhos na sobrevida dos pacientes com $\mathrm{CHC}$. $\mathrm{O}$ transplante hepático parece ser a terapia mais racional, uma vez que propicia a substituição do órgão doente por um enxerto saudável, reduzindo a possibilidade de recorrência de novos tumores. Boas taxas de sobrevida são observadas em pacientes cirróticos transplantados para tratamento do CHC: em pacientes selecionados, com único nódulo tumoral menor que 5 $\mathrm{cm}$ ou até 3 nódulos de até $3 \mathrm{~cm}$ de diâmetro, a sobrevida de 4 anos supera os $70 \%{ }^{22}$. Infelizmente, o fator limitante para o emprego dessa terapia é a falta de doadores de órgãos, que ocorre em todo o mundo e restringe o número de pacientes beneficiados por essa modalidade terapêutica ${ }^{23}$. Por outro lado, a ressecção cirúrgica do $\mathrm{CHC}$, que pode resultar em benefícios consideráveis em termos de sobrevida, pode ser realizada em apenas 9 a $27 \%$ dos pacientes, devido a vários fatores limitantes como multifocalidade da doença, alto risco cirúrgico dos pacientes cirróticos, baixa capacidade funcional hepática desses pacientes, invasão do sistema porta ${ }^{24,25}$. Nesse interim, as terapias ablativas percutâneas são freqüentemente a única modalidade terapêutica possível e têm sido utilizadas em várias regiões do mundo. 
Tabela 1 - Opções terapêuticas para o CHC

\begin{tabular}{ll}
\hline \multicolumn{1}{c}{ Tratamento } & \\
\hline Métodos curativos & Transplante \\
& Ressecção \\
& Terapias ablativas \\
\hline Métodos paliativos & Embolização * \\
& Quimioembolização \\
& Quimioterapia sistêmica \\
& Medidas de suporte * \\
\hline
\end{tabular}

* sem melhora da sobrevida

\subsubsection{Terapias ablativas percutâneas}

São consideradas o método de eleição para tratamento de pacientes que não se adéquam aos critérios para ressecção ou transplante, muito embora no Japão sejam indicadas como primeira opção terapêutica ${ }^{26}$.

\subsubsection{Injeção percutânea de etanol (PEI)}

A injeção percutânea de etanol, guiada por ultra-sonografia, foi introduzida em 1983 por Sugiura et al. para o tratamento de lesões pequenas de carcinoma hepatocelular ${ }^{27}$. Seu objetivo é induzir necrose tumoral como resultado de uma desidratação celular, desnaturação protéica e oclusão química dos vasos tumorais. A injeção sob ultra-sonografia permite controle do procedimento em tempo real, acompanhando desde a introdução da agulha na lesão até o final da injeção do etanol. São utilizadas agulhas finas com calibre de 20 a 22 G com um ou mais orifícios em sua ponta. A agulha é introduzida pela pele e posicionada em uma região 
marginal e mais distal do nódulo. Inicia-se a aplicação de etanol absoluto a 99,5\% e, na medida em que essa substância é injetada, desloca-se a agulha muito lentamente para uma posição mais proximal dentro da lesão, até que uma área de hiperecogenicidade ocupe a região em que se localiza o tumor. Em alguns casos em que se observa o extravasamento do etanol através de vasos sanguíneos adjacentes, a injeção deve ser interrompida e nova punção realizada para evitar o efeito necrotizante em estruturas externas ao nódulo. O número de sessões e a quantidade de etanol injetada podem variar amplamente, de acordo com o tamanho da lesão que será tratada, distribuição do volume dentro da lesão e tolerância do paciente ${ }^{28}$. O volume de etanol empregado pode ser estimado pela fórmula $\quad V=4 / 3 \pi(r+0,5)^{3}$, em que $V$ é o volume total e $r$ é a medida do raio da lesão nodular em centímetros $^{29}$. O tratamento compreende várias sessões realizadas com a periodicidade de uma a duas vezes por semana. O procedimento é normalmente realizado sob anestesia local, com ou sem sedação endovenosa, e freqüentemente em esquema ambulatorial, sem necessidade de internação. Alguns serviços realizam o tratamento em sessão única, sob anestesia geral $^{30,31}$.

A necrose tumoral completa de tumores com até $5 \mathrm{~cm}$ de diâmetro pode ser conseguida em cerca de 70 a 100\% dos casos, como mostram estudos baseados na análise histopatológica de lesões tumorais ressecadas cirurgicamente após PEI ou em imagens de tomografia computadorizada contrastada ${ }^{32,33}$. Entretanto, a melhor resposta é observada em tumores únicos com até $2 \mathrm{~cm}$ de diâmetro. Estudos analisaram também a sobrevida de pacientes submetidos a PEI. Para tumores de até $3 \mathrm{~cm}$ de diâmetro, a sobrevida de 3 anos varia em torno de 67 a $81,6 \%$, enquanto a de 5 anos está estimada entre 41 e $60,3 \%{ }^{34,35,36}$. Há controvérsia em estudos que compararam a sobrevida de pacientes submetidos a $\mathrm{PEI}$ e a ressecção cirúrgica: enquanto Ryu et al. encontraram taxas de sobrevida semelhantes para os dois métodos de tratamento em pacientes com condição clínica semelhante $^{37}$, Arii et al. sugeriram um melhor desempenho no grupo da 
ressecção cirúrgica ${ }^{38}$. Nenhum estudo definitivo, randomizado e controlado foi realizado até o momento.

A recorrência tumoral após tratamento é mais freqüentemente resultado de uma ocorrência "de novo" em outras regiões hepáticas nãotratadas (carcinogênese multicêntrica) do que propriamente recidiva no local do tratamento ${ }^{39}$. É um problema freqüente no acompanhamento de pacientes submetidos a $\mathrm{PEI}$, assim como no daqueles submetidos a cirurgia de ressecção tumoral. Para Takayasu et al., a taxa de recorrência não foi diferente entre pacientes submetidos a esses dois tipos de tratamento ${ }^{40}$. Recorrências podem ser tratadas também através de PEI: Ebara et al. mostraram que $50 \%$ dos pacientes com recorrência primária apresentavamse ainda dentro dos critérios exigidos para tratamento com esse método. Deve-se ressaltar que o retratamento tem valor limitado, já que o número de lesões normalmente aumenta a cada vez que surge um novo foco tumoral ${ }^{36}$.

Até recentemente, essa foi a terapia ablativa percutânea mais amplamente utilizada no mundo ${ }^{34}$. Mais recentemente, a ablação por radiofrequência tem substituído a PEI por sua maior eficiência em erradicar tumores maiores e por garantir uma margem de segurança, usualmente não obtida com a PEI ${ }^{41,42}$. Entretanto, os altos custos dessa nova técnica inviabilizam a sua ampla utilização em países em desenvolvimento como o Brasil. A PEI, por sua vez, sendo um procedimento de baixo custo, baixa complexidade técnica e alta eficácia ${ }^{34}$, continua sendo uma alternativa de tratamento viável para o carcinoma hepatocelular. No Departamento de Gastroenterologia do Hospital das Clínicas da Faculdade de Medicina da Universidade de São Paulo, foi introduzida em 1997 e tem sido utilizada até hoje. 


\subsubsection{Ablação por radiofrequência (RFA)}

É o tratamento ablativo percutâneo preferido na atualidade. Sua eficácia para tumores de até $2 \mathrm{~cm}$ de diâmetro é semelhante à da PEI, mas é melhor para tumores maiores que $2 \mathrm{~cm}$. Resposta completa à ablação por radiofrequência ocorre em 96 a 100\% dos tumores, contra 86 a $89 \%$ nos tratados com $\mathrm{PEI}^{43,44}$.Essa diferença possa talvez dever-se ao fato de que, na PEl, a difusão do etanol é bloqueada por septos fibróticos intratumorais e pela cápsula, enquanto que, na radiofrequência, essas traves são destruídas. O método consiste em introduzir no tumor um eletrodo simples ou com múltiplas agulhas em forma de ganchos que libera energia térmica, provocando necrose na periferia do dispositivo.

Na comparação da sobrevida de pacientes submetidos a RFA ou a $\mathrm{PEI}, 2$ estudos randomizados e controlados mostraram resultados contraditórios. $O$ estudo japonês de Shiina et al. mostrou sobrevida de 4 anos de $74 \%$ no grupo da RFA contra $57 \%$ no grupo da PEI ${ }^{45}$. No estudo italiano de Lencioni et al., não houve diferença entre os grupos ${ }^{44}$. A probabilidade de recorrência local, por sua vez, é mais baixa nos pacientes submetidos a radiofrequência. As principais limitações dessa nova técnica são o alto custo e as taxas mais altas de efeitos adversos quando comparada à PEI.

\subsubsection{Ressecção cirúrgica}

Esse é o tratamento de eleição para carcinomas hepatocelulares que se desenvolvem em fígados não cirróticos, que constituem menos que 5\% dos casos de $\mathrm{CHC}$ no Ocidente ${ }^{46}$. Nos fígados cirróticos, a função hepática diminuída impede, em muitos casos, esse tipo de abordagem cirúrgica.

Nas últimas duas décadas, entretanto, o emprego da ressecção hepática como terapêutica para $\mathrm{O} \mathrm{CHC}$ sofreu grandes mudanças. Inicialmente considerado um procedimento com alta mortalidade $\mathrm{e}$ complicações, que raramente proporcionava sobrevida de longo prazo, hoje 
representa um tratamento de baixa morbi-mortalidade e cuja taxa de sobrevida de 5 anos é estimada em torno de $50 \%{ }^{38,47}$. Dois fatores podem ser responsabilizados por essa modificação: a melhoria dos critérios de seleção do candidato à cirurgia e a evolução da técnica cirúrgica ${ }^{48}$.

Por muito tempo o critério de seleção de pacientes para a ressecção foi a classificação de Child-Pugh ${ }^{49}$. Esse critério não se mostrou ideal, pois mesmo um paciente classificado como Child A pode apresentar sinais de perda de função hepática, como bilirrubina aumentada, propensão à formação de ascite ou já apresentar hipertensão portal importante. Vários estudos realizados na última década identificaram variáveis que influenciam na sobrevida de pacientes submetidos a ressecção ${ }^{47,50,51,52,53}$, o que permitiu criar novos critérios para indicação desse tratamento. A ausência de hipertensão portal e níveis normais de bilirrubina mostraram-se os melhores preditores de uma boa sobrevida ${ }^{47,54}$. Foi demonstrada uma taxa de sobrevida de 5 anos de $70 \%$ em pacientes sem hipertensão portal e com níveis de bilirrubina normais. Com a presença de hipertensão portal, a sobrevida de 5 anos caiu para $50 \%$ e, em pacientes que apresentavam os dois fatores, essa taxa não atingiu $30 \%{ }^{47}$. Outros fatores identificados como preditores de sobrevida foram o tamanho do tumor, o número de nódulos tumorais, presença de invasão vascular macro e microscópica, presença de nódulos satélites. O algoritmo terapêutico proposto pelo grupo Barcelona Clínic Liver Cancer (BCLC), muito usado no Ocidente na atualidade, considera todas essas características na indicação da ressecção como tratamento do $\mathrm{CHC}^{18}$.

Quanto à evolução da técnica cirúrgica, um enorme ganho foi obtido quando se passou a realizar segmentectomias anatômicas baseadas na segmentação hepática proposta por Couinaud, ao invés de lobectomias ou nodulectomias, que proporcionavam respectivamente grande prejuízo da função hepática ou margens de segurança insuficientes ${ }^{55}$. Além disso, o uso do ultra-som intra-operatório possibilitou determinar com maior precisão a localização do nódulo tumoral e a presença de nódulos satélites ${ }^{20}$. 
Finalmente, dois problemas limitam o uso desse tipo de tratamento. $\mathrm{O}$ primeiro, já comentado, refere-se à pequena parcela de pacientes que se adéqua aos critérios de seleção. $O$ segundo, diz respeito às altas taxas de recorrência do carcinoma hepatocelular no fígado operado, estimada em mais de $70 \%$ em 5 anos $^{56,57,58}$. Essa recorrência pode ser uma recorrência verdadeira, que surge em conseqüência da disseminação do tumor ressecado através de invasão vascular não detectada no momento do tratamento, ou representar uma recorrência "de novo", que é a formação de novos tumores num fígado cirrótico propenso à carcinogênese ${ }^{59}$. Quando surge um novo nódulo, não é possível classificar, na prática clínica, qual é o tipo de recorrência, embora se saiba que uma recorrência verdadeira tenda a ter comportamento mais agressivo que um novo tumor metacrônico. Considera-se, então, que recorrências verdadeiras ocorram em até 2 anos após a ressecção. Após esse período, aumentam-se as chances de que se trate de um novo tumor ${ }^{60}$. A conduta nesses casos ainda é mal estabelecida e os resultados são pouco conhecidos. Poderá ser indicada nova ressecção ${ }^{58,61}$, se factível, ou o transplante hepático ${ }^{62}$. Alguns grupos propõem a inscrição do paciente na lista de transplante hepático se identificadas na peça anatômica da ressecção características que predizem recorrência, como presença de nódulos satélites ou invasão vascular ${ }^{63}$.

\subsubsection{Transplante hepático}

Esse é o tratamento de primeira escolha para pacientes com tumores pequenos multinodulares (até 3 tumores com até $3 \mathrm{~cm}$ de diâmetro) ou para pacientes com cirrose hepática avançada, por potencialmente promover a cura tanto da neoplasia quanto da insuficiência hepática. Essa conclusão é proveniente das observações de Mazzaferro et al. , em 1996, que mostraram uma sobrevida de 4 anos de $74 \%$ em pacientes com 1 tumor de até $5 \mathrm{~cm}$ de diâmetro ou com até 3 tumores de até $3 \mathrm{~cm}$ de diâmetro submetidos a transplante hepático, com apenas $15 \%$ de recorrência tumoral ${ }^{22}$. Problemas para a realização dessa modalidade terapêutica são a escassez de 
doadores de órgãos e, em muitos casos, a necessidade de retirar pacientes em lista de transplante devido à evolução do tumor. Terapias adjuvantes que buscam controlar a progressão tumoral podem ser usadas, porém ainda sem comprovação de seus benefícios.

\subsubsection{Quimioembolização}

Não é considerado um tratamento curativo, mas foram demonstrados benefícios estatisticamente significantes na sobrevida de pacientes tratados com essa modalidade terapêutica em uma metanálise realizada por Llovet et al. em $2003^{64}$. O aumento da sobrevida em pacientes tratados varia de 20 a $60 \%$ e a dimensão desse benefício está claramente relacionada aos critérios de seleção de pacientes e tumores tratados ${ }^{65}$.

O procedimento consiste em injetar-se um agente embolizante associado a um agente quimioterápico na rede arterial, no intuito de provocar obstrução da vasculatura que nutre o tumor, deixando no interior da neoplasia uma composição com propriedades citorredutoras. Para isso, é necessário introduzir um catéter na rede arterial até a artéria hepática e então progredir seletivamente com esse catéter até ramos lobares ou segmentares da região onde se localiza o tumor. Agentes embolizantes já utilizados foram o Gelfoam, álcool, molas metálicas ou coágulos sanguíneos. Os agentes quimioterápicos mais usados são a Cisplatina e a Adriamicina. Essa técnica induz necrose tumoral isquêmica, promovendo resposta objetiva, definida como redução da massa tumoral através de métodos de imagem, em 16 a $60 \%$ dos tumores tratados ${ }^{20}$.

Esse tratamento é indicado no presente a pacientes com $\mathrm{CHC}$ inoperável inelegíveis a tratamentos percutâneos, porém sem sintomas provocados pelo tumor, trombose de veia porta ou acometimento extrahepático. Os principais efeitos colaterais são conhecidos como "síndrome pós-embolização", que compreende febre, dor abdominal, íleo paralítico. Também podem ser observados efeitos provocados pelo quimioterápico 
injetado, como náuseas, vômitos, depressão da medula óssea, alopécia e perda de função renal. Abscesso hepático e colecistite foram complicações raramente relatadas ${ }^{20}$

\subsubsection{Tratamento sistêmico}

Até recentemente, nenhum tratamento sistêmico havia mostrado resultados em termos de melhora de sobrevida. Foram testadas diversas drogas, incluindo o Tamoxifeno, Doxorrubicina e o esquema PIAF (Cisplatina, Interferon $\alpha 2 b$, Doxorrubicina e Fluoruracil) ${ }^{66}$. Em 2007, foi aprovada nos Estados Unidos e Europa a droga Sorafenib, um agente de administração oral que demonstrou aumento da sobrevida de pacientes com $\mathrm{CHC}$ avançado em 3 meses $^{67}$. A diferença de sobrevida foi estatisticamente significante em relação ao grupo não tratado. Seu mecanismo de ação baseia-se no bloqueio da angiogênese tumoral e da proliferação celular, agindo nos receptores VEGFR2, PDGFR e b-Raf. Os principais efeitos colaterais observados consistiram em diarréia, perda de peso, reações de hipersensibilidade na pele e hipofosfatemia. Foram avaliados apenas pacientes virgens de tratamento, mas estudos em que a droga é associada a outras técnicas terapêuticas já estão em andamento. Nesses estudos, o Sorafenib usado exclusivamente deverá constituir o braço controle.

\subsection{SOBREVIDA}

\subsubsection{Sobrevida global}

Ao se falar em sobrevida, deve-se lembrar sempre que a estimativa da sobrevida dos pacientes com $\mathrm{CHC}$ depende do estágio em que é feito o diagnóstico. Em 1985, quando Okuda propôs seu sistema de estadiamento, os tumores eram diagnosticados em fases avançadas. Para aqueles 
pacientes classificados como Okuda III, ou seja, pacientes terminais, com tumores grandes, ocupando mais que $50 \%$ do fígado e/ou insuficiência hepática, a sobrevida média era de 3 a 4 meses $^{11}$. Com a publicação do sistema de estadiamento de Barcelona, o BCLC, em 1999, a sobrevida pôde ser estimada para outros grupos com tumores menos avançados ${ }^{18}$. Naqueles pacientes portadores de doença avançada, com tumores sintomáticos, invasão vascular ou acometimento extra-hepático, a sobrevida média foi estimada em 6 meses. Nos pacientes com doença intermediária, ou seja, com tumor multinodular, mas sem invasão vascular ou metástases, a sobrevida média foi de 16 meses. Pacientes com doença diagnosticada em seus estágios mais precoces não têm sua história natural bem definida e a estimativa de sobrevida é proveniente de séries em que diversos tipos de tratamento foram estudados. Em geral, a sobrevida de 5 anos pode chegar a cerca de 50 a $70 \%$ após tratamentos curativos, como $\mathrm{PEI}$, ressecção e transplante, em candidatos selecionados ${ }^{68}$.

Um estudo populacional realizado nos Estados Unidos mostra, entretanto, que numa análise global, a sobrevida de pacientes com $\mathrm{CHC}$ permanece muito baixa. Em 3600 casos diagnosticados naquele país, a sobrevida foi de $36 \%$ em 1 ano e de $17 \%$ em 3 anos $^{69}$. Contribui para essas baixas taxas o pequeno número de pacientes que pôde receber algum tipo de tratamento: apenas $12 \%$ receberam tratamento potencialmente curativo (ressecção ou transplante). Estratégias para melhorar esse prognóstico sombrio seriam ampliar programas de detecção do tumor, no intuito de antecipar o diagnóstico do $\mathrm{CHC}$ para fases em que os tratamentos curativos ainda sejam possíveis, e capacitar grupos para a realização de tratamentos que melhorem a sobrevida.

\subsubsection{Sobrevida de séries submetidas a PEI}

No Japão, Ebara et al., em 2005, avaliaram os resultados da PEl após um período de 20 anos do início de sua utilização ${ }^{36}$. 270 pacientes com 352 lesões foram incluídos na análise. Todos tinham $\mathrm{CHC}$ com no máximo 3 
lesões de $3 \mathrm{~cm}$ de diâmetro ou menos, sem invasão vascular ou trombose tumoral, sem ascite ou coagulopatia, com níveis de bilirrubina abaixo de 3 $\mathrm{mg} / \mathrm{dl}$ e albumina sérica maior que $2,5 \mathrm{~g} / \mathrm{dl}$. A sobrevida de 1,3 e 5 anos encontrada foi de 99,2\%, 81,6\% e 60,3\%, respectivamente. Omata et al., em outra experiência japonesa recente, avaliaram 1238 pacientes num período de 12 anos, tratados com diversos métodos de ablação percutânea, incluindo PEI e ablação por radiofrequência ${ }^{70}$. A sobrevida global foi de $69 \%$, $50 \%$ e $34 \%$ em 1, 3 e 5 anos, mas quando subgrupos foram analisados, os pacientes com até 3 tumores de até $3 \mathrm{~cm}$ de diâmetro tratados com PEI atingiram sobrevida de $64,7 \%$ em 5 anos.

No Ocidente, 2 estudos italianos avaliaram sobrevida pós-PEI. Livraghi et al., em 1995, avaliaram 746 pacientes cirróticos submetidos a PEI num período de 8 anos $^{71}$. A sobrevida de 1, 3 e 5 anos foi de $97 \%, 56 \%$ e $40 \%$ respectivamente para pacientes com tumor único com até $3 \mathrm{~cm}$ de diâmetro. Para aqueles pacientes com tumor único de 3 a $5 \mathrm{~cm}$, as respectivas taxas foram bem próximas: $94 \%, 57 \%$ e $37 \%$. Para pacientes com tumores múltiplos, caíram para 47 e $26 \%$ em 3 e 5 anos. Lencioni et al, em estudo de 1997, que recrutou 184 cirróticos submetidos a PEI em um período de 8 anos, mostraram sobrevidas de $67 \%$ e $41 \%$ em 3 e 5 anos $^{35}$. Nesse estudo, foram selecionados para receber PEI pacientes com um tumor único de até $3 \mathrm{~cm}$ de diâmetro, ou múltiplos tumores (até 4) com até 3 $\mathrm{cm}$, sem invasão vascular, Child $\mathrm{A}$ ou $\mathrm{B}$, com idade de até 75 anos e com atividade de protrombina maior que $40 \%$ e contagem de plaquetas maior que $40.000 / \mu \mathrm{l}$.

Mais recentemente, em 2004, o estudo de Salà et al., realizado na Espanha, foi publicado, englobando uma população de 282 cirróticos submetidos a ablação percutânea (PEI em sua maioria, mas também RFA e uma combinação entre TAE e PEI) num período de $15 \operatorname{anos}^{72}$. A taxa de sobrevida encontrada foi de $87 \%, 51 \%$ e $27 \%$ em 1, 3 e 5 anos. Nessa população, uma minoria de pacientes apresentava tumores multinodulares ou únicos, maiores que $5 \mathrm{~cm}$. Todos eram Child $A$ ou $B$ e nenhum apresentava invasão vascular. 
As publicações citadas acima estão resumidas na tabela 2:

Tabela 2 - Sobrevida de pacientes cirróticos com $\mathrm{CHC}$ submetidos a PEI

\begin{tabular}{lcccl}
\hline & $\mathbf{n}$ & $\mathbf{3}$ anos & $\mathbf{5}$ anos & Comentário \\
\hline Livraghi 1995 (Itália) & 293 & $79 \%$ & $57 \%$ & PEI Child A, 1 tu até $50 \mathrm{~mm}$ \\
& 149 & $63 \%$ & $29 \%$ & PEI Child B, 1 tu até $50 \mathrm{~mm}$ \\
& 20 & $12 \%$ & $0 \%$ & PEI Child C 1 tu até $50 \mathrm{~mm}$ \\
Lencioni 1997 (Itália) & 184 & $67 \%$ & $41 \%$ & $\mathrm{PEI}$ \\
Omata 2004 (Japão) & 524 & $66 \%$ & $48 \%$ & $\mathrm{PEI}$, até 6 tu de até $6 \mathrm{~cm}$ \\
Salà 2004 (Espanha) & 282 & $51 \%$ & $27 \%$ & $\mathrm{PEI}(203) / \mathrm{RFA}(49)$ \\
Ebara 2005 (Japão) & 270 & $81 \%$ & $60 \%$ & PEI, até 3 tu de até $3 \mathrm{~cm}$ \\
\hline
\end{tabular}

Apenas alguns dos estudos mencionaram fatores preditores de sobrevida. Foram eles: função hepática, níveis de AFP sérica, tamanho do tumor até 2 ou $3 \mathrm{~cm}$ de diâmetro, número de nódulos tumorais, grau de diferenciação histológica, resposta inicial ao tratamento.

É importante ressaltar que não há estudos randomizados e controlados que comparem pacientes tratados com PEI a pacientes nãotratados. Um estudo com esse desenho nos dias atuais seria considerado antiético. Dois estudos retrospectivos e não randomizados foram realizados no passado comparando tratamento com PEI a ausência de tratamento, em grupos de características semelhantes. Foram observadas sobrevida de 5 anos de $0 \%$ em 27 pacientes $^{73}$ e de $11 \%$ em 73 pacientes $^{74}$. Na atualidade, a influência da PEI no aumento da sobrevida pode ser avaliado através de observações indiretas e da identificação do fator "tratamento" como variável independente preditora de sobrevida.

Na América Latina, informação sobre o carcinoma hepatocelular é escassa. No Brasil, o banco de dados informatizado do DATASUS, principal fonte de dados epidemiológicos sobre mortalidade no país, não contabiliza 
óbitos específicos por neoplasia hepática. De acordo com nosso conhecimento, apenas um estudo realizado em nosso serviço avaliou taxas de sobrevida em pacientes cirróticos com $\mathrm{CHC}$ no país ${ }^{75}$. Em pacientes com até 3 tumores de até $3 \mathrm{~cm}$ de diâmetro, a sobrevida foi de $80 \%, 41 \%$ e $17 \%$ em 1, 3 e 5 anos, respectivamente. Cerca de 65\% desses pacientes haviam recebido tratamento com $\mathrm{PEI}, 5,5 \%$ haviam sido submetidos a ressecção cirúrgica e $5,5 \%$ a transplante hepático. Nenhum estudo foi publicado avaliando diretamente o efeito de um tratamento específico na sobrevida de pacientes cirróticos com $\mathrm{CHC}$. 


\section{Objetivos}


O objetivo principal deste estudo foi avaliar a sobrevida de pacientes cirróticos com diagnóstico de carcinoma hepatocelular submetidos a injeção percutânea de etanol como tratamento primário para a neoplasia.

O objetivo secundário foi avaliar variáveis associadas à sobrevida nessa população de pacientes cirróticos com diagnóstico de carcinoma hepatocelular submetidos a injeção percutânea de etanol como tratamento primário. 
3 Pacientes e Métodos 


\subsection{PACIENTES}

Foram incluídos neste estudo pacientes cirróticos com carcinoma hepatocelular confirmado, submetidos a injeção percutânea de etanol como tratamento primário para a neoplasia, selecionados consecutivamente no período de $1^{\circ}$ de setembro de 1997 a 31 de dezembro de 2005 no Serviço de Hepatologia do Departamento de Gastroenterologia Clínica do Hospital das Clínicas da Faculdade de Medicina da Universidade de São Paulo (HCFMUSP).

Nesse período, carcinoma hepatocelular foi diagnosticado em 431 pacientes cirróticos. Desses, 100 foram submetidos a injeção percutânea de etanol como primeiro tratamento. Ressecção hepática foi o primeiro tratamento em 34 casos, transplante hepático em 16, ablação por radiofrequência em 17, embolização ou quimioembolização em 74. 141 pacientes não realizaram nenhum tipo de tratamento direcionado ao tumor. Houve perda de informação em 49 pacientes (figura 1). 


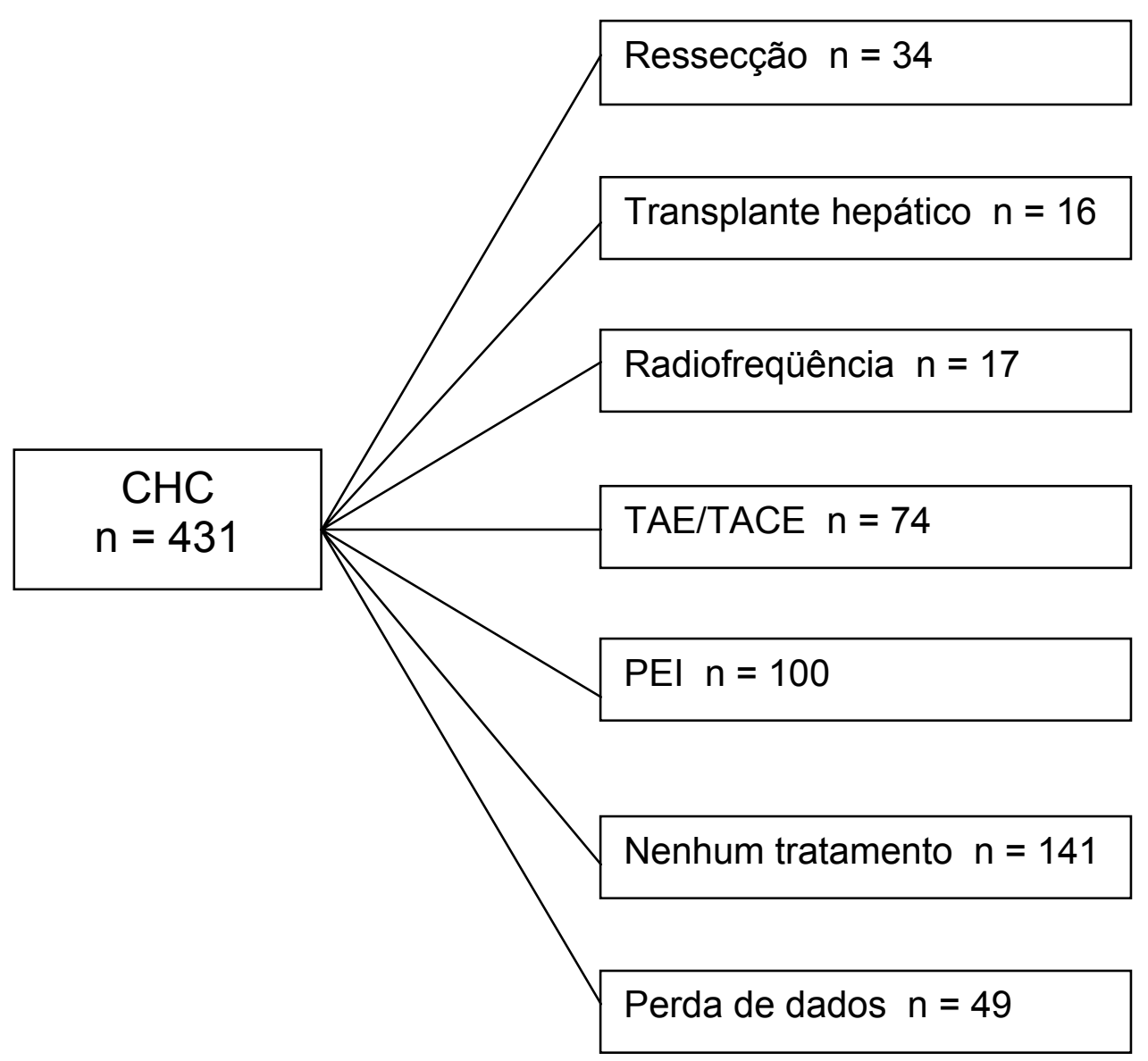

Figura 1 - Tratamento do carcinoma hepatocelular no HCFMUSP entre $1997-2005$

O diagnóstico de cirrose foi realizado através de histologia positiva em 70 casos. Nos outros 30 casos, o diagnóstico foi realizado através da somatória de exame ultrassonográfico indicando hepatopatia crônica e quadro clínico-laboratorial compatível. Foram consideradas características clínico-laboratoriais compatíveis: a presença de ascite, encefalopatia hepática, alteração de bilirrubinas, plaquetas, albumina, tempo e atividade de protrombina. 
Os critérios para diagnóstico do carcinoma hepatocelular foram os relacionados abaixo:

a) Histopatologia: histologia positiva para carcinoma hepatocelular em amostra de biópsia do nódulo;

b) Imagem: presença de imagem nodular vista em pelo menos dois exames de imagem, sendo pelo menos um deles exame contrastado, dinâmico, mostrando captação de contraste típica na fase arterial e clareamento do contraste na fase portal.

c) Imagem + dosagem de alfa-fetoproteína: presença de nódulo ou massa hepática em um exame de imagem ocorrendo simultaneamente a níveis sanguíneos de alfa-fetoproteína maiores que $200 \mathrm{ng} / \mathrm{dl}$.

\subsubsection{Critérios de Inclusão}

Foram incluídos pacientes que apresentavam todos os ítens abaixo:

a) Cirrose hepática.

b) Carcinoma hepatocelular diagnosticado por pelo menos um dos critérios relacionados anteriormente.

c) Injeção percutânea de etanol realizada como primeiro método de tratamento para o carcinoma hepatocelular.

\subsubsection{Critérios de exclusão}

Foram excluídos os pacientes que houvessem sido submetidos a qualquer outra modalidade de tratamento para o carcinoma hepatocelular antes da injeção percutânea de etanol. 


\subsection{MÉTODOS}

\subsubsection{Seleção de pacientes}

Para a seleção de pacientes cirróticos com diagnóstico de carcinoma hepatocelular foi utilizado o banco de dados informatizado do Setor de Ultrasonografia do Serviço de Hepatologia do Departamento de Gastroenterologia Clinica do HCFMUSP.

\subsubsection{Dados clínicos e laboratoriais}

Os dados clínicos e laboratoriais dos pacientes incluídos no estudo foram levantados do banco de dados informatizado do setor de Ultrasonografia do Serviço de Hepatologia do Departamento de Gastroenterologia Clínica do HCFMUSP, do arquivo informatizado do laboratório de Patologia Clínica do HCFMUSP e dos prontuários médicos arquivados na Divisão de Arquivo Médico (DAM) do HCFMUSP. Todos esses dados foram coletados por um único pesquisador.

As variáveis coletadas estão explicitadas abaixo:

- Sexo: masculino ou feminino;

- Idade: em anos;

- Etiologia da cirrose hepática: hepatite $C$, hepatite $B$, etilismo, outras causas (esteato-hepatite não alcoólica, criptogênica, hepatite autoimune, cirrose biliar primária, hemocromatose, colangite esclerosante primária, doença de Wilson e outras), causa mista (duas ou mais das causas citadas anteriormente);

- Classificação funcional da cirrose pelo critério de Child-Pugh: A, B ou C 


\subsubsection{Dados relacionados ao diagnóstico e tratamento do carcinoma hepatocelular}

Os dados relacionados ao diagnóstico e tratamento do carcinoma hepatocelular foram obtidos através da análise do banco de dados informatizado do setor de Ultra-sonografia do Serviço de Hepatologia do Departamento de Gastroenterologia Clínica do HCFMUSP, dos prontuários médicos arquivados na Divisão de Arquivo Médico (DAM) do HCFMUSP e dos laudos arquivados eletronicamente no Departamento de Anatomia Patológica. Todos esses dados foram coletados por um único pesquisador.

As variáveis coletadas estão explicitadas abaixo e resumidas na tabela 3:

- Tipo de exame de imagem de suspeição do CHC: ultra-sonografia, tomografia computadorizada de abdome, ressonância nuclear magnética de abdome ou outro;

- Data do exame de imagem de suspeição do $\mathrm{CHC}$;

- Data do fechamento do diagnóstico de $\mathrm{CHC}$;

- Método de diagnóstico do CHC: histologia, imagem ou imagem + alfafetoproteína (conforme descrição realizada anteriormente). No caso de positividade por mais de um critério, foi considerada a ordem cronológica, ou seja, o primeiro critério diagnóstico preenchido;

- Data do início do tratamento: data da primeira sessão de PEl;

- Intervalo S-D: tempo decorrido entre o exame de suspeição do $\mathrm{CHC}$ e o diagnóstico definitivo do $\mathrm{CHC}$, em dias;

- Intervalo S-T: tempo decorrido entre o exame de suspeição do $\mathrm{CHC}$ e o início do tratamento, em dias;

- Intervalo D-T: tempo decorrido entre o diagnóstico definitivo de $\mathrm{CHC}$ e o início do tratamento, em dias; 
- Dosagem de alfa-fetoproteína na época do diagnóstico do CHC, em ng/ml;

- Número de nódulos tumorais: observados na data de fechamento do diagnóstico de $\mathrm{CHC}$;

- Tamanho do maior nódulo tumoral à época da sua identificação: em milímetros;

- Segmento hepático onde se situava o maior nódulo tumoral;

- Lobo hepático onde se situava o maior nódulo tumoral (direito ou esquerdo);

- Aspecto ecográfico do maior nódulo tumoral: hipoecogênico, hiperecogênico, isoecogênico ou misto;

- Tamanho do maior nódulo tumoral à data do tratamento: em milímetros;

- Presença de invasão vascular macroscópica: detectada por métodos de imagem no momento do diagnóstico;

- Número de sessões de PEl;

- Volume total de etanol injetado no maior nódulo, em ml;

- Complicações do tratamento por PEl;

- Segundo tipo de tratamento para CHC realizado: ressecção, embolização ou quimioembolização transarterial (TAE/TACE), nenhum;

- Participação de programa de rastreamento no serviço. 
Tabela 3 - Variáveis coletadas

\begin{tabular}{llll}
\hline Pacientes & Tumor & Diagnóstico & Tratamento \\
\hline Sexo & Tamanho diagnóstico & Critério diagnóstico & Número sessões \\
Idade & Tamanho tratamento & Exame imagem deteç̧ão & Total OH injetado \\
Etiologia da cirrose & Número nódulos & Intervalo S-D & Complicações \\
Child-Pugh & Segmento & Intervalo D-T & $2^{0}$ tratamento \\
AFP diagnóstico & Lobo & Intervalo S-T & Resposta \\
Rastreamento & Aspecto ao US & & \\
& Invasão vascular macro & & \\
\hline
\end{tabular}

\subsubsection{Avaliação da resposta ao tratamento}

A avaliação da resposta ao tratamento foi realizada preferencialmente através da análise dos exames de imagem armazenados no arquivo de exames de imagem do Setor de Ultra-sonografia do Serviço de Hepatologia do Departamento de Gastroenterologia Clínica do HCFMUSP ou através de informações contidas nos laudos arquivados no mesmo setor quando houve impossibilidade de se obterem as imagens. A resposta ao tratamento foi avaliada por tomografia computadorizada helicoidal dinâmica, contrastada realizada um mês após o término do tratamento primário e classificada como completa, parcial ou ausente, conforme critérios descritos abaixo:

a) Resposta completa: ausência completa de captação de contraste pelo tumor na fase arterial.

b) Resposta parcial: presença de captação de contraste pelo tumor na fase arterial, em área menor que a observada no exame prétratamento.

c) Resposta ausente: presença de captação de contraste arterial pelo tumor em área maior ou semelhante à demonstrada no exame prétratamento, ou crescimento evidente da lesão. 


\subsubsection{Avaliação da sobrevida}

Os dados relativos à sobrevida dos pacientes foram levantados através de busca ativa, por telefonema ao paciente e aos parentes dos pacientes, por levantamento de prontuário médico ou por registro da última consulta do paciente no complexo HCFMUSP. A maior parte dos pacientes vivos encontrava-se em acompanhamento no HCFMUSP. Para a avaliação da sobrevida, foram considerados como ponto inicial a data do diagnóstico do carcinoma hepatocelular e como ponto final, a data do óbito ou a data de realização de transplante hepático caso o paciente o tivesse realizado ou a data do fim do seguimento, dia 27 de fevereiro de 2008, para os pacientes vivos e não transplantados. Esse intervalo de tempo foi calculado em meses.

\subsection{ANÁLISE ESTATÍSTICA}

As variáveis qualitativas, como sexo, etiologia da cirrose, classificação de Child-Pugh, número de tumores, segmento de localização do maior tumor, característica ultrassonográfica do tumor, resposta ao tratamento, estão apresentadas em texto e gráficos contendo freqüências absolutas e relativas. As variáveis quantitativas, como idade, diâmetro do maior tumor, dosagem de alfa-fetoproteína e outras estão apresentadas em tabelas contendo média, mediana, desvio-padrão, valores mínimos e máximos. A sobrevida global e estratificada por grupos foi avaliada através do método de Kaplan-Meier. As variáveis foram relacionadas ao evento óbito através da análise univariada pelo método de Kaplan-Meier. Os valores de $p$ inferiores a 0,05 foram considerados estatisticamente significantes. As variáveis estatisticamente significantes obtidas pela análise univariada foram submetidas a análise multivariada pelo método da regressão logística de Cox. Os valores de $p$ inferiores a 0,05 foram considerados estatisticamente significantes. O programa estatístico utilizado para os cálculos foi o SPSS versão 12.0 (SPSS Inc., Chicago, Estados Unidos). 


\subsection{ASPECTOS ÉTICOS}

De acordo com a resolução 196 do Conselho Nacional de Saúde (CNS), de 10 de outubro de 1996, que determina os referenciais básicos da bioética, as pesquisas envolvendo o ser humano, de forma direta ou indireta, incluindo o manejo de informações devem conter 0 termo de consentimento livre e esclarecido (parágrafo III.3, item g). Entretanto, como esse estudo tem caráter retrospectivo, tornou-se inviável a aplicação desse termo: grande parte dos pacientes envolvidos estava impossibilitada de contato por falecimento. Nesses casos, a mesma resolução CNS 196/96 orienta (parágrafo IV.3, item c) que isso seja documentado, com as explicações das causas da impossibilidade de aplicação do termo e parecer do Comitê de Ética em Pesquisa da Instituição responsável. A carta que solicita a dispensa do termo de consentimento livre e esclarecido à Comissão de Ética em Pesquisa, com as devidas justificativas, encontra-se no Anexo I desta dissertação.

Este projeto atende também a todas as outras exigências explicitadas na resolução CNS 196/96, em especial àquelas que dizem respeito à fundamentação científica da pesquisa, metodologia aplicada e relevância social. Todas as providências foram tomadas para que em nenhum momento a identidade dos pacientes estudados fosse revelada, bem como para que nenhuma informação fosse associada aos mesmos, obedecendo aos princípios da confidencialidade e da privacidade.

Este projeto de pesquisa foi aprovado pela Comissão de Ética em Pesquisa (CAPPesq) em 2 de abril de 2008, conforme documento em anexo (Anexo II). 


\section{Resultados}




\subsection{CARACTERÍSTICAS DA POPULAÇÃO}

\subsubsection{Sexo}

A população estudada constituiu-se de 73 (73\%) pacientes do sexo masculino e 27 (27\%) pacientes do sexo feminino (figura 2).

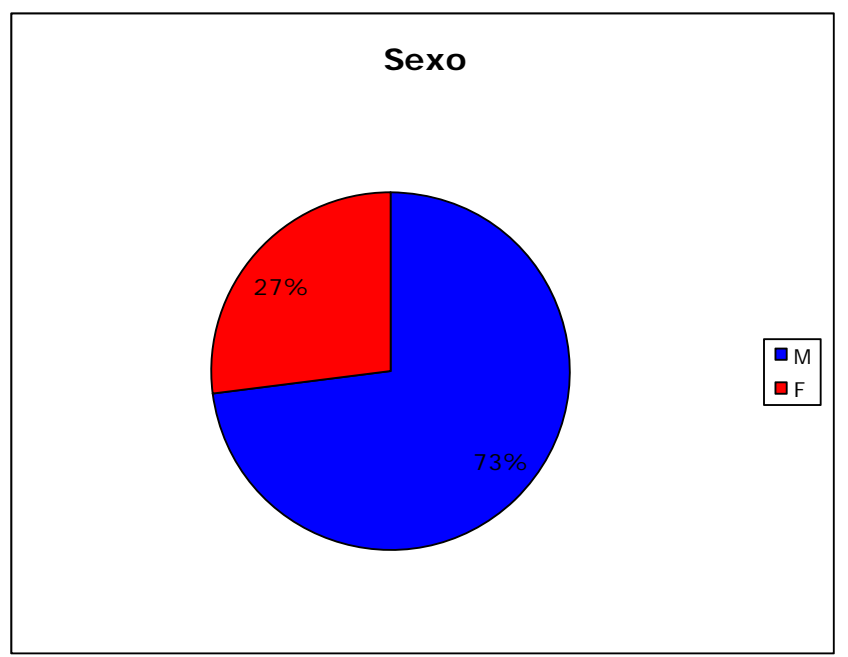

Figura 2 - Distribuição dos pacientes quanto ao sexo

\subsubsection{Idade}

A média de idade da população foi de 56,9 anos, variando de 26 a 77 anos.

Tabela 4 - Idade dos pacientes

\begin{tabular}{cc}
\hline & Idade (anos) \\
\hline Média & 56,9 \\
Mediana & 58 \\
Desvio padrão & 11,065 \\
Mínimo & 26 \\
Máximo & 77 \\
\hline
\end{tabular}




\subsubsection{Etiologia da cirrose hepática}

Todos os pacientes eram portadores de cirrose hepática, confirmada através de exame histopatológico em 70 casos $(70 \%)$ e através de exames clínico-laboratoriais e de imagem em 30 casos (30\%).

A etiologia da cirrose hepática observada nos 100 casos variou entre as seguintes:

- Hepatite $\mathrm{C}-55$ casos

- Hepatite $\mathrm{C}+$ etilismo - 9 casos

- Hepatite B - 16 casos

- Hepatite B + etilismo - 2 casos

- Hepatite C + hepatite B - 3 casos

- Etilismo crônico - 9 casos

- Esteato-hepatite não alcoólica - 2 casos

- Colangite esclerosante primária - 1 caso

- Cirrose criptogênica - 3 casos

Os pacientes distribuem-se, de acordo com a etiologia da cirrose hepática, na proporção demonstrada na figura 3 .

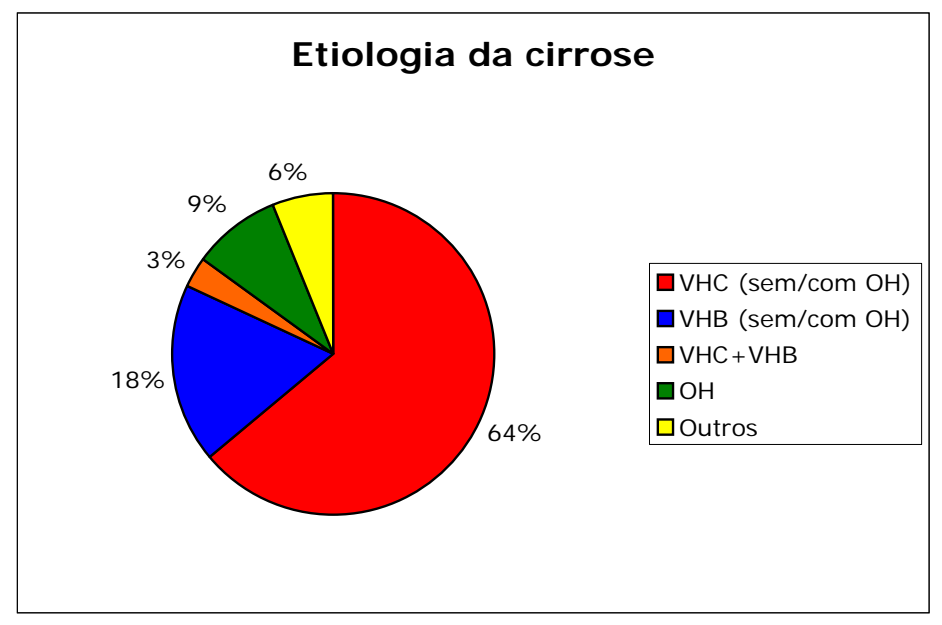

Figura 3 - Distribuição dos pacientes quanto à etiologia da cirrose hepática 


\subsubsection{Classificação funcional}

De acordo com a classificação funcional de Child-Pugh, a população estudada apresentava o seguinte perfil: 61 pacientes classificavam-se como A $(62,9 \%), 27$ como B $(27,8 \%)$ e 9 (9,3\%) como C (figura 4). Em 3 pacientes não foi possível aplicar essa classificação devido à falta de dados clínicolaboratoriais disponíveis no momento deste estudo.

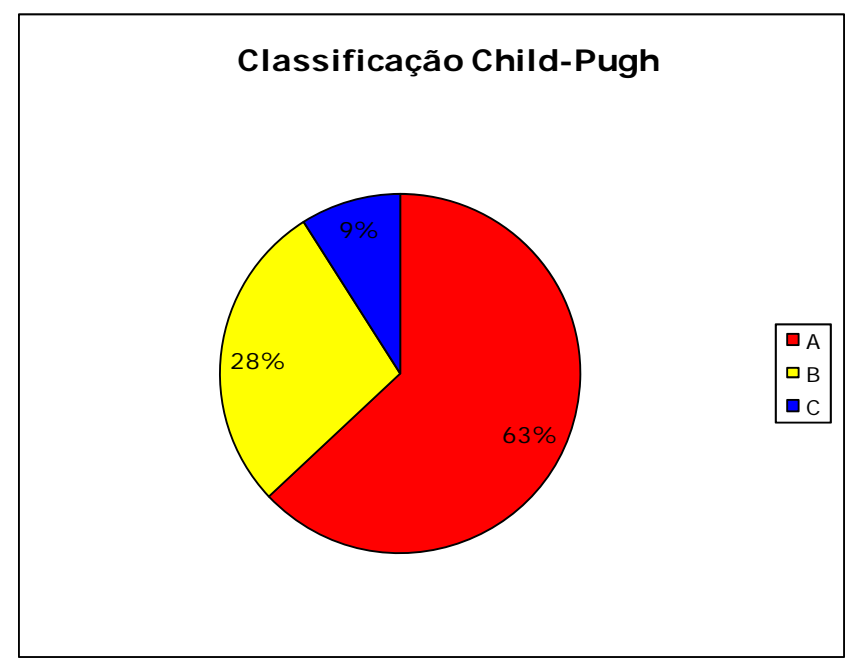

Figura 4 - Distribuição dos pacientes quanto à classificação funcional de Child-Pugh 


\subsubsection{Programa de rastreamento}

Nessa população, 39 pacientes (39\%) encontravam-se em programa de rastreamento para carcinoma hepatocelular, em que eram realizados dosagem de alfa-fetoproteína sérica e ultra-sonografia de abdome a cada 6 meses. 61 pacientes não realizavam rastreamento e constituíam pacientes encaminhados de outros serviços externos ou de outras clínicas do Hospital das Clínicas da FMUSP (figura 5).

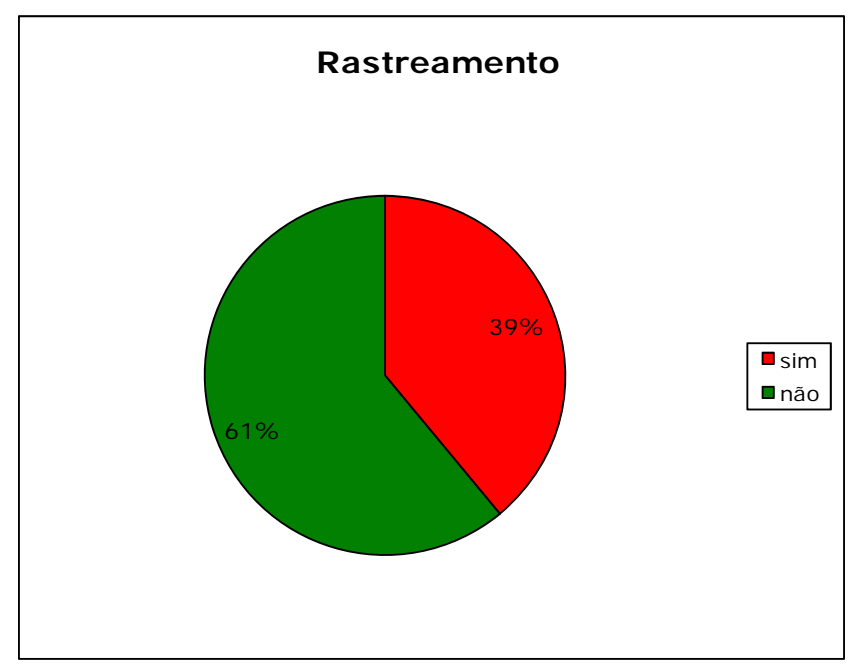

Figura 5 - Distribuição de pacientes quanto a estar ou não realizando rastreamento para o carcinoma hepatocelular 


\subsubsection{Níveis de alfa-fetoproteína sérica}

Os níveis de alfa-fetoproteína sérica na população estudada foram obtidos no momento do diagnóstico do carcinoma hepatocelular. Em 8 pacientes essa informação não estava disponível nos bancos de dados pesquisados. A mediana dos níveis de AFP foi de 15,65 ng/dl (tabela 5).

Tabela 5 - Níveis de AFP sérica ao diagnóstico

\begin{tabular}{cc}
\hline Alfa-feto proteína sérica $(\mathbf{n g} / \mathbf{d} \mathbf{l})$ & \\
\hline Média & 376,28 \\
Mediana & 15,65 \\
Desvio-padrão & 1920,11 \\
Mínimo & 1 \\
Máximo & 17028 \\
\hline
\end{tabular}

A distribuição dos pacientes segundo os níveis de AFP sérica está demonstrada na figura 6. A dosagem de AFP variou de 1 até $20 \mathrm{ng} / \mathrm{dl}$ em 50 pacientes $(54,34 \%)$, de 21 a $100 \mathrm{ng} / \mathrm{dl}$ em 26 pacientes $(28,26 \%)$ e foram maiores que $100 \mathrm{ng} / \mathrm{dl}$ em 16 pacientes $(17,4 \%)$.

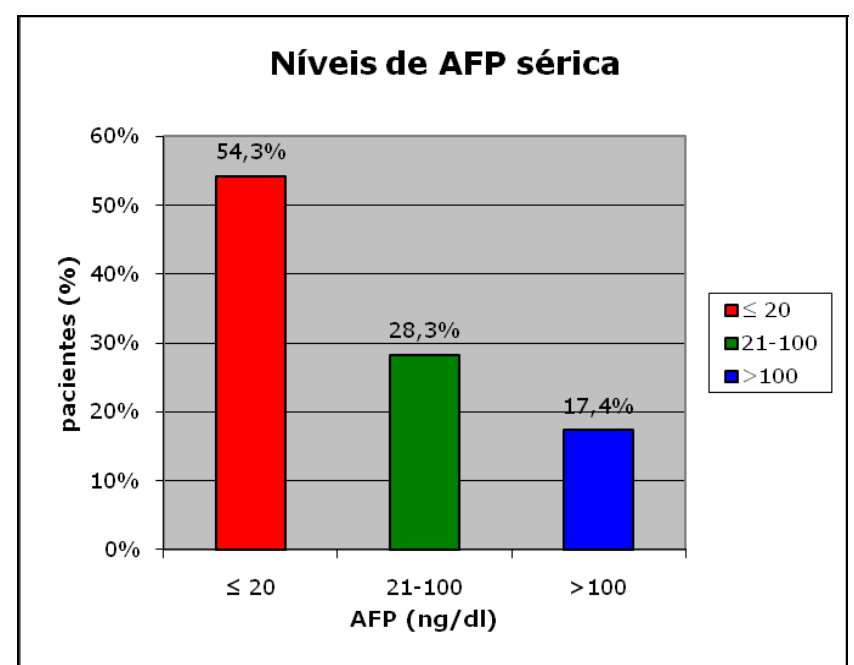

Figura 6 - Distribuição dos pacientes quanto aos níveis de alfafetoproteína sérica obtidos no momento do diagnóstico do $\mathrm{CHC}$ 


\subsection{CARACTERÍSTICAS DO TUMOR}

\subsubsection{Número de nódulos tumorais}

Ao momento do diagnóstico, foi registrado o número de nódulos tumorais identificados à ultra-sonografia. Esse número variou de 1 a 4 , na seguinte proporção: nódulo único estava presente em 79 pacientes (79\%), dois nódulos em 15 pacientes (15\%), 3 nódulos em 4 pacientes (4\%) e 4 nódulos em 2 pacientes (2\%) (figura 7 ).

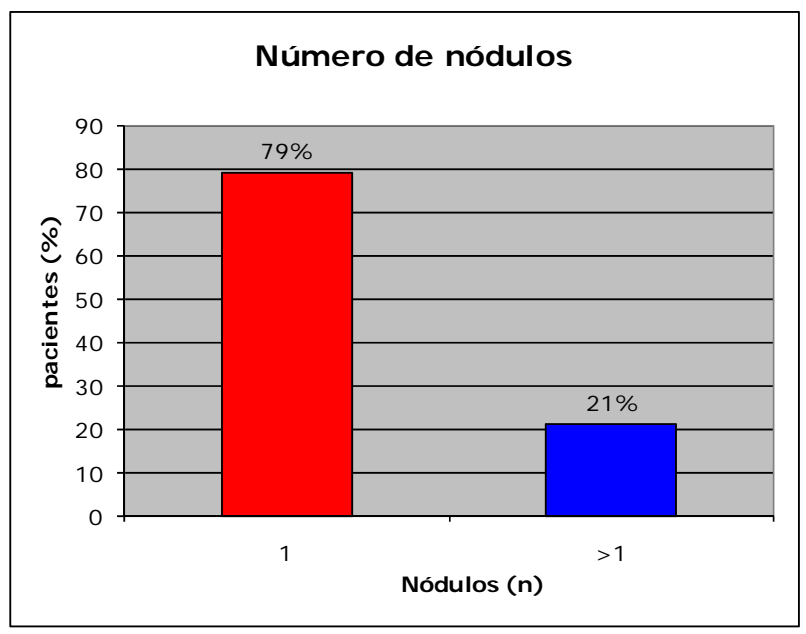

Figura 7 - Distribuição dos pacientes quanto ao número de nódulos tumorais observados à ultra-sonografia no momento do diagnóstico 


\subsubsection{Tamanho do maior nódulo tumoral}

Foi considerado neste estudo o diâmetro do maior nódulo tumoral identificado à ultra-sonografia, no momento de detecção do mesmo. A média de tamanho do maior nódulo foi de $23,33 \mathrm{~mm}$ e o tamanho variou de 9 a 50 $\mathrm{mm}$ de diâmetro (tabela 6).

Tabela 6 - Tamanho do maior nódulo tumoral no momento do diagnóstico, avaliado por ultra-sonografia

\section{Tamanho do maior tumor $(\mathrm{mm})$}

\begin{tabular}{cc}
\hline Média & 23,33 \\
Mediana & 20,5 \\
Desvio padrão & 9,225 \\
Mínimo & 9 \\
Máximo & 50 \\
\hline
\end{tabular}

Em 50 pacientes (50\%) o maior tumor presente no momento do diagnóstico media até $20 \mathrm{~mm}$ de diâmetro e nos outros 50 pacientes (50\%), o maior tumor media mais que $20 \mathrm{~mm}$ de diâmetro (figura 8).

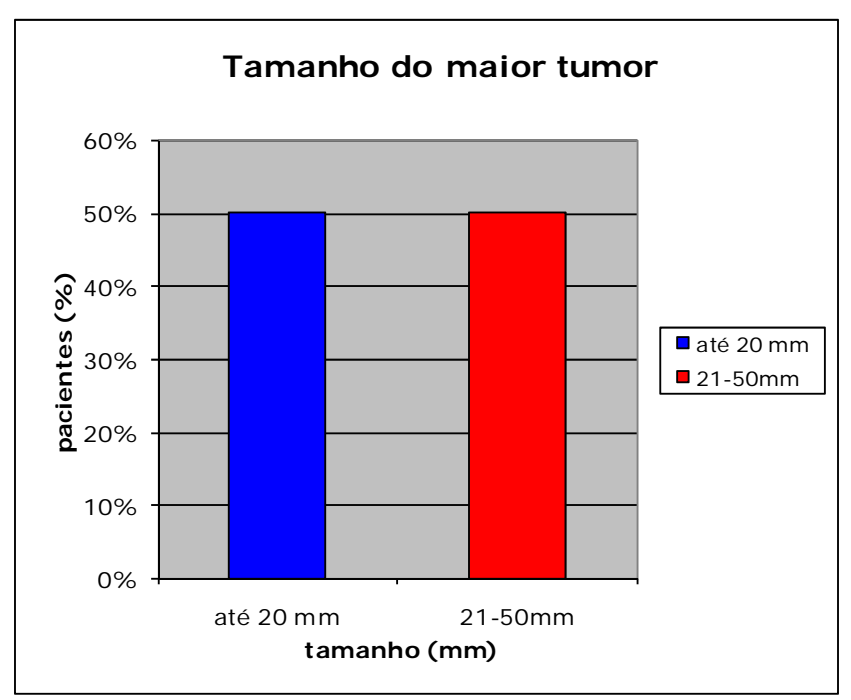

Figura 8 - Distribuição dos pacientes quanto ao tamanho do maior tumor presente no momento do diagnóstico, avaliado por ultra-sonografia 


\subsubsection{Localização do maior nódulo tumoral}

Para essa análise foi considerada a localização do maior tumor no parênquima hepático. Em 69 pacientes, o maior tumor localizava-se no lobo direito e em 31 pacientes, no lobo esquerdo (figura 9). Considerando-se cada segmento de Couinaud separadamente, 25 pacientes apresentavam o maior tumor no segmento V, 19 no segmento VIII, 13 nos segmentos IV, 13 no segmento VI, 12 no segmento VII, 11 no segmento II e 7 no segmento III, como mostra a figura 10.

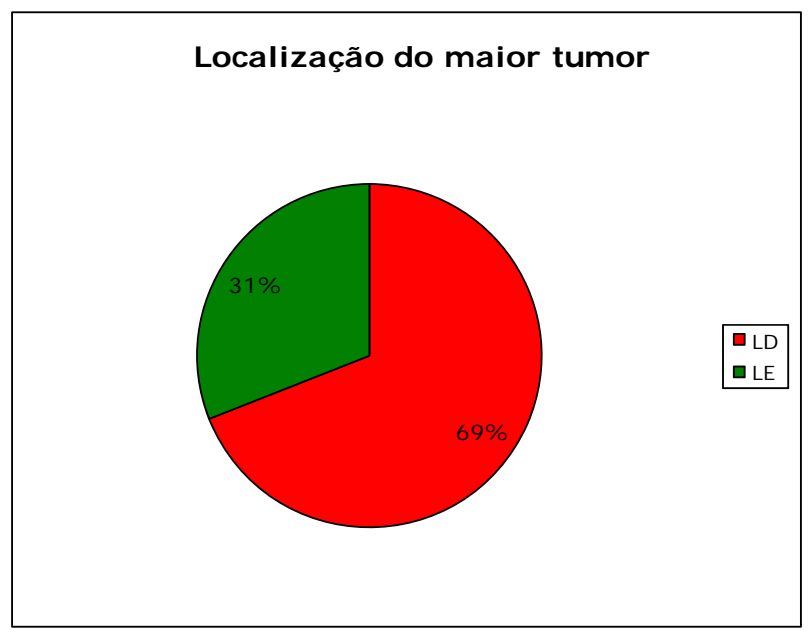

Figura 9 - Distribuição dos pacientes quanto ao lobo hepático em que se localizava o maior tumor

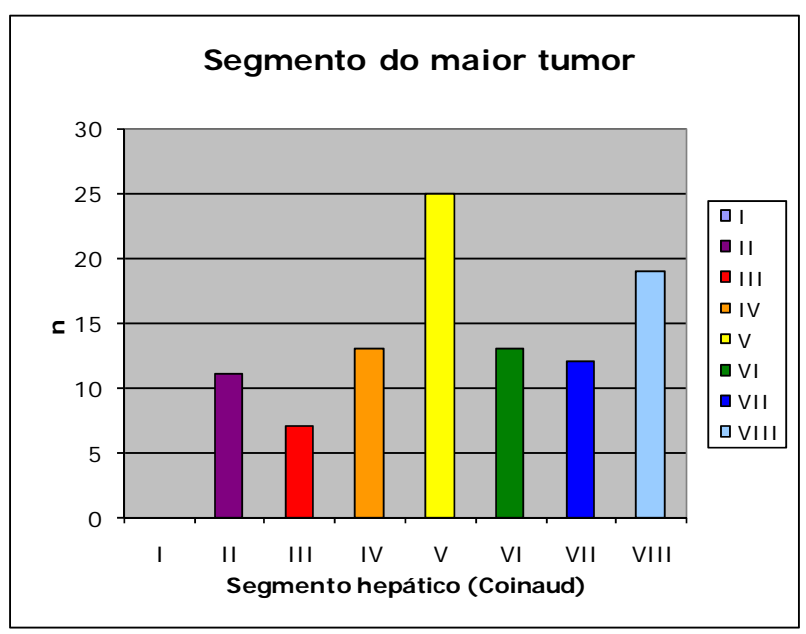

Figura 10 - Número de tumores encontrados em cada segmento hepático, segundo a classificação de Couinaud 


\subsubsection{Caracterização do maior tumor à ultra-sonografia}

O aspecto do maior tumor à ultra-sonografia foi classificado nas seguintes categorias:

- Hipoecogênico: tumor homogêneo, com ecogenicidade menor que a do fígado adjacente;

- Hiperecogênico: tumor homogêneo, com ecogenicidade maior que a do parênquima adjacente;

- Isoecogênico: tumor homogêneo, com ecogenicidade semelhante à do parênquima adjacente, na maior parte das vezes apresentando um halo periférico hipoecogênico que ajuda a delimitar o tumor;

- Misto: tumor heterogêneo, com áreas hipo, iso e/ou hiperecogênicas.

Os maiores tumores apresentaram-se, de acordo com seu aspecto ultra-sonográfico, na proporção demonstrada na figura 11. A maior parte deles tinha aspecto hipoecogênico (53\%), seguindo-se os tumores mistos (20\%).

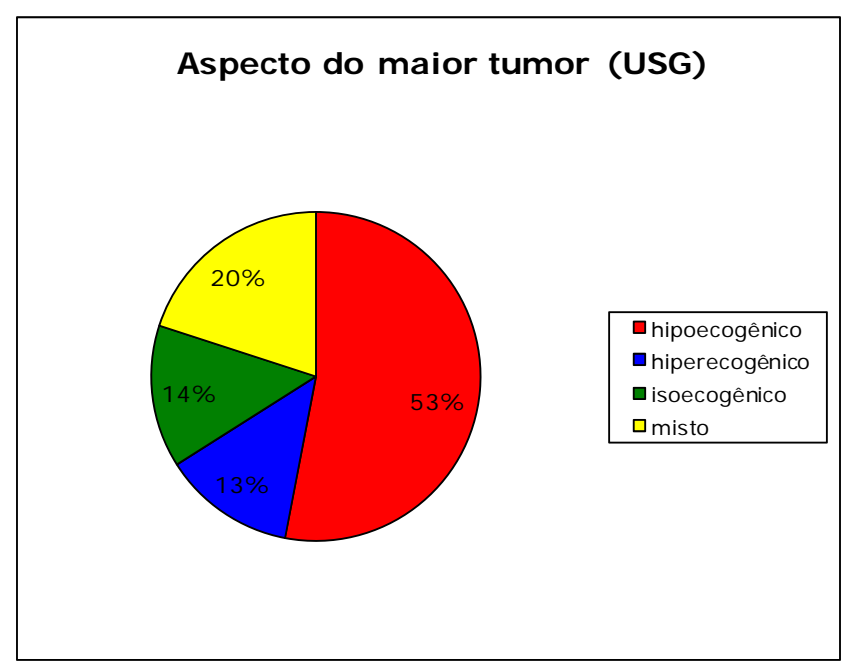

Figura 11 - Distribuição dos casos quanto ao aspecto ecográfico do maior tumor 


\subsubsection{Invasão vascular}

Foi detectada em apenas 3 pacientes (3\%). Os outros 97 pacientes não apresentavam indícios de invasão vascular aos métodos de imagem (figura 12).

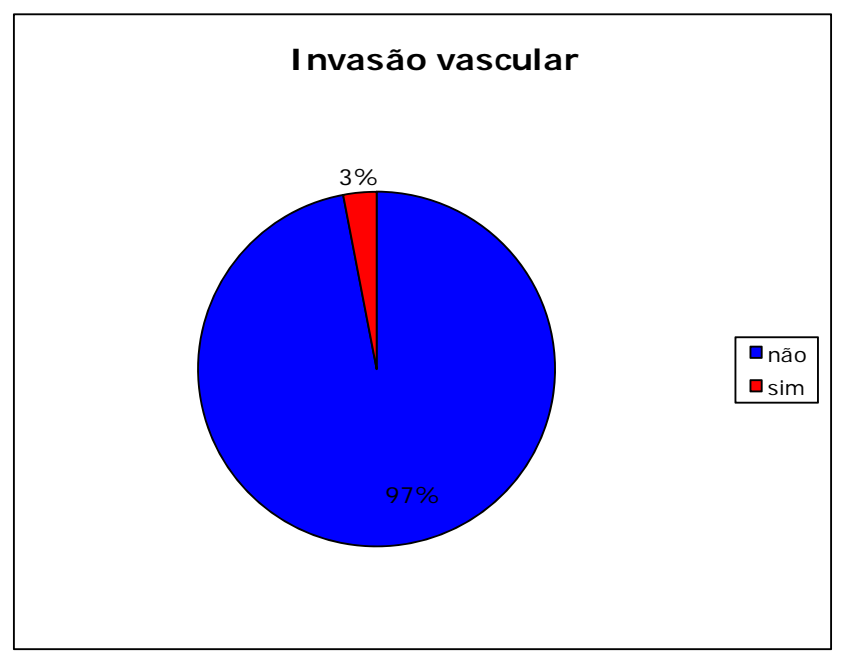

Figura 12 - Distribuição dos pacientes quanto à presença de invasão vascular macroscópica no momento do diagnóstico 


\subsection{DIAGNÓSTICO}

\subsubsection{Critérios diagnósticos}

Em 23 casos (23\%) o diagnóstico foi fechado pelo critério histopatológico. 68 casos (68\%) foram diagnosticados pelo critério imagem e 9 casos (9\%) pelo critério AFP + imagem (figura 13).

Como descrito previamente, o critério diagnóstico considerado foi o primeiro a ser atingido pela ordem cronológica. Se não considerada a ordem cronológica, a maior parte dos pacientes preencheu mais de um critério. Ao longo de sua observação, 54 pacientes (54\%) obtiveram exame histopatológico confirmando a presença de carcinoma hepatocelular.

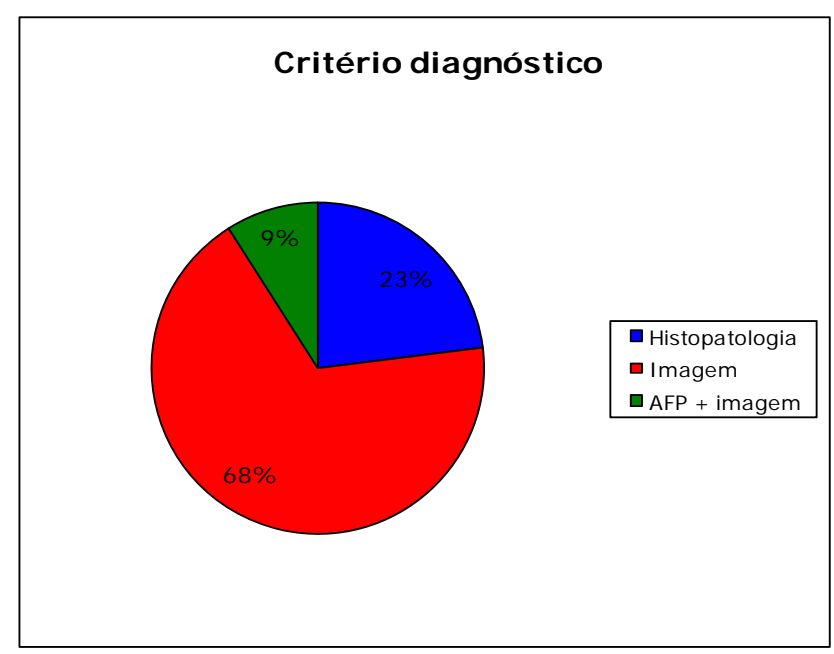

Figura 13 - Distribuição dos casos de acordo com o critério utilizado para diagnóstico do $\mathrm{CHC}$ 


\subsubsection{Detecção do tumor}

O carcinoma hepatocelular foi detectado através de ultra-sonografia hepática em 76 casos, através de tomografia computadorizada do abdome em 21 casos e por ressonância nuclear magnética do abdome em 3 casos (figura 14). Em 21 casos, níveis de alfa-fetoproteína anormais motivaram a realização de nova ultra-sonografia ou de tomografia computadorizada/ ressonância magnética.

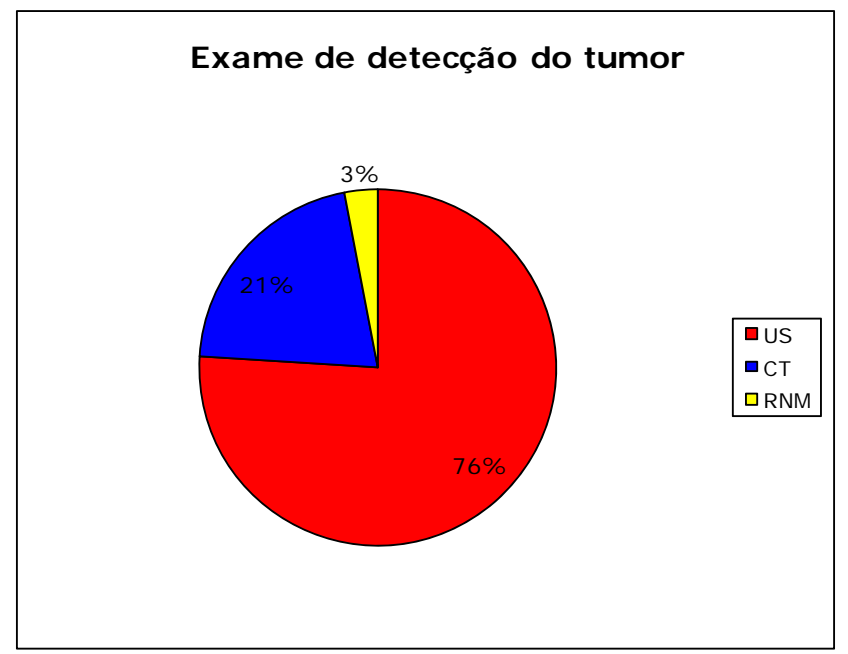

Figura 14 - Distribuição dos casos de acordo com o exame de imagem de detecção do tumor 


\subsection{TRATAMENTO}

\subsubsection{Tamanho do maior tumor à data do tratamento}

A média de diâmetro do maior tumor à data do tratamento foi de 26,35 $\mathrm{mm}$. As demais características estão listadas na tabela 4. A média de tempo desde a data do diagnóstico até a data do tratamento foi de 55,26 dias, e variou entre 0 e 361 dias (tabela 7).

Tabela 7 - Tamanho do maior nódulo tumoral à data do tratamento

Tamanho do maior tumor à data do tratamento $(\mathrm{mm})$ Média 26,35

Mediana 26

Desvio padrão

9,186

Mínimo

9

Máximo 55 


\subsubsection{Número de sessões de PEI}

A média do número de sessões de injeção percutânea de etanol foi de 3,21 e a mediana, 3 sessões. O número de sessões variou de 1 a 8 (tabela 8). 69 pacientes (69\%) realizaram mais que 2 sessões de PEI, enquanto 31 casos (31\%) realizaram apenas 1 ou 2 sessões (figura 15).

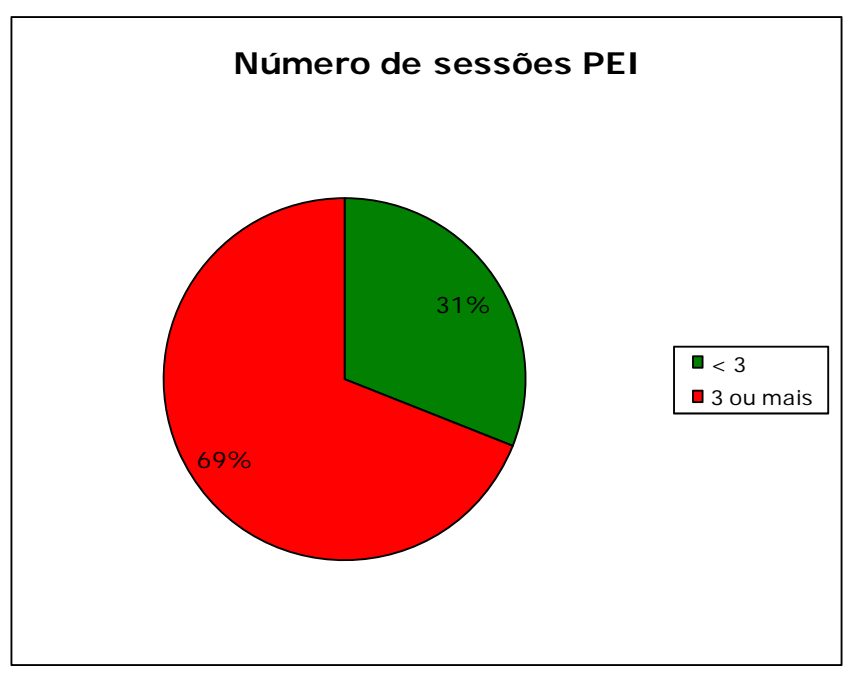

Figura 15 - Distribuição dos casos de acordo com o número de sessões de PEI que receberam 


\subsubsection{Volume de etanol injetado no maior tumor}

A média de volume de etanol absoluto injetado no maior tumor foi de $17,17 \mathrm{ml}$ e variou entre 1 e $65 \mathrm{ml}$ (tabela 8). 74 tumores foram tratados com $10 \mathrm{ml}$ ou maior volume de etanol injetado. 26 tumores foram tratados com menos de $10 \mathrm{ml}$ de etanol injetado (figura 16).

Tabela 8 - Número de sessões de PEl e volume total de etanol injetado

\begin{tabular}{lccccc}
\hline & Média & Mediana & Desvio-padrão & Min & Max \\
\hline Número de sessões & 3,21 & 3 & 1,559 & 1 & 8 \\
Volume total $\mathrm{OH}(\mathrm{ml})$ & 17,17 & 14 & 12,102 & 1 & 65 \\
\hline
\end{tabular}

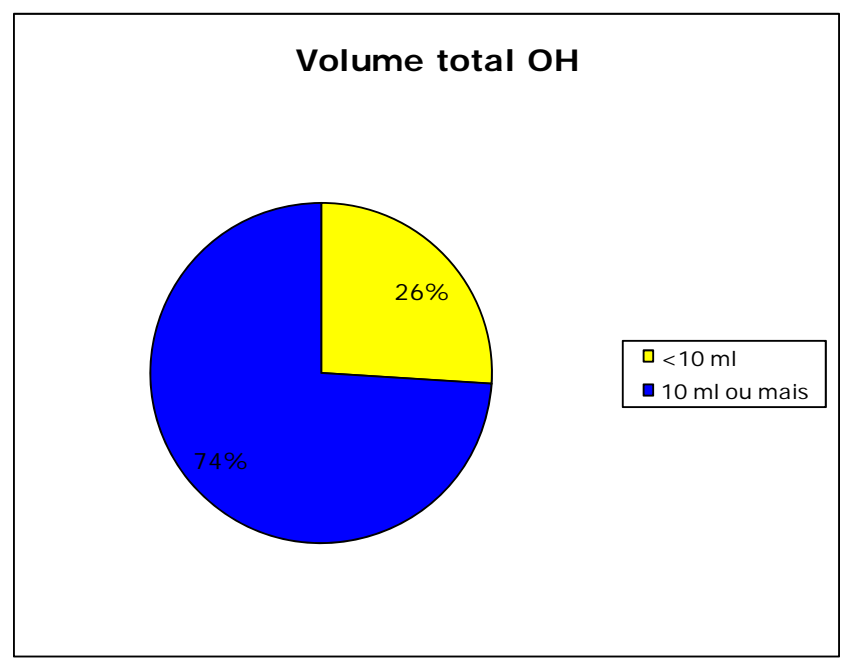

Figura 16 - Distribuição dos casos de acordo com o volume total de etanol injetado no maior tumor 


\subsubsection{Resposta ao tratamento}

Foi possível avaliar a resposta ao tratamento em 78 casos. Em 22 casos, não foi possível obter a tomografia computadorizada de controle. Isso ocorreu porque o exame não foi realizado ou por não ter sido encontrado no momento da coleta de dados. Dos 78 casos avaliados, $32(41 \%)$ obtiveram resposta completa e 46 (59\%) obtiveram resposta parcial (figura 17). As figuras 18 e 19 exemplificam o aspecto tomográfico de uma resposta completa e de uma resposta parcial ao tratamento, respectivamente. No primeiro caso, há perda completa da captação de contraste pelo tumor no exame pós-tratamento. No segundo caso, notam-se áreas hiperatenuantes residuais na periferia da lesão tumoral na fase arterial da tomografia pósPEI.

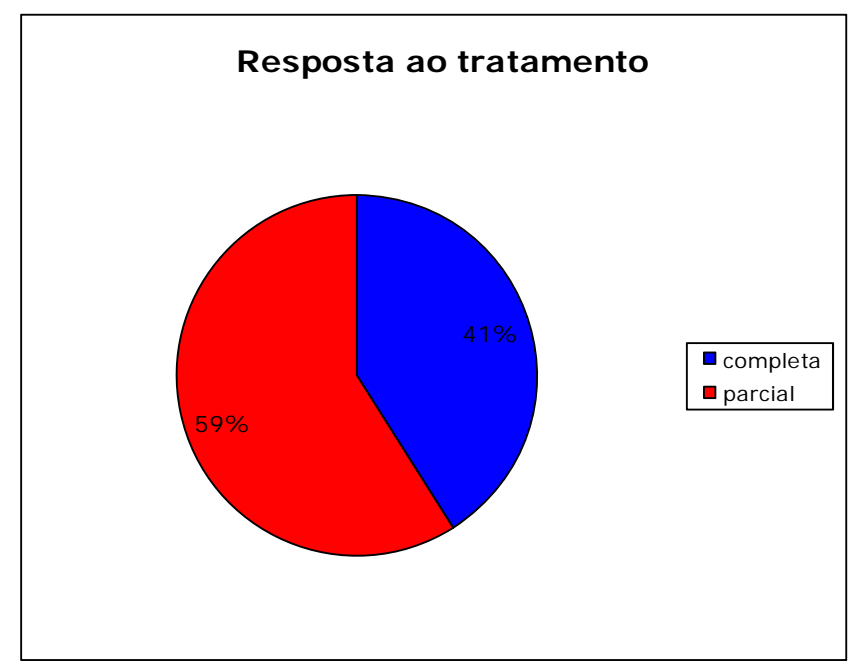

Figura 17 - Distribuição dos casos de acordo com o tipo de resposta ao tratamento obtida 


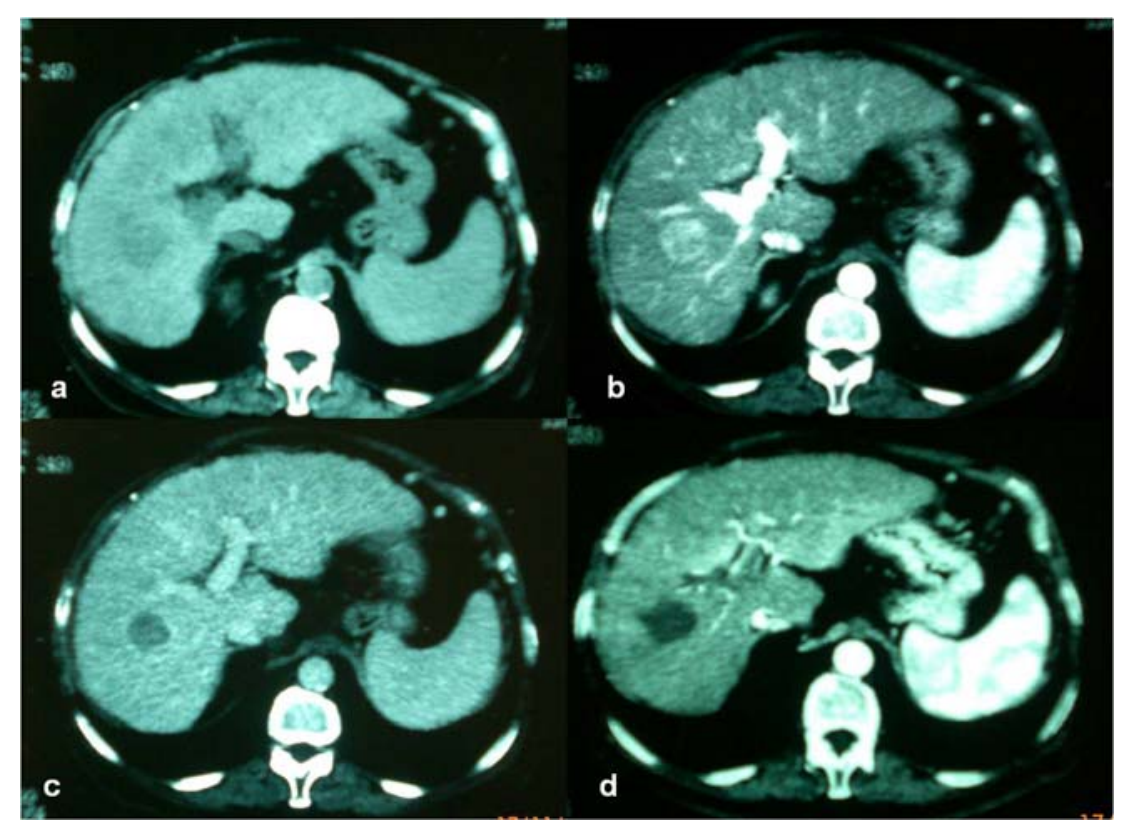

Figura 18 - Aspectos tomográficos de nódulo tumoral que obteve resposta completa ao tratamento com PEI. a. lesão nodular de aspecto hipoatenuante, na fase sem contraste b. nódulo com captação de contraste na fase arterial c. nódulo apresentando clareamento de contraste rápido ("wash-out") na fase portal $\mathbf{d}$. ausência completa de captação de contraste pelo nódulo na fase arterial 


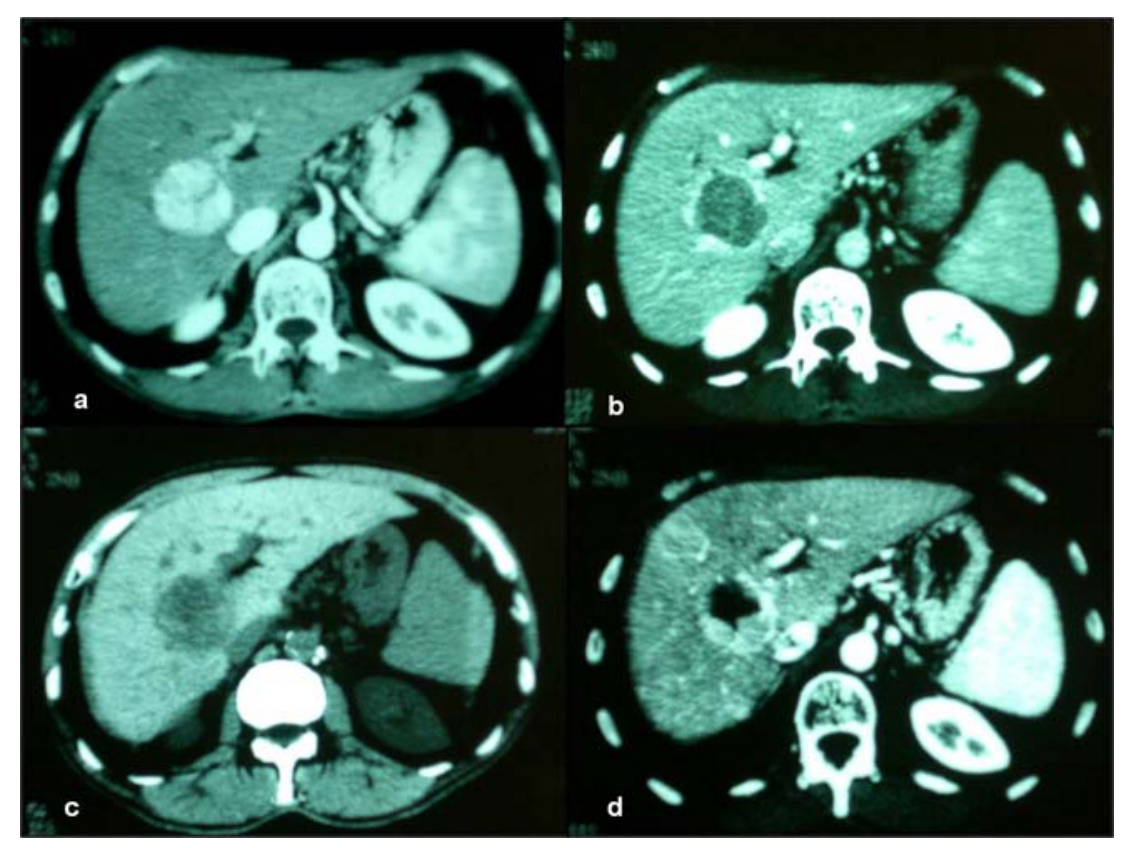

Figura 19 - Aspectos tomográficos de nódulo tumoral que obteve resposta incompleta ao tratamento com PEI. a. nódulo com intensa captação de contraste na fase arterial b. clareamento de contraste rápido ("wash-out") do nódulo na fase portal c. nódulo após tratamento com $\mathrm{PEI}$, em fase sem contraste, mostrando aspecto hipoatenuante inespecífico $\mathbf{d}$. Fase arterial de CT pósPEI, mostrando o nódulo com área necrótica central sem captação de contraste e, em suas margens, áreas de tumor viável com captação de contraste 


\subsubsection{Complicações do tratamento}

Foram obtidas informações em relação às complicações do procedimento em 94 casos. Em 6 casos não foi possível encontrar em prontuário ou nos laudos de exames informações a respeito das complicações. Apenas 13 pacientes $(13,8 \%)$ apresentaram algum tipo de complicação pós-procedimento (figura 20), a saber: ascite (7 casos), derrame pleural ( 2 casos), ascite + derrame pleural (1 caso), encefalopatia hepática (1 caso), colecistite aguda (1 caso) e implante tumoral no trajeto da agulha de alcoolização (1 caso) (figura 21).

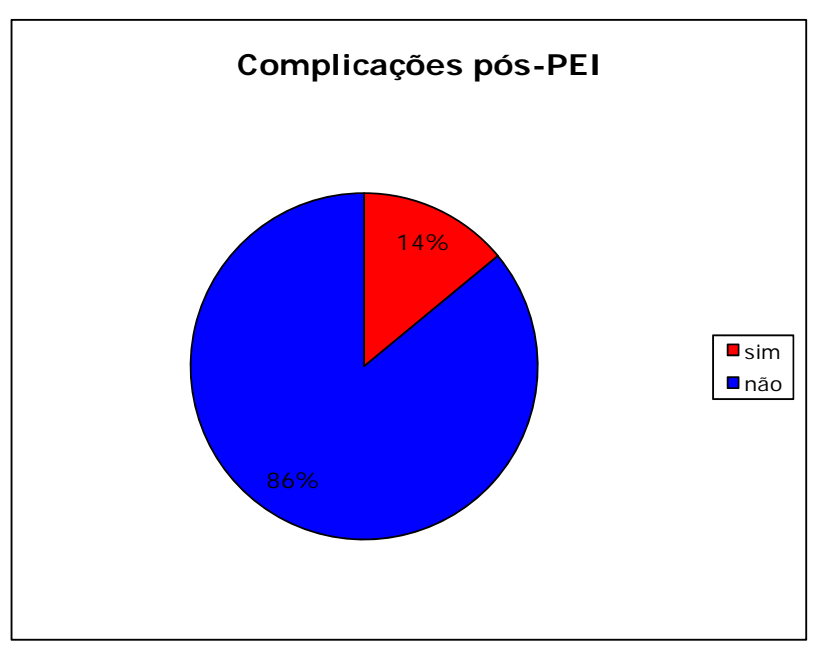

Figura 20 - Distribuição dos casos de acordo com a apresentação de complicações à PEI

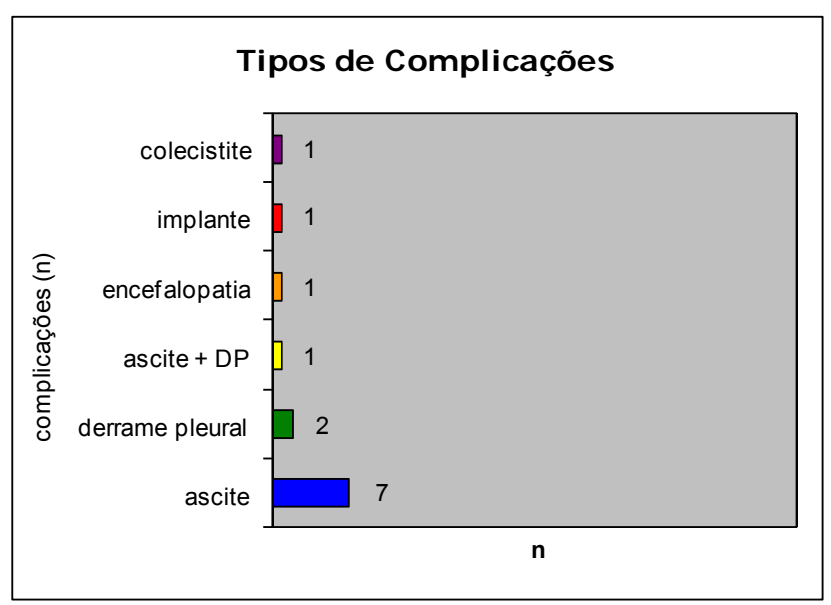

Figura 21 - Tipo e número de complicações apresentadas após tratamento com PEI 


\subsubsection{Segundo tipo de tratamento durante seguimento}

\subsubsection{Embolização / Quimioembolização transarterial}

Durante o seguimento, 24 pacientes (24\%) foram submetidos, como segundo tratamento, a embolização ou quimioembolização transarterial (figura 22).

\subsubsection{Transplante hepático}

Durante o seguimento, 15 pacientes (15\%) realizaram transplante hepático. Desses, 5 pacientes haviam realizado, além da $\mathrm{PEI}$, embolização ou quimioembolização transarterial (figura 22).

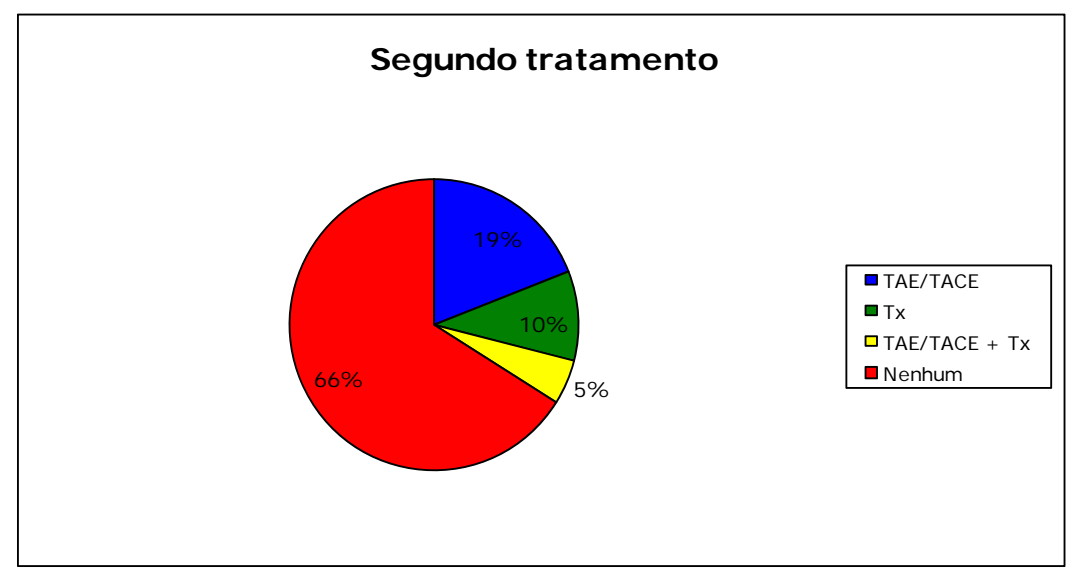

Figura 22 - Distribuição dos pacientes quanto à realização de um segundo tipo de tratamento subseqüente à $\mathrm{PEI}$ 


\subsection{TEMPO DE SEGUIMENTO}

A média de tempo de seguimento dos pacientes foi de 28,02 meses e variou de 3,3 a 76,8 meses (tabela 9).

Tabela 9 - Tempo de seguimento dos pacientes, em meses

\begin{tabular}{cc}
\hline Tempo de seguimento (meses) & \\
\hline Média & 28,018 \\
Mediana & 25,167 \\
Desvio padrão & 17,836 \\
Mínimo & 3,3 \\
Máximo & 76,8 \\
\hline
\end{tabular}




\subsection{SOBREVIDA}

\subsection{1 Óbito}

No dia 27 de fevereiro de 2008, data de fechamento da observação, 62 pacientes (62\%) estavam mortos e 38 (38\%) estavam vivos, sendo que 36 desses continuavam em acompanhamento no Hospital das Clínicas da FMUSP.

\subsubsection{Sobrevida global}

A sobrevida global da população estudada foi de $83 \%$ no primeiro ano, $41 \%$ no terceiro ano e de $29 \%$ no quinto ano. A curva de sobrevida global (Kaplan-Meier) está demonstrada na figura 23.

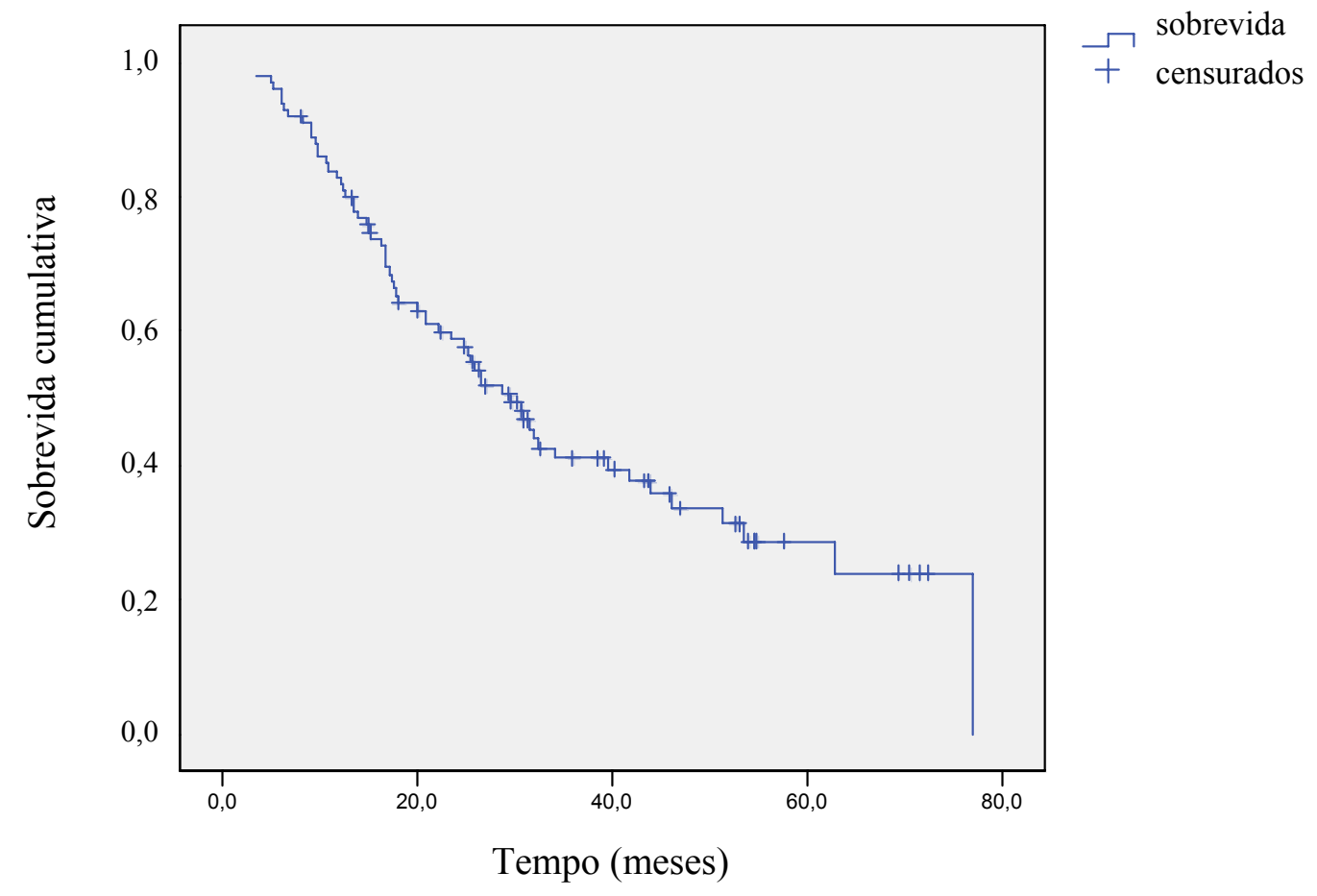

Figura 23 - Curva de sobrevida global 


\subsubsection{Sobrevida dos subgrupos}

A sobrevida dos subgrupos está relacionada na tabela 10.

A maior diferença na sobrevida ocorreu na divisão dos grupos de acordo com o tipo de resposta ao tratamento. Pacientes que obtiveram resposta completa ao tratamento apresentaram taxas de sobrevida de 90,6\% em 5 anos, $71,8 \%$ em 3 anos e 60,6\% em 5 anos, enquanto aqueles que obtiveram resposta apenas parcial, essas taxas foram respectivamente de $82,4 \%, 28,4 \%$ e $20,3 \%$.

Os pacientes que não apresentavam invasão vascular macroscópica no momento do diagnóstico tiveram taxas de sobrevida de $84,4 \%$ em 1 ano, $42,5 \%$ em 3 anos e 29,7\% em 5 anos, enquanto para aqueles apresentando invasão, a sobrevida foi de 33,3\% em 1 anos e de $0 \%$ em 3 e 5 anos.

Para pacientes cujo maior tumor media até $2 \mathrm{~cm}$ de diâmetro, a sobrevida foi de $84 \%$ no primeiro ano, $48,5 \%$ no terceiro ano e de $38,9 \%$ no quinto ano, enquanto que, para aqueles cujo maior tumor media mais que 2 $\mathrm{cm}$ de diâmetro, essas taxas foram respectivamente de $81,7 \%, 33,5 \%$ e $17,4 \%$.

Também foram estatisticamente diferentes as taxas de sobrevida do grupo de tumor que realizava rastreamento para $\mathrm{CHC}$ e o grupo que não era acompanhado: $87,2 \%$ em 1 ano e $47,7 \%$ em 3 e 5 anos no primeiro grupo, contra $80,10 \%$ em 1 ano, 36,8\% em 3 anos e 11,2\% em 5 anos no segundo grupo.

O subgrupo de pacientes definido por características ideais, isto é, com tumores cujo maior diâmetro era de até $2 \mathrm{~cm}$, sem invasão vascular macroscópica e que obteve resposta completa ao tratamento apresentou sobrevida de $88,9 \%$ em 1 ano e $70,2 \%$ em 3 e 5 anos. 
Tabela 10 - Taxas de sobrevida de 1, 3 e 5 anos em diferentes subgrupos de pacientes

\begin{tabular}{|c|c|c|c|c|}
\hline & 1 ano & 3 anos & 5 anos & $p$ \\
\hline $\begin{array}{l}\text { Resposta } \\
\text { Completa } \\
\text { Parcial } \\
\end{array}$ & $\begin{array}{l}90,60 \% \\
82,40 \% \\
\end{array}$ & $\begin{array}{l}71,80 \% \\
28,40 \% \\
\end{array}$ & $\begin{array}{l}60,60 \% \\
20,30 \% \\
\end{array}$ & $<0,001$ \\
\hline $\begin{array}{l}\text { Invasão vascular } \\
\text { Sem invasão } \\
\text { Com invasão } \\
\end{array}$ & $\begin{array}{l}84,40 \% \\
33,30 \% \\
\end{array}$ & $\begin{array}{c}42,50 \% \\
0 \% \\
\end{array}$ & $\begin{array}{c}29,70 \% \\
0 \% \\
\end{array}$ & 0,008 \\
\hline $\begin{array}{l}\text { Tamanho do }>\text { tu } \\
\text { Até } 20 \mathrm{~mm} \\
>20 \mathrm{~mm}\end{array}$ & $\begin{array}{l}84,00 \% \\
81,70 \% \\
\end{array}$ & $\begin{array}{l}48,50 \% \\
33,50 \%\end{array}$ & $\begin{array}{l}38,90 \% \\
11,20 \% \\
\end{array}$ & 0,021 \\
\hline $\begin{array}{l}\text { Rastreamento } \\
\text { Sob rastreamento } \\
\text { Sem rastreamento }\end{array}$ & $\begin{array}{l}87,20 \% \\
80,10 \% \\
\end{array}$ & $\begin{array}{l}47,70 \% \\
36,80 \% \\
\end{array}$ & $\begin{array}{l}47,70 \% \\
11,20 \% \\
\end{array}$ & 0,049 \\
\hline $\begin{array}{l}\text { Caso ideal } \\
\qquad<20 \mathrm{~mm}, \text { s/inv, RC }\end{array}$ & $88,90 \%$ & $70,20 \%$ & $70,20 \%$ & \\
\hline
\end{tabular}




\subsection{ANÁLISE UNIVARIADA}

$\mathrm{Na}$ identificação de fatores que influenciam a sobrevida, as variáveis abaixo foram testadas individualmente pelo método de Kaplan-Meier, categorizadas conforme descrição subseqüente:

- Sexo: masculino ou feminino

- Idade: < 55 anos e 55 ou mais anos

- Etiologia da cirrose: VHC, VHB ou outros

- Child: A, B ou C

- $\quad$ Número de tumores (N_TR1UM): único ou múltiplo

- Tamanho do maior tumor ao diagnóstico (T_TUMOR): $\leq 20 \mathrm{~mm}$ e $>20 \mathrm{~mm}$

- Lobo onde se situava o maior tumor: direito ou esquerdo

- Aspecto ultra-sonográfico: hipo, hiper, isoecogênico ou misto

- Níveis de AFP ao diagnóstico (AFP100): até 100 ng/dl e > 100 $\mathrm{ng} / \mathrm{dl}$

- Tamanho do maior tumor ao tratamento (TAM_TRAT)

- Invasão vascular: presente ou ausente

- Número de sessões 2 (N_SESSOES2): até 2 sessões e > 2 sessões de PEl

- Número de sessões 3 (N_SESSOES3): até 3 sessões e > 3 sessões de PEl

- Volume total de etanol injetado 10 (TotalOH10): até $10 \mathrm{ml}$ e $>10 \mathrm{ml}$

- Volume total de etanol injetado 20 (TotalOH20): até $20 \mathrm{ml}$ e $>20$ $\mathrm{ml}$

- Tratamento 2: realizou TAE/TACE ou não durante seguimento

- Resposta: completa ou parcial

- Rastreamento: sob programa ou fora de programa de rastreamento

Os resultados encontram-se na tabela 11. 
Tabela 11 - Análise univariada

\begin{tabular}{|c|c|c|c|}
\hline Variável & Valores & Pacientes & $p$ \\
\hline \multirow[t]{2}{*}{ Sexo } & $M$ & 73 & 0,757 \\
\hline & $\mathrm{F}$ & 27 & \\
\hline \multirow[t]{2}{*}{ Idade } & $<55$ & 43 & 0,57 \\
\hline & $\geq 55$ & 57 & \\
\hline \multirow[t]{3}{*}{ Etiologia } & $\mathrm{VHC}$ & 64 & 0,407 \\
\hline & VHB & 21 & \\
\hline & outras & 15 & \\
\hline \multirow[t]{3}{*}{ Child } & $A$ & 61 & 0,001 \\
\hline & B & 27 & \\
\hline & $\mathrm{C}$ & 9 & \\
\hline \multirow[t]{2}{*}{ N_TR1UM } & 1 & 79 & 0,91 \\
\hline & $>1$ & 21 & \\
\hline \multirow[t]{2}{*}{ T_TUM } & $\leq 20$ & 50 & 0,04 \\
\hline & $>20$ & 50 & \\
\hline \multirow[t]{2}{*}{ Lobo > tumor } & $\mathrm{D}$ & 69 & 0,864 \\
\hline & $E$ & 31 & \\
\hline \multirow[t]{4}{*}{ Aspecto US } & Hipoecogênico & 53 & 0,711 \\
\hline & Hiperecogênico & 13 & \\
\hline & Isoecogênico & 14 & \\
\hline & Misto & 20 & \\
\hline \multirow[t]{2}{*}{ AFP 100} & $\leq 100$ & 76 & 0,037 \\
\hline & $>100$ & 16 & \\
\hline \multirow[t]{2}{*}{ TAM_TRAT } & $\leq 20$ & 37 & 0,009 \\
\hline & $>20$ & 63 & \\
\hline \multirow[t]{2}{*}{ Invasão vascular } & presente & 3 & 0,007 \\
\hline & ausente & 97 & \\
\hline \multirow[t]{2}{*}{ N_SESSOES2 } & $\leq 2$ & 31 & $<0,001$ \\
\hline & $>2$ & 69 & \\
\hline \multirow[t]{2}{*}{ N_SESSOES3 } & $\leq 3$ & 61 & 0,011 \\
\hline & $>3$ & 39 & \\
\hline \multirow[t]{2}{*}{ TotalOH10 } & $\leq 10$ & 26 & 0,052 \\
\hline & $>10$ & 74 & \\
\hline \multirow[t]{2}{*}{ TotalOH 20} & $\leq 20$ & 69 & 0,386 \\
\hline & $>20$ & 31 & \\
\hline \multirow[t]{2}{*}{ Tratamento 2} & $\operatorname{sim}$ & 24 & 0,004 \\
\hline & não & 76 & \\
\hline \multirow[t]{2}{*}{ Resposta } & completa & 32 & $<0,001$ \\
\hline & parcial & 46 & \\
\hline \multirow[t]{2}{*}{ Complicações } & $\operatorname{sim}$ & 13 & 0,489 \\
\hline & não & 81 & \\
\hline \multirow[t]{2}{*}{ Rastreamento } & $\operatorname{sim}$ & 61 & 0,013 \\
\hline & não & 39 & \\
\hline
\end{tabular}


$\mathrm{Na}$ análise univariada, apresentaram melhor sobrevida os pacientes classificados como Child $\mathrm{A}$, com maior tumor de até $20 \mathrm{~mm}$ de diâmetro no momento do diagnóstico e principalmente no momento do tratamento, com AFP < $100 \mathrm{ng} / \mathrm{dl}$, sem invasão vascular, participantes de programa de rastreamento para $\mathrm{CHC}$. Pacientes que realizaram mais sessões de PEI (>2 e >3 sessões), que realizaram TAE/TACE durante o seguimento e que tiveram resposta completa ao tratamento também tiveram melhor sobrevida. Para as outras variáveis testadas, não houve diferença estatisticamente significante entre os grupos na análise da sobrevida. 


\subsection{ANÁLISE MULTIVARIADA (REGRESSÃO DE COX)}

Realizou-se a análise multivariada através da regressão logística de Cox utilizando as variáveis que obtiveram significância estatística na análise univariada. Esse método identificou como variáveis independentemente associadas a sobrevida o tamanho do tumor ao diagnóstico, invasão vascular, ter realizado segundo tratamento com TAE/TACE, tipo de resposta ao tratamento e pertencer a programa de rastreamento. O "hazard ratio" foi estimado para cada uma dessas variáveis, conforme mostra a tabela 12.

Tabela 12 - Análise multivariada

\begin{tabular}{lccc}
\hline Variável & $\mathbf{p}$ & Hazard Ratio & IC \\
\hline T_TUM & 0,021 & $2,6 \mathrm{x}$ & $1,155-5,925$ \\
Invasão vascular & 0,008 & $10,7 \mathrm{x}$ & $1,836-63,027$ \\
Tratamento 2 & $<0,001$ & $22,8 \mathrm{x}$ & $7,185-72,597$ \\
Resposta & $<0,001$ & $251,1 \mathrm{x}$ & $8,542-73,826$ \\
Rastreamento & 0,049 & $2,1 \mathrm{x}$ & $1,002-4,593$ \\
\hline
\end{tabular}

As figuras 24, 25, 26, 27 e 28 mostram as diferenças das curvas de sobrevida entre os subgrupos determinados por cada variável estatisticamente significante na análise multivariada. 


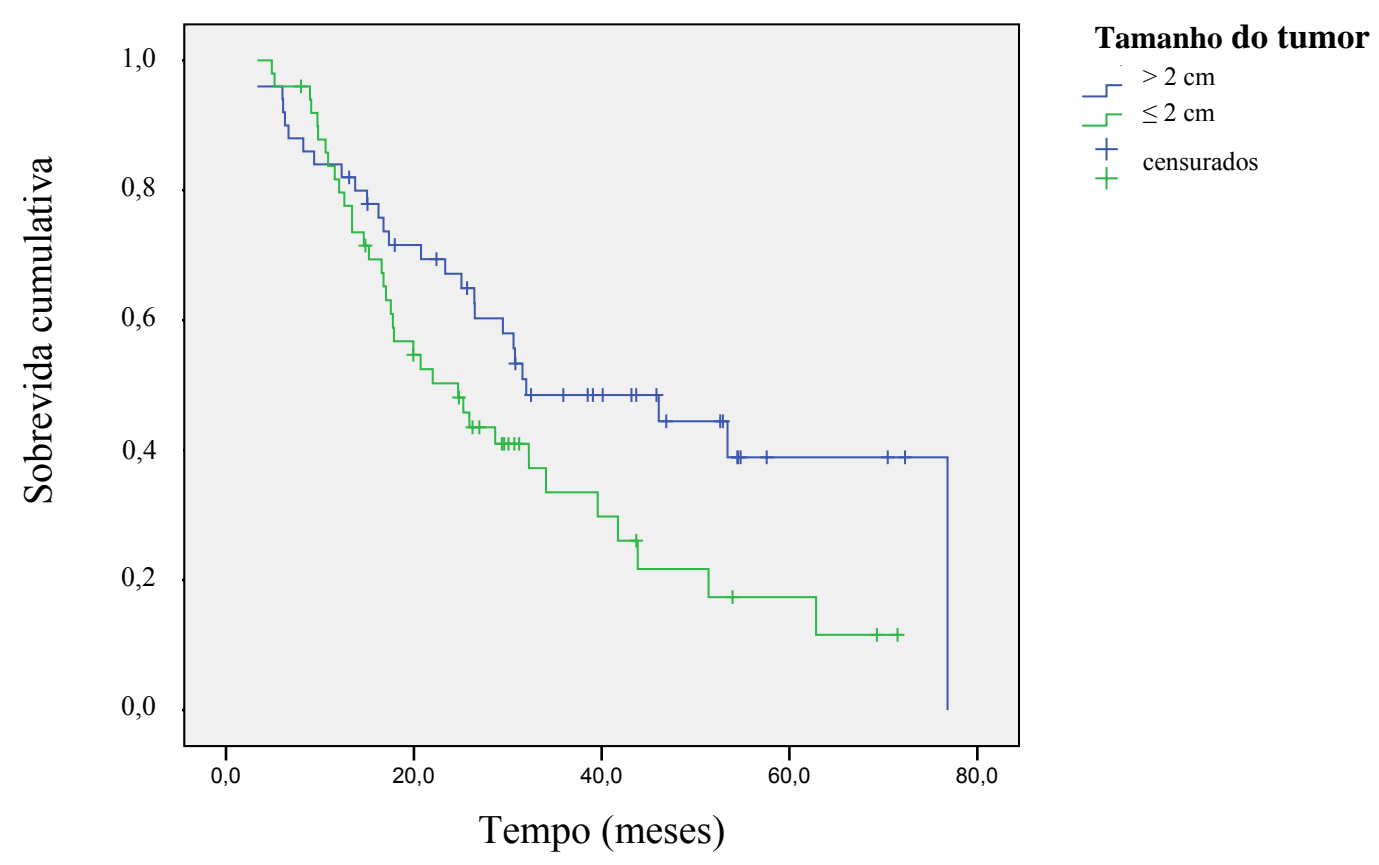

Figura 24 - Curvas de sobrevida conforme tamanho do tumor ( $\leq 20 \mathrm{~mm}$ e $>$ $20 \mathrm{~mm}$ )

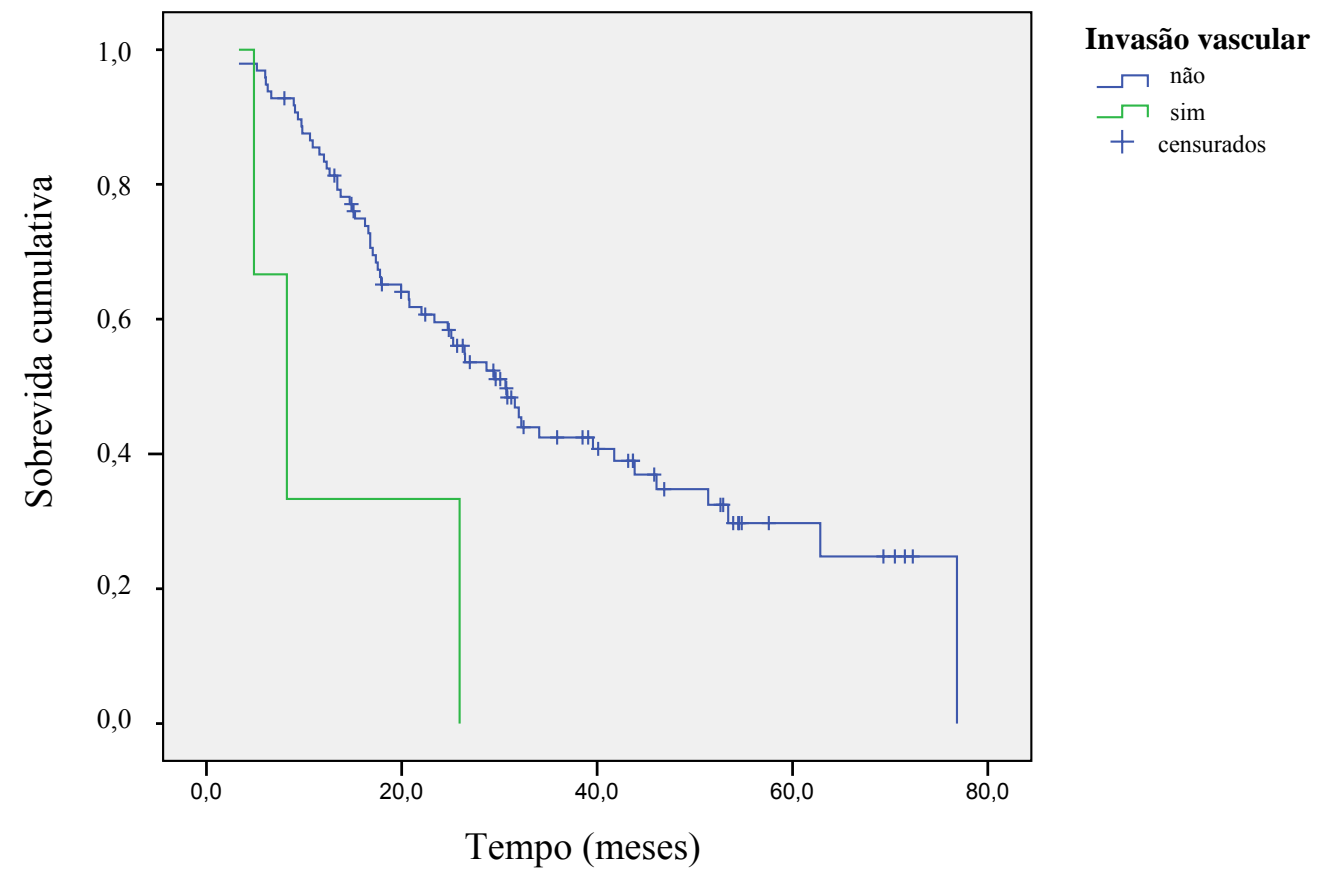

Figura 25 - Curvas de sobrevida conforme presença de invasão vascular 


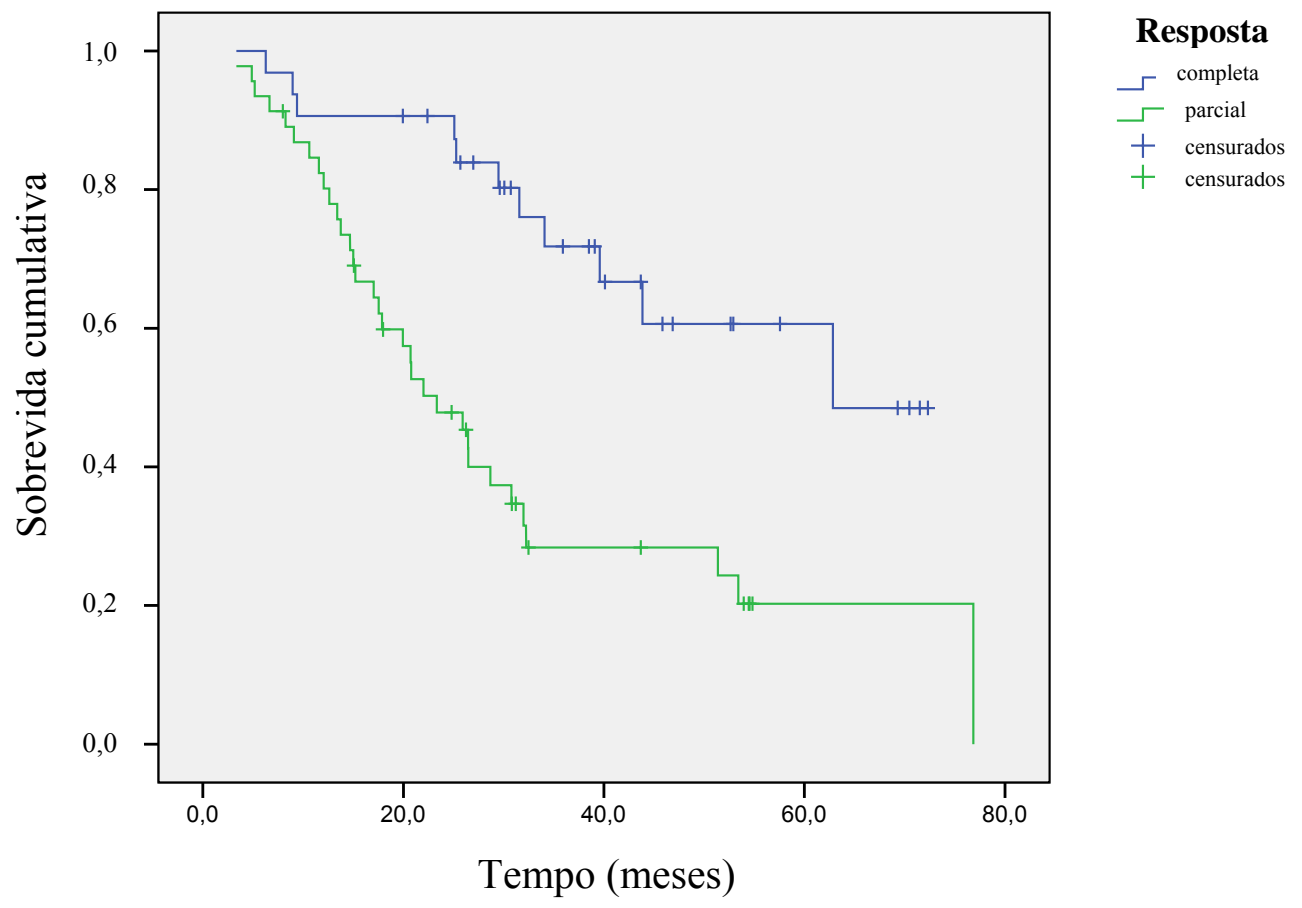

Figura 26 - Curvas de sobrevida conforme tipo de resposta ao tratamento com PEI

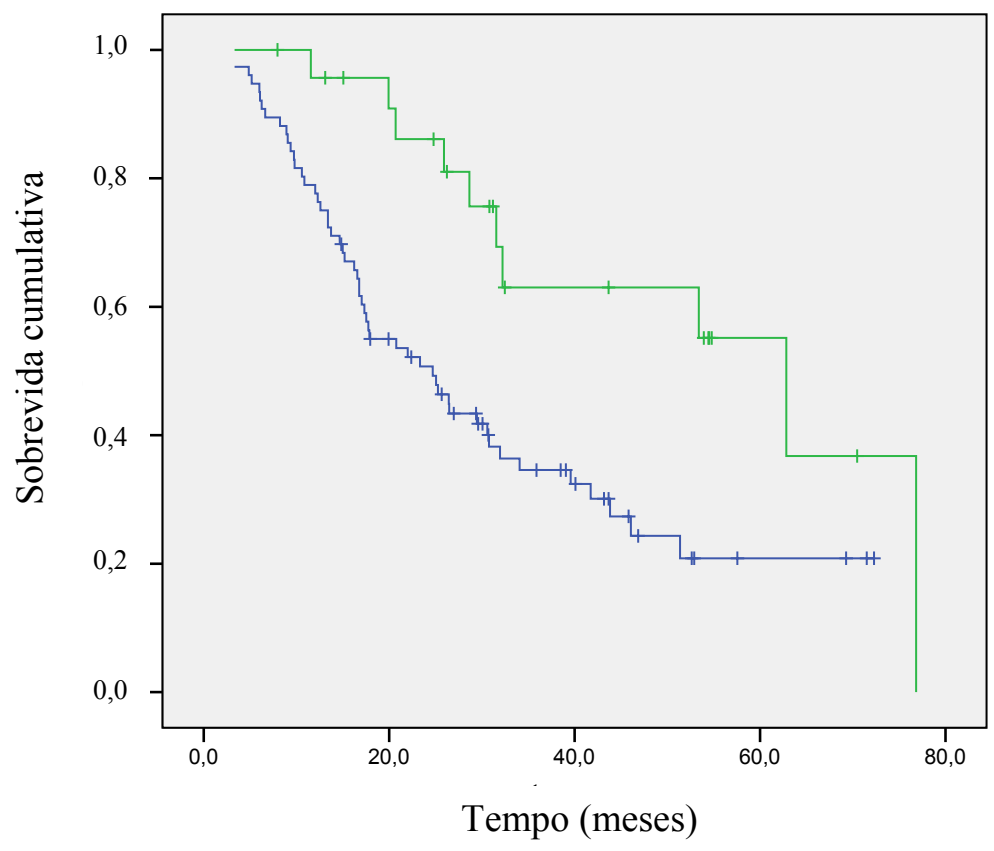

Segundo tratamento

$\neg$ não

sim

+ Censurados

+ Censurados

Figura 27 - Curvas de sobrevida conforme realização de tratamento posterior com TAE ou TACE 


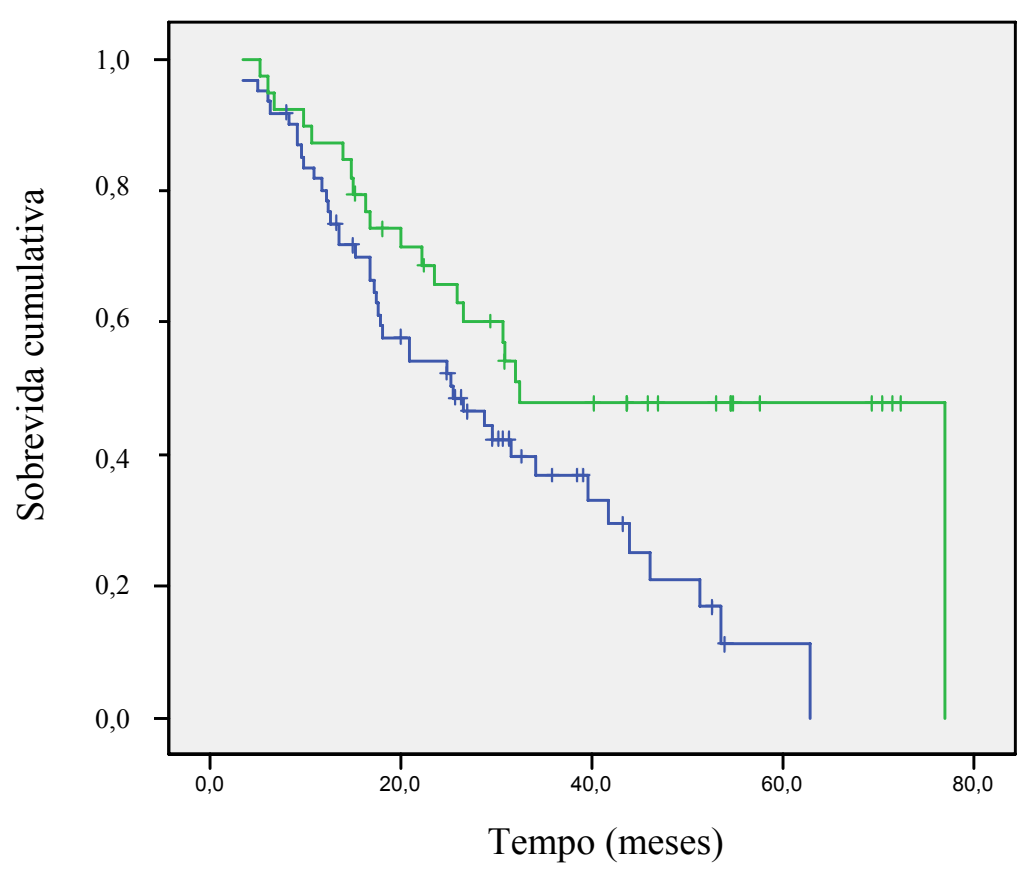

\section{Rastreamento}

$$
\begin{array}{ll}
\_ & \text {Não } \\
\leftarrow & \text { Sim } \\
+ & \text { Censurados } \\
+ & \text { Censurados }
\end{array}
$$

Figura 28 - Curvas de sobrevida conforme pertencer a programa de rastreamento para $\mathrm{CHC}$ 


\section{Discussão}




\subsection{CASUÍSTICA}

No período abordado por este estudo, foram registrados 431 casos de pacientes com diagnóstico de carcinoma hepatocelular. Em 49 desses casos não foram encontradas informações sobre o acompanhamento médico dos pacientes. Dos 382 pacientes de quem se puderam obter informações de seguimento, mais de um terço $(n=141)$ não foram submetidos a nenhum tipo de tratamento. Isso ocorreu porque, na maior parte das vezes, os pacientes eram encaminhados de outros serviços apresentando tumores avançados ou função hepática muito alterada, afastando qualquer possibilidade terapêutica. Esse panorama observado reflete a realidade dos serviços de saúde brasileiros, onde poucos conseguem realizar um rastreamento eficaz para o $\mathrm{CHC}$.

Entre os pacientes tratados, o método mais utilizado foi a PEI (100 casos), seguido pela TAE ou TACE (74 casos). A cirurgia de ressecção foi o tratamento de escolha para 34 pacientes, ou seja, menos de $10 \%$ do total de casos. Esse número confirma dados da literatura, mostrando que apenas uma pequena fração de pacientes tem condições de ser submetida a hepatectomia para 0 tratamento do $\mathrm{CHC}^{36,71,76}$. A ablação por radiofrequência foi utilizada em 17 casos, num período em que foi tentada a introdução desse método no Departamento de Gastroenterologia do HCFMUSP. Devido ao seu alto custo, não foi possível dar continuidade a essa técnica de ablação percutânea.

O transplante hepático como tratamento primário foi realizado em 16 casos. O transplante é considerado a primeira alternativa terapêutica para o $\mathrm{CHC}$ pequeno nos Estados Unidos ${ }^{21}$ e Europa ${ }^{20}$ e esse baixo número poderia ser questionado. Porém, os pacientes do nosso estudo foram selecionados no período de 1997 a 2005, época em que vigorava no Brasil uma lista de espera para o transplante baseada na ordem cronológica de inscrição do paciente. Apenas em julho de 2006 foi adotada no Brasil a lista de transplante baseada no sistema de estadiamento MELD (Model of end- 
stage liver disease), ou seja, priorizando pacientes com doença mais grave ou câncer.

\subsection{PACIENTES}

A maioria dos pacientes em nosso estudo era do sexo masculino (73\%), como encontrado em trabalhos semelhantes ${ }^{35,36,71,72}$, que relatam proporções de 2 a 3 pacientes do sexo masculino para 1 do sexo feminino. A média de idade, 56,9 \pm 11 anos, é aparentemente mais baixa do que a de algumas casuísticas publicadas anteriormente, como a de Ebara et al., no Japão $^{36}$, cuja média de idade foi de $61 \pm 8$ anos, a de Livraghi et al. ${ }^{71}$, na Itália, com média de 64,3 anos e a de Salà et al. ${ }^{72}$, na Espanha, que foi de $67 \pm 7$ anos. A etiologia da cirrose hepática foi predominantemente o vírus da hepatite $\mathrm{C}$, como também ocorreu nos trabalhos europeus e nos japoneses $^{35,36,71,72}$, seguida de infecção pelo vírus B e etilismo crônico. Essa predominância de carcinoma hepatocelular em cirróticos por vírus $\mathrm{C}$ reflete a predominância de cirrose pelo vírus $\mathrm{C}$ observada também em nosso serviço.

\subsection{ALFA-FETOPROTEÍNA}

No momento de detecção do tumor, os níveis de alfa-fetoproteína foram menores ou iguais a $20 \mathrm{ng} / \mathrm{dl}$ em $54 \%$ dos casos e maiores que 20 ng/dl nos outros $46 \%$. No estudo espanhol de Salà et al. ${ }^{72}, 71 \%$ dos casos tinham níveis de AFP de até $20 \mathrm{ng} / \mathrm{dl}$, enquanto que no japonês de Ebara et al. ${ }^{36}$, essa taxa foi de $44 \%$. Apenas 9 pacientes $(9,8 \%)$ apresentavam níveis de AFP superiores a $200 \mathrm{ng} / \mathrm{dl}$. Em outras três séries publicadas ${ }^{35,36,77}$, esse percentual variou de 10 a 14\%. Não estão esclarecidos os fatores que provocam essas diferenças, mas desses números depreende-se que, mesmo quando utilizado um valor de corte tão baixo quanto $20 \mathrm{ng} / \mathrm{dl}$, a sensibilidade da AFP para diagnóstico do $\mathrm{CHC}$ pequeno é bastante baixa. Nas diretrizes publicadas em 2005 pela $A A S L D^{20}$, essa sensibilidade foi descrita como sendo de $60 \%$ e o valor preditivo positivo, de $84,6 \%$, para 
esse valor de corte. No presente estudo, a dosagem de AFP foi de pouco valor para estabelecimento diagnóstico do $\mathrm{CHC}$. Mesmo assim, nesta amostragem esse exame teve um valor importante: em 23 casos (25\%) a elevação de alfa-fetoproteína a níveis acima de $20 \mathrm{ng} / \mathrm{dl}$ deflagrou a realização de novos exames de imagem que resultaram na identificação do tumor. Em 7 desses casos, o nódulo tumoral só foi identificado através da realização da tomografia computadorizada e deixaria de ser diagnosticado se esse exame não tivesse sido solicitado.

\subsection{ASPECTO ECOGRÁFICO DO TUMOR}

São variadas as apresentações do CHC à ecografia. Tumores maiores são em geral heterogêneos, em padrão mosaico, e podem apresentar diversas outras características secundárias como halo hipoecogênico, sombra acústica lateral e reforço acústico posterior ${ }^{78}$. Tumores com até $2 \mathrm{~cm}$ de diâmetro foram descritos como sendo homogêneos, na maioria das vezes hipoecogênicos, bem ou parcialmente bem definidos. Cerca de $30 \%$ dos tumores até esse tamanho podem ser hiperecogênicos ${ }^{79}$. Não parece haver correlação entre o aspecto ecográfico do tumor e o tipo histológico ou grau de diferenciação ${ }^{80}$. Na nossa casuística, confirmou-se a predominância dos tumores hipoecogênicos, mas também foram encontrados tumores de outros aspectos. O achado de $20 \%$ de tumores mistos reflete a seleção de tumores maiores que $2 \mathrm{~cm}$ de diâmetro. Essa característica (aspecto ecográfico do tumor) não influenciou, entretanto, a probabilidade de resposta completa ou a sobrevida dos pacientes tratados.

\subsection{RASTREAMENTO}

Desde 1985, quando Okuda e colaboradores publicaram o seu clássico artigo sobre a história natural do carcinoma hepatocelular ${ }^{11}$, consideráveis mudanças têm sido observadas no diagnóstico, tratamento e 
prognóstico da doença. Uma grande diferença, que pode ser atribuída à instituição de programas de rastreamento do $\mathrm{CHC}$, refere-se ao perfil de apresentação da doença: em centros que se dedicam ao acompanhamento de pacientes cirróticos, tumores hepáticos são detectados num estágio menos avançado do que o observado há cerca de $20 \operatorname{anos}^{81}$. No Hospital das Clínicas da FMUSP, no período de 1987 a 1983, 68\% dos CHC diagnosticados tinham mais que $5 \mathrm{~cm}$ de diâmetro e apenas $14 \%$ tinham menos que $3 \mathrm{~cm}$. No período de 1998 a 2005, após a introdução do rastreamento, o quadro inverteu-se: $6 \%$ dos $\mathrm{CHC}$ foram diagnosticados com mais de $5 \mathrm{~cm}$, e $65 \%$ com menos de $3 \mathrm{~cm}$ (dados não publicados). A maioria dos tumores detectados na atualidade são uninodulares e não apresentam invasão vascular macroscópica. Muitos pacientes apresentam-se ainda, no momento de detecção da lesão tumoral, com função hepática preservada, ao contrário do que ocorria quando o diagnóstico baseava-se no surgimento de sintomas clínicos. Essa tendência ao diagnóstico mais precoce favorece a intervenção terapêutica.

Nesta casuística, menos da metade dos pacientes faziam parte de um programa de rastreamento para detecção do CHC. Esse dado denota o perfil do Departamento de Gastroenterologia do HCFMUSP, que, como centro terciário, recebe uma grande quantidade de pacientes encaminhados com patologias complexas. A maior parte dos pacientes com $\mathrm{CHC}$ era proveniente de outros serviços e não se encontrava em acompanhamento no ambulatório de Hepatologia do HCFMUSP. Interessantemente, foi observado que pertencer a um programa de rastreamento trouxe benefícios em termos de sobrevida. Como já discutido em literatura, talvez isso se deva ao diagnóstico de tumores em tamanhos menores na população rastreada, mas também a um melhor acompanhamento do paciente sob vigilância ${ }^{82}$. $\mathrm{Na}$ situação estudada, a equipe clínica que acompanhava o paciente cirrótico estava diretamente envolvida, desde o diagnóstico até o final do tratamento com PEI, diferentemente do que ocorria quando o paciente pertencia a outros serviços e continuava o acompanhamento fora do HCFMUSP. 


\subsection{CRITÉRIOS DIAGNÓSTICOS}

Os critérios diagnósticos do carcinoma hepatocelular foram bem estabelecidos pelo Consenso Europeu em 200121 e aperfeiçoados pelo Consenso Americano publicado em $2005^{20}$. A biópsia do nódulo não é mais considerada imprescindível para a realização do diagnóstico. Apesar da histologia ainda representar o padrão-ouro para o diagnóstico do $\mathrm{CHC}$, algumas dificuldades são relacionadas, como a grande porcentagem de falsos negativos, que giram em torno de $30 \%$ em mãos experientes, a dificuldade de diferenciação entre um carcinoma hepatocelular bem diferenciado e um nódulo displásico de alto grau ou mesmo entre aquele e um fígado normal, por parte dos patologistas ${ }^{82} \mathrm{e}$, além de tudo, o fato de ser um exame invasivo em que algumas complicações como sangramento ${ }^{83} \mathrm{e}$ implante de células neoplásicas no trajeto da agulha ${ }^{84,85}$ já foram descritas. O diagnóstico através de exames de imagem tem se tornado cada vez mais freqüente e foi referendado pelo Consenso Americano de $2005^{20}$, segundo o qual, para a confirmação do diagnóstico de $\mathrm{CHC}$ em tumores com mais de 2 $\mathrm{cm}$ de diâmetro, é necessário apenas um exame de imagem com estudo da vascularização, desde que seu padrão seja típico, ou seja, que mostre vascularização arterial e clareamento rápido do contraste ("wash-out"). Caso o padrão do exame não seja típico, um segundo exame de imagem demonstrando hipervascularização arterial é imprescindível para o diagnóstico. Para nódulos com tamanhos entre 1 e $2 \mathrm{~cm}$ de diâmetro, são necessários 2 exames de imagem dinâmicos para confirmação diagnóstica. A especificidade e valor preditivo positivo atribuídos à soma de 2 exames concordantes são de $100 \%$ e 100\%, independentemente de o padrão de vascularização ser típico ou não ${ }^{86}$. Métodos de imagem não devem, entretanto, ser utilizados para confirmação diagnóstica em nódulos menores que $1 \mathrm{~cm}$ de diâmetro, devido ao alto percentual de falsos positivos nessa situação. A dosagem de alfa-fetoproteína tem valor no diagnóstico do $\mathrm{CHC}$ no seguinte quadro: presença de uma massa ou nódulo com características de $\mathrm{CHC}$, em qualquer método de imagem, associada a uma dosagem de 
alfa-fetoproteína sérica maior que 200 ng/dl fecham o diagnóstico de carcinoma hepatocelular $^{87,88}$.

Em 1997, início do nosso estudo, os critérios diagnósticos para $\mathrm{CHC}$ não estavam tão bem estabelecidos. Ao se realizar a coleta de dados, foram considerados 3 critérios para diagnóstico do $\mathrm{CHC}$ : biópsia positiva, dosagem de alfa-fetoproteína maior que $200 \mathrm{ng} / \mathrm{dl}$ em paciente apresentando nódulo suspeito à ultra-sonografia, ou ainda lesão sugestiva de $\mathrm{CHC}$ à ultrasonografia mostrando hipervascularização e clareamento rápido em um segundo exame de imagem, como tomografia computadorizada ou ressonância nuclear magnética. $68 \%$ dos diagnósticos foram realizados através do critério imagem. Em 23\% dos casos o diagnóstico foi fechado através de biópsia e em 9\%, através de dosagem de alfa-fetoproteína associada a imagem ultra-sonográfica. Nesse ponto, este estudo é passível de críticas, pois os critérios de diagnóstico por imagem não são os mesmos considerados na atualidade. Entretanto, apesar de apenas 23\% dos pacientes terem tido seu diagnóstico estabelecido através de biópsia, $54 \%$ tiveram, ao longo de seu acompanhamento, um estudo anatomopatológico positivo para $\mathrm{CHC}$, seja em biópsia realizada posteriormente ao diagnóstico ou após análise de peça de explante hepático. A maior parte dos casos com diagnóstico por imagem, que realizaram apenas um exames de imagem contrastado e dinâmico, apresentavam tumores maiores que $2 \mathrm{~cm}$, havendo concordância, portanto, com os critérios atuais. Caso fossem aplicadas as diretrizes atuais para diagnóstico, apenas 8 casos seriam considerados dúvidas diagnósticas.

Note-se que, nesta casuística, o principal método diagnóstico foi o de imagem. Isso reflete uma postura adotada no serviço, que é investigar de forma mais extensiva e detalhada o surgimento de uma imagem suspeita de carcinoma hepatocelular antes de se realizar a biópsia. Ao se detectar um nódulo no programa de rastreamento ou mesmo num primeiro exame de um paciente, a primeira atitude é a solicitação de um exame de imagem de alta resolução para detalhar as características da lesão e estudar seu padrão de vascularização. No Hospital das Clínicas, devido à grande demanda, há 
restrições para a realização desses exames. O mais facilmente conseguido é a tomografia computadorizada helicoidal e a maior parte dos pacientes desse estudo teve o diagnóstico confirmado través desse tipo de exame. Em menor freqüência, a ressonância magnética é também utilizada. O serviço trabalha com cotas mensais regulamentadas pelo Serviço de Radiologia para a realização de CT e RNM. O diagnóstico por imagem é uma tendência observada na atualidade e vem evoluindo muito nas últimas décadas, principalmente com o desenvolvimento de novas tecnologias, como a tomografia computadorizada helicoidal multislice, que é de grande valor na detecção de lesões hepáticas pequenas. Contudo, não é a realidade de muitos países subdesenvolvidos e em desenvolvimento usufruírem de todo esse avanço tecnológico. Mesmo assim, o diagnóstico do $\mathrm{CHC}$ ainda pode ser realizado através da biópsia das lesões suspeitas, a um baixo custo, investindo-se apenas no treinamento de pessoal e numa aparelhagem básica de ultra-sonografia. Na experiência japonesa de Ebara com PEI, $81,9 \%$ dos $\mathrm{CHC}$ foram confirmados através de biópsia ${ }^{36}$.

Na população estudada, a ultra-sonografia foi o exame que detectou a presença de um nódulo suspeito em $76 \%$ dos casos. Porém, 21 casos tiveram suas lesões detectadas inicialmente por tomografia computadorizada e 3 casos, através de ressonância magnética. Em metade deles, o que motivou o pedido de exames complementares foi uma dosagem de AFP elevada. Como já discutido anteriormente, a dosagem de AFP pode ter um papel complementar no programa de rastreamento do carcinoma hepatocelular.

\subsection{TRATAMENTO DO CARCINOMA HEPATOCELULAR}

Além da ressecção cirúrgica tradicionalmente utilizada para 0 tratamento de tumores, métodos ablativos locais, de abordagem percutânea, mostraram-se eficazes para o tratamento de lesões tumorais pequenas de carcinoma hepatocelular e foram introduzidos na prática clínica. $O$ transplante hepático, inicialmente usado com restrições para o tratamento 
dessa neoplasia, mostrou-se uma modalidade terapêutica aceitável para o tratamento do $\mathrm{CHC}$, com baixas taxas de recorrência e boa sobrevida, desde que obedecidos critérios de tamanho e número de lesões tumorais ${ }^{22}$. Embora as diretrizes atuais publicadas restrinjam a $\mathrm{PEI}$ a pacientes não passíveis de ressecção cirúrgica ou transplante ${ }^{4}$, não há comprovação que ela seja pior que os dois métodos citados. Não há estudos randomizados e controlados que comparem a PEI ao transplante ou à ressecção. Baseandose na análise de coortes que avaliaram cada tratamento separadamente, percebe-se uma taxa de sobrevida muito semelhante entre os 3 métodos, quando respeitados critérios que selecionem pacientes adequados. Em publicação de Livraghi et al., em 1995, a taxa de sobrevida de 1272 pacientes Child $A$, com tumores de até $5 \mathrm{~cm}$ de diâmetro submetidos a ressecção cirúrgica foi estimada em $49 \%{ }^{71}$. Kotoh et al. encontraram uma sobrevida de 5 anos de $53 \%$ para pacientes com $\mathrm{CHC}$ submetidos a ressecção cirúrgica, contra $64 \%$ para pacientes submetidos a $\mathrm{PEI}^{89}$. Onodera et al. obtiveram sobrevida de 3 anos de $53 \%$ para a ressecção cirúrgica e $90 \%$ para $\mathrm{PEI}^{90}$. Por outro lado, Arii et al. reportaram vantagens na sobrevida para pacientes submetidos a tratamento cirúrgico, com taxa estimada em cerca de $50 \%$ em 5 anos $^{38}$. O transplante hepático pode ser mais vantajoso que a PEI por apresentar menor recorrência/recidiva da doença, além de promover a resolução da cirrose hepática. Foram reportadas taxas de sobrevida de 5 anos variando entre 60 e $75 \%^{91,92}$, mas essas estimativas podem variar amplamente de acordo com a técnica e experiência de cada serviço. Além dos tratamentos em monoterapia, alternativas que já começaram a ser empregadas são as combinações entre dois ou mais métodos, como ressecção e transplante, TAE/TACE e transplante, tratamentos ablativos percutâneos e transplante. O objetivo dessa abordagem é evitar a progressão tumoral em pacientes que aguardam o transplante, quando a expectativa do tempo de espera pela doação do órgão for longa. 


\subsection{INJEÇÃO PERCUTÂNEA DE ETANOL (PEI)}

A injeção percutânea de etanol foi introduzida em 1982 no Japão por Sugiura et al. ${ }^{27}$ para o tratamento de $\mathrm{CHC}$ pequenos e desde então vem sendo utilizada em todo o mundo. Sua eficácia em causar redução tumoral ou necrose completa foi demonstrada em estudos que avaliaram segmentos hepáticos contendo nódulos tumorais submetidos a PEI posteriormente ressecados ${ }^{83,84}$. Em um deles, a injeção de etanol foi capaz de provocar necrose tumoral completa em 17 de 23 nódulos tratados ${ }^{71}$. $O$ álcool absoluto injetado dentro do tumor causa necrose coagulativa do tecido tumoral e da camada mais próxima de parênquima adjacente e provoca trombose e oclusão dos vasos sanguíneos que nutrem a neoplasia.

Diversas vantagens podem ser atribuídas a esse procedimento terapêutico. Uma delas é que se trata de um processo bastante seletivo para o tecido neoplásico, que causa mínimo dano hepático. O álcool difunde-se mais facilmente pelo tumor, cujo tecido é menos denso do que o do fígado cirrótico adjacente, e que é freqüentemente limitado por uma cápsula. Não há perda importante de tecido hepático não-tumoral, como ocorre nas cirurgias de ressecção. Além disso, o etanol não é tóxico e pode ser aplicado no fígado repetidamente. No aspecto técnico, o procedimento é simples e reprodutível, facilmente realizado por ultrassonografistas experientes, tem baixo custo e pode ser realizado com segurança na maioria dos pacientes, excetuando-se naqueles cuja função hepática esteja muito deteriorada ${ }^{73}$.

Como infiltração de células neoplásicas ocorre comumente na periferia do tumor, a PEI deve ser preferencialmente utilizada em pacientes com nódulos de até $3 \mathrm{~cm}$ de diâmetro, para que sua ação atinja uma margem de segurança. No presente estudo, nódulos de tamanhos maiores foram submetidos à $\mathrm{PEI}$. $\mathrm{Na}$ época em que o procedimento foi iniciado no serviço, tumores maiores que $3 \mathrm{~cm}$ de diâmetro haviam sido tratados em outras séries de pacientes publicadas ${ }^{35,71,72,77}$, com resultados aceitáveis. Posteriormente foi constatado que o grau de necrose provocado pelo álcool 
absoluto está relacionado ao diâmetro do tumor e a PEl é atualmente indicada apenas para tumores de até $3 \mathrm{~cm}$ de diâmetro.

Outra vantagem associada à PEl é a segurança do método. As séries relatadas mostram um percentual de complicações graves de aproximadamente $2 \%{ }^{36,71,96}$. Na nossa série, a taxa de complicações foi semelhante à da literatura. Um paciente evoluiu com colecistite aguda após o tratamento, o que resultou em óbito um mês depois. Em outro paciente foi detectado implante tumoral no trajeto da agulha. Esse paciente, embora tenha sido retirado da lista de transplante, encontrava-se vivo na data da conclusão da pesquisa, cerca de 6 anos após a realização da PEI. Outras complicações relatadas e que ocorreram em 11 pacientes, como desenvolvimento de ascite, derrame pleural e encefalopatia hepática, foram consideradas complicações menores, com possibilidade de tratamento. A sobrevida média do grupo que apresentou complicações menores foi de 24 meses e variou de 9,4 a 52,6 meses.

\subsection{AVALIAÇÃO DA RESPOSTA AO TRATAMENTO}

Uma das questões mais difíceis em tratamentos intervencionistas de ablação percutânea é a correta confirmação da necrose completa do tumor tratado. A prova da eficácia do tratamento seria indicada pela ausência de células tumorais viáveis, o que é impossível de se comprovar histologicamente. Nova biópsia da lesão tratada só poderia ser considerada confiável para avaliação da resposta terapêutica quando mostrasse malignidade viável, e não quando resultasse negativa. Dosagem de AFP tem utilidade limitada, já que seus níveis são na maior parte das vezes normais ou baixos no momento do diagnóstico da neoplasia e, mesmo quando há elevação de seus valores, sua diminuição ou retorno a patamares normais podem ocorrer mesmo quando a necrose tumoral é parcial ${ }^{97}$. Até então a avaliação do efeito terapêutico dos procedimentos de ablação percutânea é baseado em exames de imagem. A ultra-sonografia não é adequada para esse fim, já que é praticamente impossível diferenciar ecograficamente a 
área de necrose produzida pela $\mathrm{PEI}$ das áreas de tecido neoplásico viável ${ }^{98}$. A redução do tamanho tumoral ocorre com o tempo e pode ser avaliada por ultra-sonografia $^{73}$, mas esse parâmetro exige um período observacional demasiadamente longo, inaceitável para se obter essa resposta. O uso da ultra-sonografia contrastada vem crescendo para avaliação do $\mathrm{CHC}$, mas ainda apresenta limitações importantes. Alguns tumores primários, como os bem diferenciados grau 1 de Edmondson, podem não demonstrar um contraste intra-tumoral distinto ${ }^{99}$. Pequenas porções de tecido neoplásico viável podem deixar de ser detectadas por esse método, especialmente em lesões localizadas em áreas anatômicas difíceis de explorar, como a cúpula hepática ${ }^{97}$. Finalmente, consideramos que essa técnica ainda encontra-se num estágio inicial de uso clínico ${ }^{97}$, especialmente em nosso país, e necessita ser mais bem testada para comprovação de sua especificidade e reprodutibilidade.

O uso da tomografia computadorizada dinâmica contrastada e da ressonância nuclear magnética são os métodos padronizados para avaliar a resposta do tratamento do $\mathrm{CHC}$ com $\mathrm{PEI}^{100}$. Na CT dinâmica, lesões tratadas com PEI aparecem como áreas hipoatenuantes e sem captação de contraste, tanto na fase arterial quanto na portal. Entretanto, é observada forte captação de contraste na fase arterial em áreas de tecido neoplásico viável, que se sobressaem em relação ao contraste leve apresentado pelo parênquima hepático não-tumoral adjacente ${ }^{97}$. O padrão de contraste da área adjacente ao tumor tratado deve ser cuidadosamente observado. Em particular, o achado de uma área cuneiforme de captação de contraste na periferia do tumor tratado logo após o tratamento não deve ser confundido com infiltração por células tumorais viáveis, representando mais freqüentemente uma área de anormalidade de perfusão comumente observada após a PEI. Essas anormalidades de perfusão periféricas ao local do tratamento são provavelmente causadas por uma trombose química induzida pelo álcool nos ramos portais ao redor da lesão ou por shunts arteriovenosos produzidos pela inserção da agulha no tumor ${ }^{101}$. Outro aspecto que não deve ser interpretado como persistência de neoplasia é a 
presença de um halo hipercaptante na periferia do nódulo tratado, que normalmente representa tecido inflamatório de granulação normal após o dano celular ocorrido. Nesses casos, a imagem hiperatenuante em forma de halo é observada tanto nas fases arterial quanto portal, enquanto que nos casos de persistência do tumor, o contraste se dá apenas na fase arterial, deixando de ser observado na fase portal ${ }^{102}$. A distinção entre esses artefatos e tecido tumoral pode ser difícil e exigir comparação entre as imagens pré e pós-tratamento ou o acompanhamento através de tomografias ou ressonância magnética seriadas.

Na ressonância magnética, além do estudo dinâmico conseguido com a injeção de contraste, à maneira do realizado na tomografia computadorizada, uma área de tumor viável pode ser detectada através da persistência do padrão de alto sinal em imagens ponderadas em T2. As áreas tumorais que sofreram necrose coagulativa por ação do álcool surgem, por sua vez, como áreas hipointensas em T2 $2^{103,104}$. Como já relatado, entretanto, há tumores que não apresentam o padrão hiperintenso em T2 num momento pré-tratamento e essa característica não pode, nesses casos, ser usada para avaliar persistência ou recidiva da neoplasia ${ }^{102}$.

Neste trabalho, a tomografia helicoidal dinâmica foi utilizada para avaliação da resposta à PEl, e em alguns casos, dúvidas foram esclarecidas com o auxílio da ressonância nuclear magnética. $O$ equipamento utilizado e a técnica não foram padronizados: alguns exames de controle foram até mesmo realizados em serviços externos. Por isso, não obtivemos aqui uma avaliação da resposta terapêutica protocolada e controlada, mas sim uma reprodução do que ocorre na prática clínica diária. Para minimizar erros nessa avaliação, os mesmos exames de imagem foram apreciados por dois médicos experientes e, se houvesse de discordância de resultados, os casos eram debatidos até que se chegasse a um consenso.

Diferentemente de alguns estudos prévios, como o japonês de Ebara $^{36}$, em que a resposta completa ao tratamento foi obtida em todos os casos, no nosso trabalho encontramos muitos casos de resposta incompleta. 
Como será discutido à frente, isso pode ter ocorrido devido a volume de etanol injetado ou número se sessões de PEI insuficientes. Entretanto, a única variável identificada por análise univariada como preditora de boa resposta ao tratamento foi número se sessões de PEI maior que 2. Nenhum caso de resposta ausente foi identificado, talvez pelo fato do exame de imagem de controle ter sido realizado cerca de 1 mês após o término da PEI - período provavelmente insuficiente para que se observasse crescimento evidente da lesão.

\subsection{SOBREVIDA}

Com a comprovação do benefício de variadas formas de tratamento, tornou-se eticamente impossível observar a história natural dos carcinomas hepatocelulares pequenos sem realizar intervenções terapêuticas. Dessa forma, o estudo da sobrevida de pacientes com carcinoma hepatocelular é realizado, no presente, em séries de pacientes tratados.

Alguns artigos publicados avaliaram a sobrevida de pacientes com CHC submetidos à injeção percutânea de etanol. Esse procedimento, introduzido em 1983 por Sugiura e colaboradores ${ }^{27}$, foi adotado por outros grupos no Oriente e na Europa para tratamento de $\mathrm{CHC}$ pequenos. Séries de pacientes mostram sua utilização para tratamento de nódulos tumorais de até $6 \mathrm{~cm}$ de diâmetro, sendo que posteriormente o tamanho tumoral (até 2 ou $3 \mathrm{~cm}$ de diâmetro) foi identificado como um fator determinante da resposta ao tratamento. Na Universidade de Chiba, Japão, a sobrevida de 1 , 3,5 e 10 anos foi de $99,2 \%, 81,6 \%, 60,3 \%$ e $20,7 \%{ }^{36}$. Nessa casuística, os pacientes selecionados obedeciam a critérios de inclusão rigorosos: apresentavam tumores de até $3 \mathrm{~cm}$ de diâmetro, número máximo de lesões igual a 3, com visualização completa das lesões pela ultra-sonografia, ausência de invasão vascular ou trombo tumoral, ausência de ascite volumosa, boas condições de coagulação sanguínea, níveis de albumina sérica maiores que $2,5 \mathrm{~g} / \mathrm{dl}$ e bilirrubina sérica menor que $3 \mathrm{mg} / \mathrm{dl}$. Na casuística italiana publicada em 1995, com 293 pacientes de classificação 
funcional Child $A$, com tumores únicos de até $5 \mathrm{~cm}$ de diâmetro, a sobrevida de 1,3 e 5 anos foi de $98 \%, 79 \%$ e $47 \%{ }^{71}$. Na nossa casuística a sobrevida de 1,3 e 5 anos foi de $83 \%, 41 \%$ e $29 \%$, mais baixa que as apresentadas anteriormente. Deve-se ressaltar, porém, que os critérios de seleção foram bastante abrangentes: foram alcoolizadas lesões tumorais de até $5 \mathrm{~cm}$, e, em 3 casos, invasão vascular macroscópica havia sido detectada. Apenas $63 \%$ dos pacientes eram Child A e 9\% eram Child C. 2 pacientes apresentavam 4 nódulos tumorais no momento do diagnóstico. Fatores relacionados ao tratamento diferiram bastante também entre o nosso levantamento e outros realizados: enquanto na casuística de Salà a média de etanol injetado foi de $22 \pm 13 \mathrm{ml}$ de etanol numa média de $7 \pm 4$ sessões $^{72}$, no nosso serviço o volume de etanol injetado foi em média de $17 \pm 14 \mathrm{ml}$, numa média de $3 \pm 1,5$ sessões. O número de sessões foi identificado na nossa análise como único fator preditor de resposta completa ao procedimento. A casuística japonesa de Ebara e colaboradores apresenta valores de etanol injetados mais próximos à nossa, com uma média de 14,6 $\pm 5 \mathrm{ml}$ em uma média de $5 \pm 1,5$ sessões $^{36}$. Entretanto, deve-se observar que os tumores tratados eram menores e o tratamento, muito mais homogêneo, como evidenciado pelo desvio-padrão de 5 no volume de etanol injetado (contra 13 na nossa casuística). Englobamos em nossa casuística 26 pacientes que receberam injeção de menos que $10 \mathrm{ml}$ de etanol na principal lesão tumoral. Dentre esses, a maioria (13 pacientes) recebeu menos que $6 \mathrm{ml}$ de etanol injetado. 31 pacientes realizaram menos que 3 sessões de alcoolização. Essas diferenças deveram-se provavelmente ao pior grau de função hepática em que se encontravam nossos pacientes (37\% Child B ou C), que evoluíam com piora do estado clínico, piora dos níveis de coagulação sanguínea e da função hepática em geral ao longo do tratamento com $\mathrm{PEI}$, impossibilitando o término do tratamento. Outro fator que pode ter influenciado essa baixa adesão ao tratamento foi o fato de uma parte considerável da nossa casuística ser formada por pacientes externos à Gastroenterologia Clínica, em alguns casos até mesmo provenientes de outros estados, que não retornaram para o término do tratamento. 
Finalmente cabe observar que, provavelmente em conseqüência de todos os fatores aqui apresentados, a taxa de resposta completa à PEI nesta casuística foi de $41 \%$, diferentemente da casuística de Ebara, em que essa mesma taxa foi de $100 \%{ }^{36}$ ou de Salà, com $73 \%$ de resposta completa inicial $^{72}$.

As taxas de sobrevida encontradas foram independentemente relacionadas, pela análise multivariada, ao tipo de resposta ao tratamento, presença de invasão vascular, tamanho do maior tumor, realização de tratamento de resgate com embolização ou quimioembolização posteriormente ao tratamento com PEI e pertencer a programa de rastreamento, como revelou a análise multivariada pela regressão logística de Cox. Resposta completa ao tratamento já havia sido identificado como o principal fator relacionado a sobrevida no estudo espanhol ${ }^{72}$. No nosso trabalho, foram pesquisadas variáveis que poderiam influenciar na resposta ao tratamento, como: tamanho do tumor, segmento hepático em que se localizava o maior tumor, ecogenicidade ultra-sonográfica, número de sessões de $\mathrm{PEI}$ realizadas, volume total de etanol injetado, intervalo de tempo entre a suspeição do tumor e tratamento, intervalo entre a suspeição e o diagnóstico definitivo e intervalo entre o diagnóstico e o tratamento. Embora a única variável relacionada à resposta completa pela análise univariada tenha sido o número de sessões de $\mathrm{PEI}$ realizadas, o pequeno número de casos com resposta completa estudados $(n=32)$ não permite uma conclusão definitiva.

No subgrupo de pacientes que obtiveram resposta completa, a sobrevida de 1 , 3 e 5 anos foi de $90,6 \%, 71,8 \%$ e $60,6 \%$, valores bem mais próximos aos das outras séries citadas. Naqueles pacientes em que a resposta foi apenas parcial, essas taxas foram respectivamente $82,4 \%$, $28,4 \%$ e 20,3\%. Pacientes cujo maior tumor media até $2 \mathrm{~cm}$ de diâmetro apresentaram sobrevida de $84 \%, 48,5 \%$ e $38,9 \%$, contra $81,7 \%, 33,5 \%$ e $17,4 \%$ daqueles que tinham o maior tumor maior que $20 \mathrm{~mm}$. Pacientes sem invasão vascular macroscópica no momento do diagnóstico apresentaram sobrevida de 1 , 3 e 5 anos de $84,4 \%, 42,5 \%$ e 29,7\%, enquanto naqueles 
com invasão vascular, as respectivas taxas foram de 33\%, $0 \%$ e $0 \%$. Embora o número de casos com invasão vascular tenha sido pequeno $(n=3)$, foi possível conseguir significância estatística nessa comparação, o que ressalta a importância da associação. Resposta completa ao tratamento e tamanho do tumor menor do que $2 \mathrm{~cm}$ já haviam sido identificadas em outros estudos como variáveis preditoras de melhor sobrevida. Invasão vascular foi uma variável excluída da maior parte dos estudos no momento da seleção dos pacientes. Outras variáveis preditoras de sobrevida anteriormente identificadas são estágio segundo a classificação de Child-Pugh e níveis de alfa-fetoproteína, que surgiram como fatores preditores de sobrevida nesta casuística apenas na análise univariada. No nosso estudo, outros dois fatores foram relacionados a melhor sobrevida: um deles, ter realizado TAE ou TACE como terapia de resgate posteriormente à PEI, pode ser explicado pela grande proporção de pacientes que obtiveram apenas resposta parcial ao tratamento com PEI. Na evolução, esses pacientes provavelmente apresentaram crescimento do tumor, recorrência local ou recorrência em outro segmento hepático e podem ter se beneficiado de nova terapia com TAE ou mais provavelmente com TACE, cujo benefício em termos de sobrevida já foi demonstrado em meta-análise previamente publicada. $O$ outro fator identificado, pertencer a um programa de rastreamento, é também inédito na literatura. Pode estar relacionado a um diagnóstico mais precoce do tumor em pacientes com melhores condições clínicas ou até mesmo refletir um grupo em que o tratamento e o acompanhamento da doença tenham sido feitos de uma forma mais controlada e mais cuidadosa. Entretanto, essa variável complexa merece cuidado em sua interpretação: em primeiro lugar, por causa do valor limítrofe de sua significância estatística $(p=0,049)$ e também porque essa diferença pode ser atribuída a um viés provocado pelo diagnóstico precoce ("lead time bias"): como o tempo de sobrevida foi calculado do momento do diagnóstico até um evento final, pacientes rastreados podem ter apresentado sobrevida maior apenas pelo fato de terem realizado seu diagnóstico mais precocemente que a população não rastreada. 
Finalmente, foi realizada como última análise uma estimativa de sobrevida para um grupo que preencheu critérios de seleção ideais: os pacientes com os principais tumores menores ou iguais a $2 \mathrm{~cm}$ de diâmetro, sem invasão vascular macroscópica no momento do diagnóstico e que obtiveram uma resposta completa ao tratamento. As taxas encontradas foram de $88,9 \%, 70,2 \%$ e 70,2\%. Nesse grupo incluíam-se apenas 18 pacientes (de 78 que puderam ter sua resposta avaliada) e os fatores que mais contribuíram para a exclusão de pacientes para essa análise foram o tamanho do tumor no momento do diagnóstico e a impossibilidade de se obter resposta completa (25 excluídos do grupo ideal por apresentarem os dois fatores, 21 excluídos por terem tido resposta parcial e 14 excluídos por terem tamanho maior que $2 \mathrm{~cm}$ ao diagnóstico). As taxas de sobrevida encontradas nesse grupo ideal são excelentes, até mesmo quando comparadas aos grupos de pacientes submetidos a ressecção cirúrgica ou a transplante hepático. Embora tão poucos pacientes tenham atendido a esses critérios de seleção, esse quadro pode ser modificado com a implementação de programa de rastreamento e vigilância para o carcinoma hepatocelular com alcance global entre a população de cirróticos, visando identificar tumores pequenos, melhorando a técnica de tratamento ao aumentar o volume de etanol injetado e o número de sessões, e controlando melhor os pacientes em protocolo de tratamento. Essas medidas, que podem ser conseguidas na maior parte dos serviços comprometidos com o tratamento do carcinoma hepatocelular sem grandes investimentos em aparelhagem e sem grandes alterações em sua rotina, podem significar um aumento importante na sobrevida dos pacientes tratados com PEI, que pode chegar, como mostra este trabalho, a $70 \%$ em 5 anos.

Uma das principais críticas realizadas a esse tipo de estudo que avalia a sobrevida dos pacientes com $\mathrm{CHC}$ é que em geral, sofrem do viés do diagnóstico precoce ("lead-time bias"), ou seja, têm sua sobrevida superestimada não por benefício do tratamento, mas por terem tido o $\mathrm{CHC}$ diagnosticado mais precocemente. Esse problema só seria resolvido numa comparação de grupos semelhantes de pacientes tratados contra não 
tratados. Não é possível realizar um estudo com esse desenho nos tempos atuais, em que o tratamento do $\mathrm{CHC}$ está bem estabelecido. Entretanto, nesse estudo, dois grupos distintos acabaram surgindo: o grupo com resposta completa e o grupo com resposta parcial. O segundo, cujo tratamento foi insuficiente, comporta-se provavelmente como um grupo não tratado e, quando comparado ao grupo cuja resposta ao tratamento foi completa, apresentou taxas de sobrevida significativamente piores. Evidentemente, esses dois grupos delineados não foram randomizados e controlados, mas apresentam características semelhantes em relação ao grau de função hepática dos pacientes e em relação às características de seus tumores. Assim, concluímos ser muito provável que a injeção percutânea de etanol tenha um efeito positivo real na sobrevida dos pacientes tratados.

\subsection{LIMITAÇÕES DO ESTUDO}

Este estudo é o primeiro no Brasil e na América Latina a descrever a resposta de pacientes com $\mathrm{CHC}$ tratados com $\mathrm{PEI}$ e a sobrevida relacionada a esse tipo de tratamento. Contudo, devido ao seu caráter retrospectivo, apresenta algumas limitações. Não havia no período avaliado pelo estudo um protocolo de acompanhamento dos pacientes após a realização da PEI. Por isso, não foi possível obter informações sobre recidiva e recorrência tumoral. A maioria das publicações que avaliaram os resultados da PEI fornecem essas informações e detectaram o que parece ser o principal problema desse tipo de tratamento. Como a PEI trata os tumores localmente, não impede o surgimento de novas lesões no mesmo segmento ou em outras regiões do fígado. Os primeiros resultados da PEI publicados, por Ebara et al, em 1990, relatam uma taxa de recorrência de 33,8\% em 1 ano, $60,8 \%$ em 2 anos e 65,7\% em 3 anos $^{73}$. Em 46 pacientes que apresentaram algum tipo de recorrência, 33,3\% tiveram recorrência local e $66,7 \%$, recorrência em outro segmento. Na publicação mais recente do mesmo grupo japonês ${ }^{36}$, a recorrência foi de 18,7\% em 1 ano, 62,1\% em 3 
anos e $81,7 \%$ em 5 anos. Em $28 \%$ dos casos, a recorrência aconteceu no mesmo segmento do tumor tratado, em 55,6\% em outros segmentos e em $16,2 \%$, em ambos os segmentos. Lencioni et al. relataram taxas de recorrência de $15 \%, 51 \%$ e $78 \%$ em 1, 3 e 5 anos $^{35}$. Salà et al. encontraram nos mesmos períodos recorrência de $16 \%$, 36\% e $51 \%{ }^{72}$. Essas taxas são muito próximas às encontradas em séries de pacientes submetidos a ressecção cirúrgica (75 a 100\% em 5 anos).

Outra limitação importante do estudo, ainda atribuída ao seu caráter retrospectivo, é não ter sido possível separar as causas de óbito por falência hepática e por progressão tumoral. Na literatura, o óbito é atribuído a progressão tumoral quando a neoplasia ocupa pelo menos $50 \%$ do volume hepático no momento do óbito, quando êmbolos tumorais são observados no tronco portal, no ramo primário da veia porta e/ou na veia cava inferior e quando a causa direta do óbito for ruptura do tumor ou metástases remotas. Segundo as experiências anteriores, o óbito por progressão tumoral ocorre em cerca de 25 a $60 \%$ dos $\operatorname{casos}^{36,72}$.

Contudo, este estudo pode ser considerado um ponto de partida para análises futuras no Brasil e na América Latina. No nosso serviço, sua realização contribuiu para melhorar a estruturação de nossa assistência médica, ao estimular um maior controle de nossos pacientes e o aperfeiçoamento do diagnóstico e tratamento do carcinoma hepatocelular, e ainda para a formação um banco de dados de pacientes com $\mathrm{CHC}$. Consideramos, em última análise, que os resultados obtidos com este estudo representem uma forte razão para que a injeção percutânea de etanol continue a ser empregada para o tratamento do carcinoma hepatocelular, e para que seu uso seja estimulado, divulgado e ensinado, em nosso país e em países com realidades semelhantes à nossa ao longo de todo o mundo. 


\section{Conclusões}


1. A sobrevida de pacientes cirróticos com carcinoma hepatocelular submetidos ao tratamento com injeção percutânea de etanol foi de $83 \%$ em 1 ano, $41 \%$ em 3 anos e $29 \%$ em 5 anos.

2. As variáveis independentemente associadas a sobrevida foram: tamanho do maior tumor de até $2 \mathrm{~cm}$ de diâmetro, ausência de invasão vascular, resposta completa ao tratamento, realização de embolização ou quimioembolização como terapia de resgate posteriormente à injeção percutânea de etanol e pertencer a um programa de rastreamento para o carcinoma hepatocelular.

3. Uma melhor seleção de pacientes que serão submetidos à injeção percutânea de etanol e o aperfeiçoamento da técnica do tratamento objetivando melhorar as taxas de resposta completa podem contribuir para a melhora da sobrevida associada a esse tipo de tratamento, potencialmente associado a sobrevida de $88,9 \%$ em 1 ano e $70,2 \%$ em 3 e 5 anos, como observado num subgrupo selecionado deste estudo. 


\section{Anexos}




\begin{abstract}
ANEXO I
À CEC

Comissão Ético-Científica do Departamento de Gastroenterologia e À CAPPesq - HCFMUSP

Comissão de Ética para Análise de Projetos de Pesquisa do HCFMUSP.
\end{abstract}

Ilmos. Senhores,

De acordo com a resolução do Conselho Nacional de Saúde (CNS) 196/96 de 10 de outubro de 1996, parágrafo IV.3, item c, vimos solicitar através deste documento a dispensa do termo de consentimento livre e esclarecido para o projeto de pesquisa intitulado "Avaliação da injeção percutânea de etanol como tratamento para carcinoma hepatocelular em pacientes cirróticos: experiência de 8 anos no Hospital das Clínicas da Faculdade de Medicina da Universidade de São Paulo". Trata-se de um projeto de pesquisa de caráter retrospectivo, cuja metodologia consiste na coleta de dados de prontuários, de bancos de dados informatizados e da análise de arquivos de exames de imagem, no período de $1^{\circ}$ de setembro de 1997 a 31 de dezembro de 2005. A solicitação faz-se necessária porque grande parte dos pacientes estão impossibilitados de serem contactados, por alteração de cadastro ou falecimento.

A condução do projeto de pesquisa e seus resultados não influenciarão nas decisões sobre o tratamento dos pacientes. Não haverá riscos ou benefícios para a população envolvida. A pesquisa que pretende ser realizada é bem fundamentada pela literatura científica, obedece a uma metodologia científica adequada e bem definida e será realizada por pesquisadores idôneos, não vinculados a patrocinadores. Justifica-se devido a sua relevância social e enquadra-se em todas as exigências da resolução CNS 196/96.

Asseguramos que todas as providências serão tomadas para preservar a privacidade dos pacientes e a confidencialidade das informações coletadas. Em nenhum momento os envolvidos terão sua identidade revelada e nenhuma informação será associada aos mesmos.

Comprometemo-nos a informar à Comissão de Ética sobre o desenvolvimento do projeto na forma regulamentada e sempre que houver solicitação por parte dessa entidade.

Atenciosamente,

Luciana Teixeira de Campos Cella

Pesquisadora responsável pelo projeto de pesquisa

CRM-SP: 91267

Dra. Denise Cerqueira Paranaguá Vezozzo

Orientadora do projeto de pesquisa

CRM-SP: 65879 


\section{ANEXO II}

usuário: lucianatcampos | Configurações | Ajuda | Sair

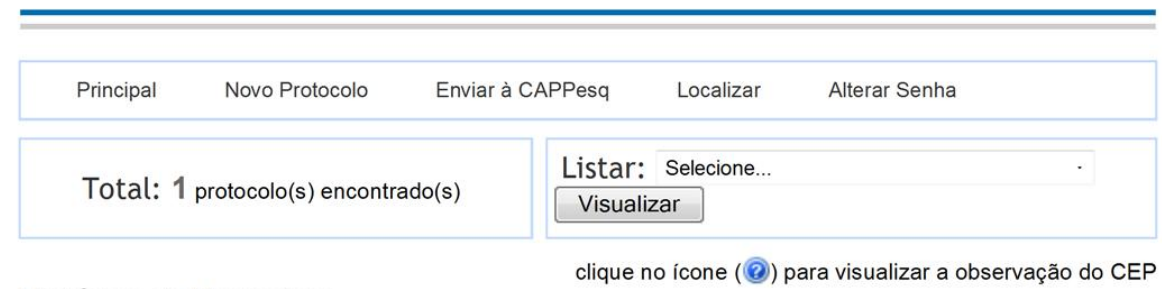

Histórico da Pesquisa:

clique no ícone (?) para visualizar a observação do CEP

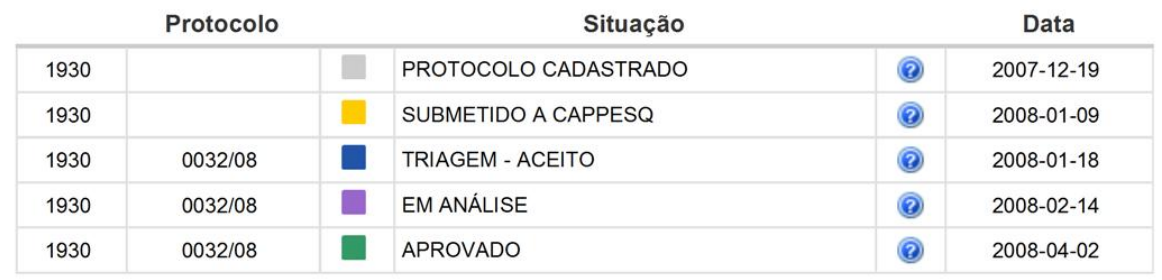

Voltar

Desenvolvido por NAPesq - Núcleo de Apoio à Pesquisa Clínica | Diretoria Clínica 2006 - 2007 | HCFMUSP 
8 Referências 
1) El-Serag HB, Mason AC. Rising incidence of hepatocellular carcinoma in United States. N Engl J Med 1999;340:745-750.

2) Bosch FX. Global epidemiology and hepatocellular carcinoma. In: Okuda K, Tabor E, ed. Liver Cancer. Churchill Livingstone, New York, 1987:13-28.

3) Sangiovanni A, Del Ninno E, Fasani $P$, et al. Increased survival of cirrhotic patients with a hepatocellular carcinoma detected during surveillance. Gastroenterology 2004;126:1005-1014.

4) Kiyosawa K, Umemura T, Ichijo T, Matsumoto A, Yoshizawa K, Gad A, Tanaka E. Hepatocellular carcinoma: recent trends in Japan. Gastroenterology 2004;127:s17-s26.

5) Jemal A, Clegg LX, Ward E, Ries LAG, Wu X, Jamison PM, Wingo PA, Howe HL, Anderson RN, Edwards BK. Annual report to the nation on the status of cancer, 1975-2001, with a special feature regarding survival. Cancer 2004;101:3-27.

6) La Vecchia C, Lucchini F, Franceschi S, Negri E, Levi F. Trends in mortality from primary liver cancer in Europe. Eur $\mathrm{J}$ Cancer 2000;36:909-915.

7) Simonetti RS, Cammà C, Fiorello F, D'Amico G, Pagliaro L. Hepatocellular carcinoma. A worldwide problem and the major risk factors. Dig Dis Sci 1991;36:962-972.

8) Bosch FX, Ribes J, Borras J. Epidemiology of primary liver cancer. Semin Liver Dis 1999;31:508-513. 
9) Fattovich G, Stroffolini T, Zagni I, Donato F. Hepatocellular carcinoma in cirrhosis: incidence and risk factors. Gastroenterology 2004;127:s35:s50.

10) Elmberg M, Hultcrantz R, Ekbom A, Brandt L, Olsson S, Olsson R, et al. Cancer risk in patients with hereditary hemochromatosis and in their first-degree relatives. Gastroenterology 2003;125:1733-1741.

11) Okuda K, Ohtsuki T, Obata H, Tomimatsu M, Okazaki N, Hasegawa $\mathrm{H}$, et al. Natural history of hepatocellular carcinoma and prognosis in relation to treatment. Study of 850 patients. Cancer 1985;56:918-928.

12) Chevret $S$, Trinchet JC, Mathieu $D$, Rached AA, Beaugrand $M$, Chastang C. A new prognostic classification for predicting survival in patients with hepatocellular carcinoma. Groupe d'Étude et de Traitement du Carcinome Hepatocellulaire. J Hepatol 1999;31:133141.

13) The Cancer of the Liver Italian Program (CLIP) investigators. A new prognostic system for hepatocellular carcinoma: a retrospective study of 435 patients. Hepatology 1998;28:751-755.

14) Tateishi R, Yoshida H, Shiina S, Imamura H, Hasegawa K, Teratani $T$, Obi S, Sato S, Koike Y, Fujishima T, Makuuchi M, Omata M. Proposal of a new prognostic model for hepatocellular carcinoma: an analysis of 403 patients. Gut 2005;54:419-425.

15) Kudo $M$, Chung $H$, Osaki $Y$. Prognostic staging system for hepatocellular carcinoma (CLIP score): its value and limitations, and a proposal for a new staging system, the Japan Integrated Staging Score (JIS score). J Gastroenterol 2003;38:207-215. 
16) Leung TW, Tang AM, Zee $B$, Lau WY, Lai PB, Leung $K L$, et al. Construction of the Chinese University Prognostic Index for hepatocellular carcinoma and comparison with the TNM staging system, the Okuda system, and the Cancer of the Liver Italian Program staging system: a study based on 926 patients. Cancer 2002;94:1760-1769.

17) Liver (including intrahepatic bile ducts). In: Green F, Page D, Fleming I, et al., editors. AJCC Cancer Staging Handbook, $6^{\text {th }}$ ed. New York: Springer;2002, p.131-144.

18) Llovet JM, Brú C, Bruix J. Prognosis of hepatocellular carcinoma: the BCLC staging classification. Semin Liver Dis 1999;19:329-338.

19) Conill C, Verger E, Salamero M. Performance status assessment in cancer patients. Cancer 1990;65:1864-1866.

20) Bruix J, Sherman M. Management of hepatocellular carcinoma. AASLD Practice Guideline. Hepatology 2005;42(5)1208-1235.

21) Bruix J, Sherman M, Llovet JM, Beaugrand M, Lencioni R, Burroughs $A K$, et al. Panel of Experts on HCC. Clinical management of hepatocellular carcinoma. Conclusions of the Barcelona-2000 EASL conference. European Association for the Study of the Liver. J Hepatol 2001;35;421-430.

22) Mazzaferro V, Regalia E, Doci R, Andreola S, Pulvirenti A, Bozzetti F, et al. Liver transplantation for the treatment of small hepatocellular carcinoma in patients with cirrhosis. N Engl J Med 1996;334:693-699.

23) Bismuth $H$, Majno PE, Adam R. Liver transplantation for hepatocellular carcinoma. Semin Liver Dis 1999;19(3)311-322. 
24) Lai EC, Fan ST, Lo CM, Chu KM, Liu CL, Wong J. Hepatic resection for hepatocellular carcinoma. An audit of 343 patients. Ann Surg 1995;221(3):291-298.

25) Primary liver cancers in Japan. Cancer 1980,45:2663-2669.

26) Sato $S$, Shiratori $Y$, Imamura $M$, Teratani $T$, Obi $S$, Koike $Y$ et al. Power Doppler signals after percutaneous ethanol injection therapy for hepatocellular carcinoma predict local recurrence of tumors: a prospective study using 199 consecutive patients. J Hepatol 2001;35:225-234.

27) Sugiura N, Takara K, Ohto M, Okuda K, Hirooka N. Ultrasound-guided ethanol injection for the treatment of small hepatocellular carcinoma. Acta Hepatol Jpn 1983;21:920 (em japonês).

28) Lencioni R, Cioni D, Crocetti L, Bartolozzi C. Percutaneous ablation of hepatocellular carcinoma: state-of-the-art. Liver transplantation 2004;10(2):s91-s97.

29) Shiina $S$, Teratani $T$, Obi $S$, Hamamura $K$, Koike $Y$, Omata M. Percutaneous ethanol injection therapy for liver tumors. Eur $\mathrm{J}$ Ultrasound 2001;13(2):95-106.

30) Giorgio A, Tarantino L, Mariniello N, de Stefano G, Perrotta A, Aloisio V, Voza A, Finizia L, Alaia A, Del Viscovo L. Percutaneous ethanol injection under general anaesthesia for hepatocellular carcinoma: 3 years survival in 112 patients. Eur J Ultrasound 1998;8:201-208.

31) Livraghi T, Vettori C, Torzilli G, Lazzaroni S, Pellicanò S, Ravasi S. Percutaneous ethanol injection of hepatic tumours: single-session therapy under general anesthesia. Am J Radiol 1993;161:1065-1069. 
32) Shiina S, Tagawa K, Unuma T, Takanashi R, Yoshikura K, Komatsu Y, et al. Percutaneous ethanol injection therapy for hepatocellular carcinoma. A histopathologic study. Cancer 1991;68(7):1524-1530.

33) Vilana R, Bruix J, Brú $C$, Ayuso $C$, Solé $M$, Rodès J. Tumor size determines the efficacy of percutaneous ethanol injection for the treatment of small hepatocellular carcinoma. Hepatology 1992;16(2):353-357.

34) Shiina S, Teratani T, Obi S, Hamamura K, Koike Y, Omata M. Percutaneous ethanol injection therapy for liver tumors. Eur $\mathrm{J}$ Ultrasound 2001;13(2):95-106.

35) Lencioni R, Pinto F, Armillotta N, Bassi AM, Moretti M, Di Giulio $M$, Marchi S, Uliana M, Della Campanna S, Lencioni M, Bartolozzi C. Long-term results of percutaneous ethanol injection therapy for hepatocellular carcinoma in cirrhosis: a European experience. Eur Radiol 1997;7:514-519.

36) Ebara M, Okabe S, Kita K, Sugiura N, Fukuda H, Yoshikawa M, Kondo F, Saisho H. Percutaneous ethanol injection for small hepatocellular carcinoma: therapeutic efficacy based on 20-year observation. J Hepatol 2005;43:458-464.

37) Liver Cancer Group of Japan. The general rules for the clinical and pathological study of primary liver cancer. 2nd ed. Tokyo: Kanehara and Co. Ltda; 2003: 23-25. 
38) Arii S, Yamaoka Y, Futagawa S, Inoue K, Kobayashi K, Kojiro M, et al. Results of surgical and nonsurgical treatment for small-sized hepatocellular carcinomas: a retrospective and nationwide survey in Japan. The Liver Cancer Study Group of Japan. Hepatology 2000;32(6):1224-1229.

39) Ikeda K, Arase Y, Kobayashi M, Saitoh S, Someya T, Hosaka T et al. Significance of multicentric cancer recurrence after potentially curative ablation of hepatocelular carcinoma: a longterm cohort study of 892 patients with viral cirrhosis. J Gastroenterol 2003;38:865-876.

40) Takayasu K, Muramatsu Y, Moriyama N, Hasegawa H, Makuuchi M, Okazaki $\mathrm{N}$ et al. Clinical and radiologic assessments of the results of hepatectomy for small hepatocellular carcinoma and therapeutic arterial embolization for postoperative recurrence. Cancer 1989;64:1848-1852.

41) Lin SM, Lin CJ, Hsu CW, Chen YC. Randomised controlled trial comparing percutaneous radiofrequency thermal ablation, percutaneous ethanol injection and percutaneous acetic acid injection to treat hepatocellular carcinoma of $3 \mathrm{~cm}$ or less. Gut 2005;54(8):1151-1156.

42) Livraghi T, Lazzaroni S, Meloni F. Radiofrequency thermal ablation of hepatocellular carcinoma. Eur J Ultrasound 2001;13:159-166.

43) Livraghi T, Goldberg SN, Lazzaroni S, Meloni F, Solbiati L, Gazelle GS. Small hepatocellular carcinoma: treatment with radiofrequency ablation versus ethanol injection. Radiology 1999;210(3):655-661. 
44) Lencioni RA, Allgaier HP, Cioni D, Olschewski M, Deibert P, Crocetti $\mathrm{L}$, et al. Small hepatocellular carcinoma in cirrhosis: randomized comparison of radio-frequency thermal ablation versus percutaneous ethanol injection. Radiology 2003;228(1):235-240.

45) Shiina S, Teratani T, Obi S, Sato S, Tateishi R, Fujishima T, et al. A randomized controlled trial of radiofrequency ablation with ethanol injection for small hepatocellular carcinoma. Gastroenterology 2005;129:122-130.

46) Belghiti J, Hiramatsu K, Benoist S. Seven hundred forty-seven hepatectomies in the 1990s: an update to evaluate the actual risk of liver resection. J Am Coll Surg 2000;191:38-46.

47) Llovet JM, Fuster J, Bruix J. Intention-to-treat analysis of surgical treatment for early hepatocellular carcinoma: resection versus transplantation. Hepatology 1999;30:1434-1440.

48) Makuuchi M, Sano K. The surgical approach to HCC: our progress and results in Japan. Liver Transpl 2004;10:S46-S52.

49) Pugh RNH, Murray-Lyon IM, Dawson JL, Pietroni MC, Williams R. Transection of the oesophagus for bleeding oesophageal varices. $\mathrm{Br} \mathrm{J}$ Surg 1973;60(8):646-649.

50) Zhou XD, Tang ZY, Yang BH, Lin ZY, Ma ZC, Ye SL et al. Experience of 1000 patients who underwent hepatectomy for small hepatocellular carcinoma. Cancer 2001;91:1479-1486.

51) Vauthey J, Lauwers G, Esnaola N, Do KA, Belghiti J, Mirza N et al. Simplified staging for hepatocelullar carcinoma. J Clin Oncol 2002;20:1527-1536. 
52) Poon RT, Fan ST, Lo CM, Liu CL, Wong J. Long-term survival and pattern of recurrence after resection of small hepatocellular carcinoma in patients with preserved liver function: implications for a strategy of salvage transplantation. Ann Surg 2002;235:373-382.

53) Ikai I, Arii $S$, Kojiro $M$, Ichida $T$, Makuuchi $M$, Matsuyama $Y$ et al. Reevaluation of prognostic factors for survival after liver resection in patients with hepatocellular carcinoma in a Japanese nationwide survey. Cancer 2004;101:796-802.

54) Bruix J, Castells A, Bosch J, Feu F, Fuster J, Garcia-Pagan JC et al. Surgical resection of hepatocellular carcinoma in cirrhotic patients: prognostic value of preoperative portal pressure. Gastroenterology 1996;11:1018-1022.

55) Marin-Hargreaves G, Azoulay D, Bismuth H. Hepatocellular carcinoma: surgical indications and results. Crit Rev Oncol Hematol 2003;47:13-27.

56) Okada S, Shimada K, Yamamoto J, Takayama T, Kosuge T, Yamasaki $S$ et al. Predictive factors for postoperative recurrence of hepatocellular carcinoma. Gastroenterology 1994;106:1618-1624.

57) Poon RT, Fan ST, Lo CM, Liu CL, Wong J. Intrahepatic recurrence after curative resection of hepatocellular carcinoma: long-term results of treatment and prognostic factors. Ann Surg 1999;229:216-222.

58) Minagawa M, Makuuchi M, Takayama $T$, Kokudo N. Selection criteria for repeat hepatectomy in patients with recurrent hepatocellular carcinoma. Ann Surg 2003;238:703-710. 
59) Imamura H, Matsuyama Y, Tanaka E, Ohkubo T, Hasegawa K, Miyagawa $S$ et al. Risk factors contributing to early and late phase intrahepatic recurrence of hepatocellular carcinoma after hepatectomy. J Hepatol 2003;38:200-207.

60) Kumada T, Nakano S, Takeda I, Sugiyama K, Osada T, Kiriyama S et al. Patterns of recurrence after initial treatment in patients with small hepatocellular carcinoma. Hepatology 1997;25:87-92.

61) Takayasu K, Marumatsu Y, Moriyama N, Hasegawa H, Makuuchi M, Okazaki $\mathrm{N}$ et al. Clinical and radiologic assessments of the results of hepatectomy for small hepatocellular carcinoma and therapeutic arterial embolization for postoperative recurrence. Cancer 1989;64:1848-1852.

62) Majno PE, Sarasin FP, Mentha G, Hadengue A. Primary liver resection and salvage transplantation or primary liver transplantation in patients with single, small hepatocellular carcinoma and preserved liver function: an outcome-oriented decision analysis. Hepatology 2000;31:899-906.

63) Salà M, Fuster J, Llovet JM, Navasa M, Solé $M$, Varela $M$ et al. High pathological risk of recurrence after surgical resection for hepatocellular carcinoma: an indication for salvage liver transplantation. Liver Transpl 2004;10:1294-1300.

64) Llovet JM, Bruix J. Systematic review of randomized trials for unresectable hepatocellular carcinoma: chemoembolization improves survival. Hepatology 2003;37:429-442. 
65) Bruix J, Salà M, Llovet JM. Chemoembolization for hepatocellular carcinoma. Gastroenterology 2004;127(5 Supl 1):S179-S188.

66) Llovet JM, Bruix J. Novel advancements in the management of hepatocellular carcinoma in 2008. J Hepatol 2008;48(Supl1):S20-S37.

67) Llovet JM, Ricci S, Mazzaferro V, Hilgard P, Raoul J, Zeuzem S, et al. Sorafenib improves survival in advanced hepatocellular carcinoma (HCC): results of a phase III randomized placebo-controlled trial. J Clin Oncol 2007;25:LBA1.

68) Llovet JM, Burroughs A, Bruix J. Hepatocellular carcinoma. Lancet 2003;362:1907-1917.

69) El-Serag HB. Hepatocellular carcinoma: recent trends in the United States. Gastroenterology 2004;127(5 Supl1):S27-S34.

70) Omata M, Tateishi R, Yoshida H, Shiina S. Treatment of hepatocellular carcinoma by percutaneous tumor ablation methods: ethanol injection therapy and radiofrequency ablation. Gastroenterology 2004;127(5 Supl1):S159-166.

71) Livraghi T, Giorgio A, Marin G, Salmi A, de Sio I, Bolondi L, Pompili M, Brunello F, Lazzaroni S, Torzilli G, Zucchi A. Hepatocellular carcinoma and cirrhosis in 746 patients: long-term results of percutaneous ethanol injection. Radiology 1995;197:101-108.

72) Salà M, Llovet JM, Vilana R, Bianchi L, Solé M, Ayuso C, Brú C, Bruix J. Initial response to percutaneous ablation predicts survival in patients with hepatocellular carcinoma. Hepatology 2004;40:1352-1360. 
73) Ebara $M$, Ohto $M$, Sugiura $N$, Okuda $K$, Kondo $F$, Kondo $K$. Percutaneous ethanol injection for the treatment of small hepatocellular carcinoma: study of 95 patients. J Gastroenterol Hepatol 1990;5:616-626.

74) Livraghi $T$, Bolondi $L$, Cottone $M$, et al. No treatment, resection and ethanol injection in hepatocellular carcinoma: a retrospective analysis of survival in 391 cirrhotic patients. J Hepatol 1995;22:522-526.

75) Kikuchi LOO. Análise da sobrevida de pacientes com carcinoma hepatocelular pequeno [dissertação]. São Paulo: Faculdade de Medicina, Universidade de São Paulo; 2007. 110p.

76) Jansen MC, Hillegersberg R, Chamuleau RAFM, Delden OM, Gouma DJ, Gulik TM. Outcome of regional and local ablative therapies for hepatocellular carcinoma: a collective review. EJSO 2005;31:331-347.

77) Livraghi T, Bolondi L, Lazzaroni S, Marin G, Morabito A, Rapaccini GL, Salmi A, Torzilli G. Percutaneous ethanol injection in the treatment of hepatocellular carcinoma in cirrhosis. Cancer 1992;69:925-929.

78) Kim KA, Lee WJ, Park CM, Park CK, Cha IH, Seol HY. Small hepatocellular carcinoma: ultrasonographic findings and histopathologic correlation. Clin Imaging 2003;27(5):340-345.

79) Wachsberg RH, Klein KM, Von Hagen S. Non-Asian hepatocellular carcinoma: correlation between histologic features and echogenicity. J Ultrasound Med 2000;19(4):231-4.

80) Tanaka S. The correlation between histologic features and the ecogenicity in Asian hepatocellular carcinomas (HCCs) is not applicable to non-Asian HCCS. J Ultrasound Med 2000;19(10):687-8. 
81) Bruix J. Clinical presentation. In: Livraghi T, Makuuchi M, Buscarini L, editors: Diagnosis and treatment of hepatocellular carcinoma. London, Greenwich Medical Media, 1997. p.53-58.

82) Kojiro M. Focus on dysplastic nodules and early hepatocellular carcinoma: an Eastern point of view. Liver Transpl 2004;10(2 Suppl 1): S3-S8.

83) De Sio I, Castellano L, Calandra M. Hemobilia following percutaneous ethanol injection for hepatocellular carcinoma in a cirrhotic patient. $J$ Clin Ultrasound 1992;20:621-623.

84) Cedrone A, Rapaccini GL, Pompili M. Neoplastic seeding complicating percutaneous ethanol injection for treatment of hepatocellular carcinoma. Radiology 1992;183:787-788.

85) Goletti O, De Negri F, Pucciarelli M, et al. Subcutaneous seeding after percutaneous ethanol injection of liver metastasis. Radiology 1992;183:185-786.

86) Forner A, Vilana R, Ayuso C, Bianchi L, Solé M, Ayuso JR, Boix L, Salà M, Varela M, Llovet JM, Brú C, Bruix J. Diagnosis of hepatic nodules $20 \mathrm{~mm}$ or smaller in cirrhosis: prospective validation of the noninvasive diagnostic criteria for hepatocellular diagnosis. Hepatology 2008;47(1):97-104.

87) Torzilli G, Minagawa M, Takayama T, Inoue K, Hui AM, Kubota K, et al. Accurate preoperative evaluation of liver mass lesions without fine needle biopsy. Hepatology 1999;30:889-893. 
88) Levy I, Greig PD, Gallinger S, Langer B, Sherman M. Resection of hepatocellular carcinoma without preoperative tumor biopsy. Ann Surg 2001;234:206-209.

89) Kotoh K, Sakai H, Sakamoto $\mathrm{S}$, et al. The effect of percutaneous ethanol injection therapy on small solitary hepatocellular carcinoma is comparable to that of hepatectomy. Am J Gastroenterol 1994;89:194198.

90) Onodera $\mathrm{H}$, Ukai $\mathrm{K}$, Nakano $\mathrm{N}$, et al. Outcomes of 116 patients with hepatocellular carcinoma. Cancer Chemother Pharmacol 1994;33(suppl):103-108.

91) Iwatsuki S, Starzl TE, Sheahan DG, et al. Hepatic resection versus transplantation for hepatocellular carcinoma. Ann Surg 1991;214(3):221-229.

92) Ringe B, Pichlmayr R, Wittekind C, Tusch G. Surgical treatment of hepatocellular carcinoma: experience with liver resection and transplantation in 198 patients. World J Surg 1991;15:270-285.

93) Shiina S, Tagawa K, Unuma T, Takanashi R, Yoshiura K, Komatsu Y, et al. Percutaneous ethanol injection therapy for hepatocellular carcinoma: a histopathologic study. Cancer 1991;68:1524-1530.

94) Castroagudin JF, Delgado M, Martinez SM, Abdulkader I, Potel J, Tome S, Otero E, Varo E. Prospective histopathological analysis of hepatocellular carcinoma treated with percutaneous ethanol injection in patients on the waiting list for liver transplantation. Transplantation Proceedings 2005;37:1477-1479. 
95) Becker CD, Grossholz M, Mentha G, et al. Ablation of hepatocellular carcinoma by percutaneous ethanol injection: imaging findings. Cardiovasc Intervent Radiol 1997;20:204-210.

96) Seki T, Nonaka T, Kubota Y, Mizuno T, Sameshima Y. Ultrasonically guided percutaneous ethanol injection therapy for hepatocellular carcinoma. Am J Gastroenterol 1989;84:1400-1407.

97) Cioni D, Lencioni R, Bartolozzi C. Percutaneous ablation of liver malignancies: imaging evaluation of treatment response. Eur $\mathrm{J}$ Ultrasound 2001;13:73-93.

98) Bartolozzi C, Lencioni R. Ethanol injection for the treatment of hepatic tumours. Eur Radiol 1996;6:682-696.

99) Bartolozzi C, Lencioni R, Ricci P, Paolicchi A, Rossi P, Passariello R. Hepatocellular carcinoma treatment with percutaneous ethanol injection: evaluation with contrast-enhanced color DopplerUS. Radiology 1998;209:387-93.

100) Becker CD, Grossholz M, Mentha G, et al. Ablation of hepatocellular carcinoma by percutaneous ethanol injection: imaging findings. Cardiovasc Intervent Radiol 1997;20:204-210.

101) Kim TK, Choi BI, Chung JW, Park JH, Han MC. Nontumorous arterioportal shunt mimicking hypervascular tumor in cirrhotic liver: two-phase spiral CT findings. Radiology 1998;208:597-603.

102) Ebara M, Kita K, Sugiura N, Yoshikawa M, Fukuda H, Ohto M, Kondo $F$, Kondo $Y$. Therapeutic effect of percutaneous ethanol injection on small hepatocellular carcinoma: evaluation with CT. Radiology 1995;195:371-377. 
103) Kubota $Y$, Nakano $T$, Seki $T$, et al. Validity of $M R$ imaging for monitoring effects of percutaneous ethanol injection for HCC. Hepatogastroenterology 1989;36:262-265.

104) Nagel HS, Bernardino ME. Contrast-enhanced MR imaging of hepatic lesions treated with percutaneous ethanol ablation therapy. Radiology 1993, 189:265-270. 